\title{
Field analysis and design of a moving iron linear alternator for use with linear engine
}

Dulpichet Rerkpreedapong

West Virginia University

Follow this and additional works at: https://researchrepository.wvu.edu/etd

\section{Recommended Citation}

Rerkpreedapong, Dulpichet, "Field analysis and design of a moving iron linear alternator for use with linear engine" (1999). Graduate Theses, Dissertations, and Problem Reports. 993.

https://researchrepository.wvu.edu/etd/993

This Thesis is protected by copyright and/or related rights. It has been brought to you by the The Research Repository @ WVU with permission from the rights-holder(s). You are free to use this Thesis in any way that is permitted by the copyright and related rights legislation that applies to your use. For other uses you must obtain permission from the rights-holder(s) directly, unless additional rights are indicated by a Creative Commons license in the record and/ or on the work itself. This Thesis has been accepted for inclusion in WVU Graduate Theses, Dissertations, and Problem Reports collection by an authorized administrator of The Research Repository @ WVU. For more information, please contact researchrepository@mail.wvu.edu. 
Field Analysis and Design of a Moving Iron Linear Alternator for Use with Linear Engine

\author{
Dulpichet Rerkpreedapong
}

Thesis submitted to the College of Engineering and Mineral Resources at West Virginia University

\author{
Master of Science \\ In \\ Electrical Engineering
}

\author{
Dr. Parviz Famouri (chair) \\ Dr. Muhammad A. Choudhry \\ Dr. Wils L. Cooley
}

Department of Computer Science and Electrical Engineering

Morgantown, WV

1999

Keywords: Linear Alternator, Linear Engine Copyright 1999 Dulpichet Rerkpreedapong 


\author{
ABSTRACT \\ Field Analysis and Design of a Moving Iron \\ Linear Alternator for Use with Linear Engine \\ Dulpichet Rerkpreedapong
}

The previous research at West Virginia University has developed a permanent magnet linear alternator and linear combustion engine for testing and studying the performance. In this prototype, magnets are part of the moving part.

This research will present a new type of linear alternator with permanent magnets installed on stationary called Moving Iron Linear Alternator (MILA). MILA offers several advantages over other types such as rugged structure, and low cost production. First, MILA will be designed for use with the existing linear engine. An optimization methodology will be applied to obtain optimal design parameters. Next, a MILA model will be created in EMAS, field analysis software, to determine the machine flux. Later, the simulation will be performed for calculating the back emf and current of MILA. Finally, the simulation results will be discussed and explanations will be given. 


\section{ACKNOWLEDGEMENTS}

I would like to express my sincere appreciation to my research advisor, Dr. Parviz Famouri, for his guidance and encouragement throughout this research. I would like to thank Dr. Muhammad A. Choudhry and Dr. Wils L. Cooley for serving on my examining committee and for their valuable suggestions.

A special thanks goes to my colleague, Jingdong Chen, who always has time for research discussions. It was my great time. I would like to credit my close friend, Juchirl Park, who worked very hard and was a good example for me. I would like to thank Watchara Chatwiriya (Puak), who gave me helpful tips for my presentation. I would also

like to thank my roommate, Pisut Raphisak (Den), who helped me correct mistakes on my thesis.

I must also thank my lovely girlfriend Jubjang for her love and understanding. Most importantly, I would like to thank my dad, mom, younger sister and brothers for their unconditional love, support and constant encouragement. Having them in my mind, I never feel that I am so far away. 


\section{Table of Contents}

Title Page $\quad$ i

Abstract

Acknowledgements

Table of Contents $\quad$ iv

Chapter 1 Introduction 1

1.1 Moving Coil Linear Alternator 2

1.2 Moving Magnet Linear Alternator 3

1.3 Moving Iron Linear Alternator (MILA) 5

1.4 Goal of Research 6

$\begin{array}{lll}\text { Chapter } 2 & \text { Principle of Operation and Machine Analysis } & 8\end{array}$

2.1 Principle of Operation 8

$\begin{array}{ll}2.2 \text { Description of MILA } & 10\end{array}$

$\begin{array}{lll}2.3 & 12\end{array}$

Chapter 3 Conceptual Design of MILA 28

3.1 Linear Internal Combustion Engine 28

3.2 MILA Design Procedure 29

Chapter $4 \quad$ Optimization Design 45

4.1 Overview of MATLAB Constrained Optimization Routine 45

4.2 Optimization Design Development 48

4.3 Optimization Results $\quad 51$ 
Chapter 5 Field Analysis 53

5.1 Magnetostatic Finite Element Method 53

5.2 Overview of EMAS Field Analysis Software 55

5.3 Approach to MILA Model Using EMAS 56

5.4 Simplified Model 62

$\begin{array}{lll}\text { Chapter } 6 & \text { Simulation and Results } & 67\end{array}$

6.1 Simulation Preparation 67

6.2 MILA Simulation at No Load 69

6.3 MILA Simulation under Load Conditions 71

6.4 Simulation Results 73

$\begin{array}{lll}\text { Chapter } 7 & \text { Conclusion } & 79\end{array}$

7.1 MILA Structure and Design 79

7.2 Field Analysis and Simulation 80

$\begin{array}{lll}7.3 & \text { Future Work } & 81\end{array}$

References $\quad 82$

$\begin{array}{ll}\text { Appendix } & 84\end{array}$ 


\section{INTRODUCTION}

At the present, need of remote power generation has increased dramatically in industrial, military, transportation, and spacecraft. To achieve an optimal operation, the power generation unit is developed to be more reliable, compact, and lightweight everyday. Power generation system consists of two parts. One is the linear propellant engine such as combustion engine, or stirling engine [1]-[2]. The other is the rotary generator that converts the mechanical energy to electrical energy. Due to the rotary operation, the linear force transferred to the rod by the engine is to be converted to a rotary torque through a crankshaft mechanism. Having several moving parts, the rotary auxiliary power unit has significant frictional losses. And crankshaft-housing volume is more than half of the total engine volume. Thus elimination of crankshaft makes the engine compact. The linear auxiliary power system is subsequently used to overcome these problems. A linear alternator that functions like its rotary counterparts is used in this system. The linear alternator can directly extract the energy from the linear engine. This helps the linear alternator to be more compact with high efficiency and a fewer moving parts.

Currently, a linear alternator and engine system project is being conducted at West Virginia University. The linear internal combustion engine and brushless permanent magnet linear alternator (PMLA) [3] have been developed for testing and studying the performance. Several types of linear alternators are being explored for the existing linear engine for different applications. Due to a number of advantages, mainly ease of mass production, the Moving Iron Linear Alternator (MILA) [4] will be studied in this thesis. Subsequently, MILA will be designed for using with the linear internal combustion engine. The MILA simulation will be performed to obtain the performance. Finally, the simulation results are discussed and demonstrated that MILA is a good candidate for the existing linear engine. 
The operation of linear alternators is based on the Faraday's law of electromagnetic induction.

$$
e=-\frac{d \lambda}{d t}
$$

where

$\mathrm{e}$ is the induced voltage in a coil

$\lambda$ is the flux linkage varying with time $t$

Linear alternator can be classified as three types

1) Moving coil type

2) Moving magnet type

3) Moving iron type

Each type has advantages and disadvantages of its own. Greater details of all types are described by explanations and figures below.

\section{$\underline{1.1 \text { Moving Coil Linear Alternator }}$}

The moving coil linear alternator shown in Figure 1.1 includes a coil moving reciprocatingly along the airgap [5]. The stator core consists of a set of laminations and has stator coils winding along the core. The dc current in moving coil establishes magnetic flux around the moving coil. As the moving coil is oscillated by the spring force, the amount of magnetic flux established through the stator core varies relative to the position of the mover. Consequently, causes an induced voltage across the terminals of the stator coils. 


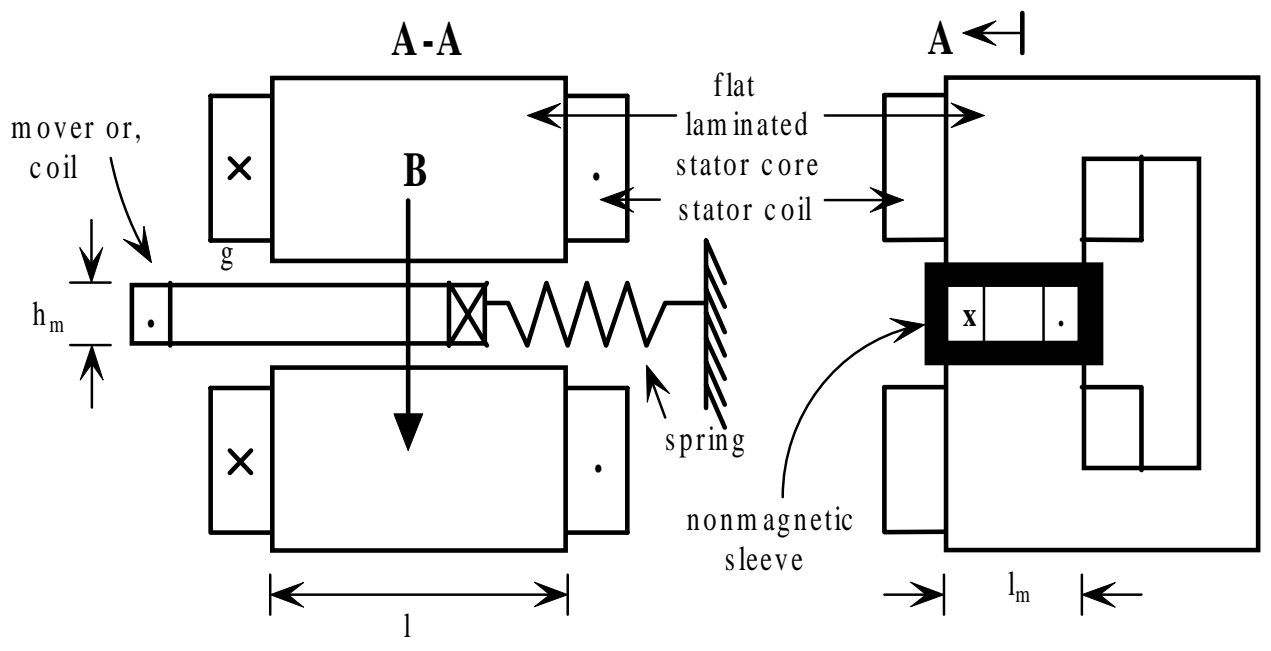

Figure 1.1 A moving coil linear alternator

Moving coil linear alternators have been applied to loudspeakers, vibrators, etc. The operating frequency of this type is rather high up to $2 \mathrm{kHz}$ and thrusts up to a few hundred newtons for stroke length less than 10-15 mm. Because of the light mover mass, the oscillation frequency occurs in high level. In case of higher thrust at a lower frequency, some iron may be attached to the moving coil to increase magnetic flux for higher weight. Unfortunately, the moving coil type requires flexible leads, which is easy to wear out, especially in high-power machines. In addition, this type has very low efficiency and specific power as compared with other types.

\subsection{Moving Magnet Linear Alternator}

The moving magnet linear alternator is a popular option for most present applications because there are a number of advantages such as high power density, strength of field, low weight, and high efficiency. The configuration of permanent magnet linear alternator (PMLA) can be designed in various ways. To facilitate understanding of principle of operation, a simple configuration of PMLA [5] is presented in Figure 1.2. 


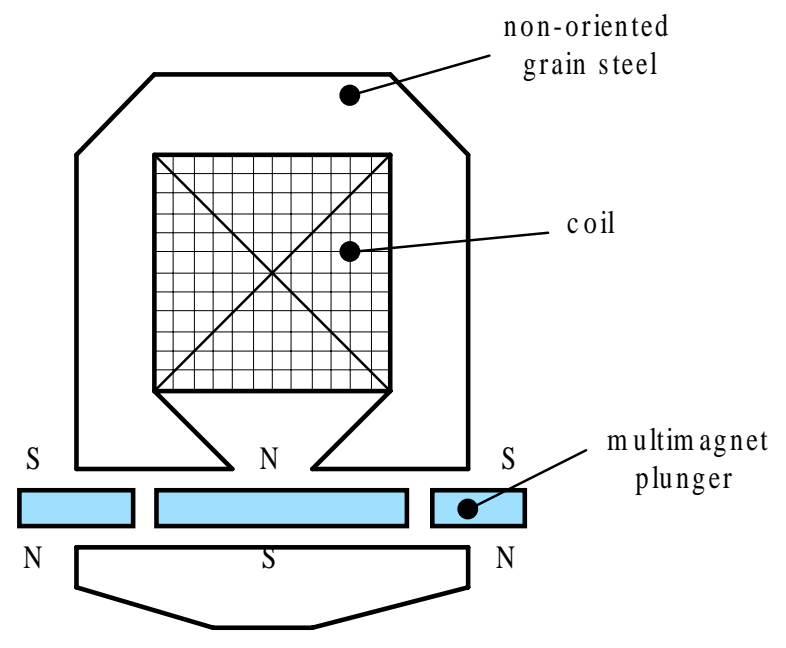

Figure 1.2 A cross sectional view of a moving magnet linear alternator

This permanent magnet linear alternator is designed as tubular shape. There is one coil installed in the stator core. The steel stator core has an annular space at the center where a set of ring-shape permanent magnets is placed, which are free to oscillate along the axial airgap. As the permanent magnet mover is oscillated by the linear engine in a back and forth fashion, the magnetic flux established in the stator core or through the coil will vary between positive and negative maxima depending on the position of the magnet mover. Similar to the moving coil type, changes of the magnetic flux produce the induced voltage between the terminals of the coil.

However, the moving magnet type has a few drawbacks [4]. For example,

1) The brittle structure of high strength magnet material may degrade due to stress imposed by high speed reciprocating action of the translator.

2) Permanent magnets would weaken with increased temperature and cooling of moving permanent magnets is rather difficult because the magnets are installed inside the stator housing.

3) With heat caused by the radial radiation of the magnets, the efficiency of operation is decreased greatly.

4) Regulating the output voltage of the machine is much difficult because the field flux produced from the permanent magnets is not controllable. 
5) Installation of the magnets is also difficult, and not easy to make low cost mass production.

6) Under fault condition, armature short circuit would demagnetize the permanent magnets.

\subsection{Moving Iron Linear Alternator}

From the problems stated earlier, a new type of linear alternator, moving iron linear alternator (MILA) [5], is presented to reduce most of mentioned problems. Configurations of moving iron type can be designed in several ways. To elucidate operation of the machine, a simple model is drawn in Figure 1.3.

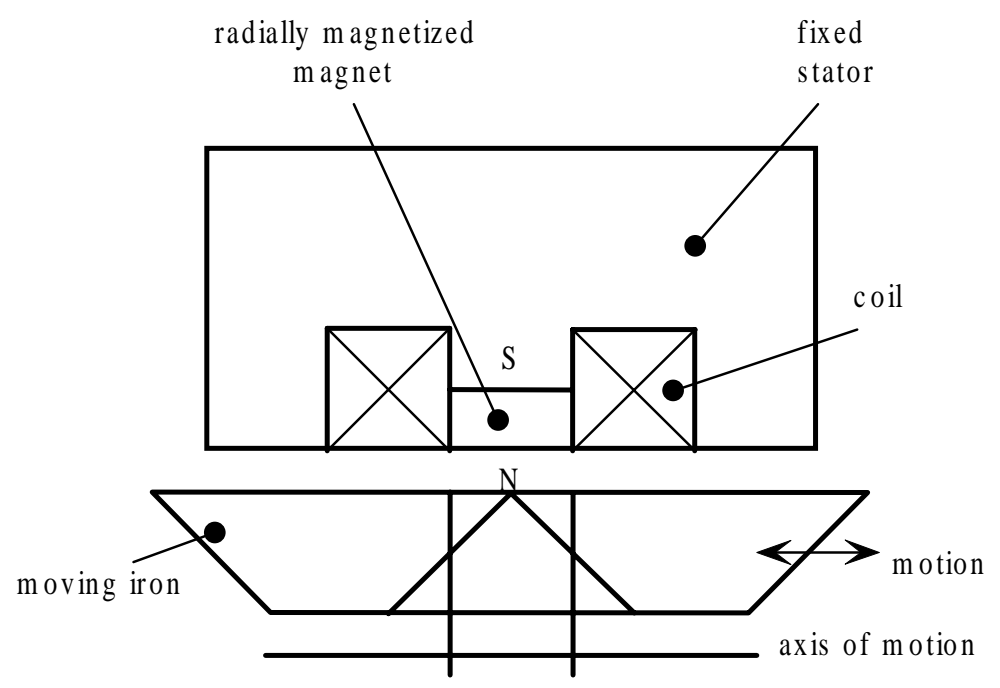

Figure 1.3 A cross sectional view of a moving iron linear alternator

The moving iron linear alternator (MILA) shown above consists of a tubular stator core having the permanent magnets, and the annular iron mover moving reciprocatingly along the axis of motion. Unlike the moving magnet type, the annular permanent magnets are mounted on the stator core. Two identical coils are placed in left and right sides of the permanent magnets. The field flux, produced by the permanent magnets, will flow in closed-path from the magnets through the airgap and iron mover and flowing back to the stator core. Changes of the mover position will change the field flux established through the coil and will induce voltage at the stator coil. 
In the next chapter, a more practical model is introduced with detailed explanations. From Figure 1.3 and above explanations, it is apparent that MILAs are easy to cool because the magnets are mounted on the stationary. Due to this reason, in addition, the magnets are well protected and not subject to dynamic motion of the mover, so MILAs are rugged and much reliable. Due to using radial lamination, MILAs are convenient to manufacture and repair because the stator and mover laminated cores are similar to their rotary counterparts [4]. According to the existing MILAs, the permanent magnets are also easy to install and maintain. All of these advantages make the moving iron linear alternator ideal for mass production. Efficiency and specific power of MILAs can be designed as much as those of their rotary counterpart [6]. Even though, the MILA offers a number of advantages, but there are still a few disadvantages. For example, the mass of the moving iron and steel core is rather high, so the frequency of oscillations is limited to a few Hertz. As a result, the power/weight of this type is rather less than that of the moving magnet type [5].

\subsection{Goal of Research}

This thesis applies a novel type of linear alternators that has the magnets on stationary with flux linkage reversal called moving iron linear alternator (MILA) to the linear engine as the prime mover. The moving iron linear alternator is rugged and easy to build. A number of advantages will be presented in this thesis to show that MILA is a good alternative for the proposed applications.

The permanent magnet linear alternator (PMLA) or moving magnet type has been designed and constructed for the existing linear engine in the laboratory [3]. The experiments, that were done, provide number of data useful to this research.

Conceptual design will be proceeded in Chapter 3 following the analytical concept [5] that is developed in Chapter 2. Of course, the numerical data of the existing linear engine such as the stroke length, frequency of oscillations, etc., are very crucial factors for the design process. The translator of the moving iron type is designed to have the same weight as that of the existing moving magnet type so that the pistons of the engine keep oscillating at same frequency. This helps to compare the output power of both types at the same frequency by using the existing data. 
Optimization is an important part of machine design. To construct an ideal machine, engineers tend to minimize the mass, and to maximize the efficiency as much as possible. This optimization methodology will be applied in this research to obtain an optimum model of MILA.

In Chapter 4, after numerical parameter and geometry of the machine are generated from the optimization design process, these data are then used to draw a machine model in EMAS, field analysis software based on finite element method, for field analysis task. Based on the Faraday's law, the output voltage of MILAs indeed comes from changes of the field flux with respect to time. For this reason, the field analysis part is crucial to obtain accurate results of the magnetic field for the machine operation. In Chapter 2, the magnetic circuit, that represents the MILA, is developed to roughly analyze the magnetic flux established in the machine. As a matter of fact, the magnetic circuit analysis is just an approximate method, and the finite element method will be more helpful for obtaining high accurate results.

To obtain the flux changes with respect to position $\left(\frac{d \phi}{d x}\right)$, the mover will be shifted along the axial direction by finite positions. At each mover position, the field analysis package (EMAS) will be run to calculate the magnetic flux flowing through the stator core. Unfortunately, a great amount of time is used by EMAS for completing one round ( $3 \mathrm{Hrs}$ ). In Chapter 5, a two-dimensional simplified model will be developed to overcome this problem.

In Chapter 6, simulations of MILA are done by interaction of EMAS and MATLAB. The induced voltage and electric current will be solved point by point regarding the translator position. The output results will be analyzed and discussed in the final section of the chapter. 


\section{PRINCIPLE OF OPERATION \& MACHINE ANALYSIS}

\subsection{Principle of operation}

A basic configuration of moving iron linear alternator (MILA) is presented in Figure 2.1. The structure of MILAs [7] is simple and easy to build. Principle of operation of MILAs can be explained by Figure 2.1.

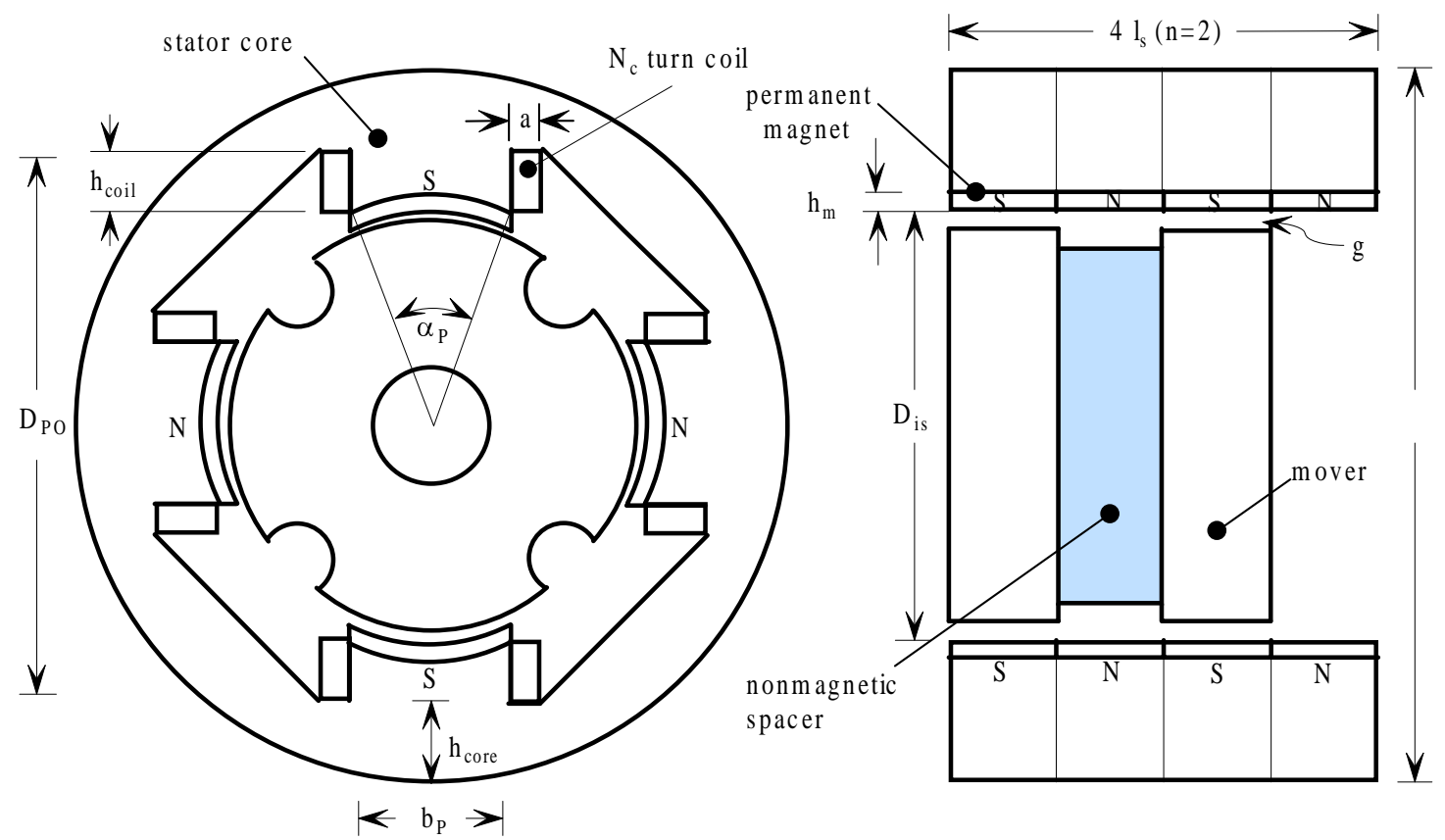

a) front view

b) side view

Figure 2.1 A cross sectional view of a novel moving iron linear alternator 
The moving iron linear alternator (MILA) has permanent magnets generating the magnetic flux reversible on the stator poles [7]. MILA has a laminated cylindrical core with four salient poles similar to a switched reluctance rotary machine. These machines use simple unexcited variable reluctance rotor or translator to produce magnetomotive force (MMF) as rotor or mover position changed. The magnetic flux produced from the permanent magnets is established through the stator core and mover as closed paths shown in Figure 2.2.

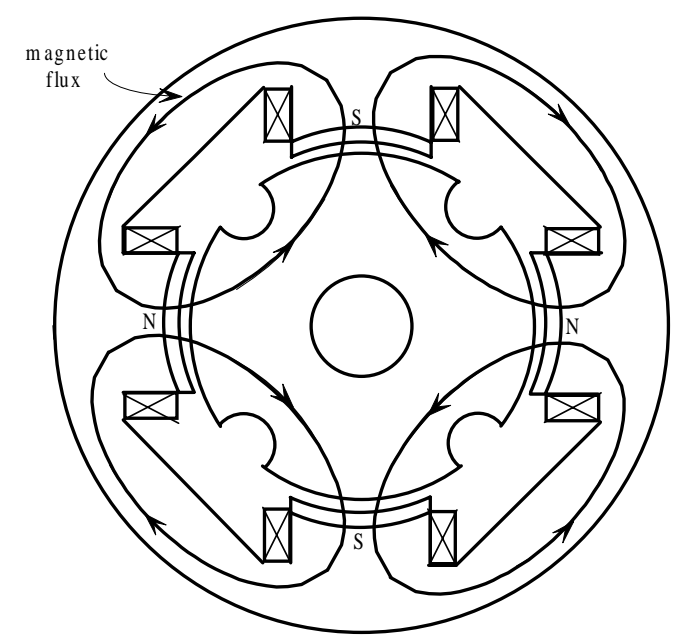

Figure 2.2 A closed path of magnetic flux established in the machine

The circumferential poles have the surface mounted permanent magnets with alternating polarities and radially magnetized. Along the stator length, each stator pole has four permanent magnet sections of alternate polarities, and also has a coil winding around it. These four coils are connected in series. The mover consists of two parts separated from each other by one pole pitch with a lightweight nonmagnetic spacer. Each part is made of a bunch of stacked annular laminations of iron. Practically, the mover could be designed to have only one part or more, depending on the expected output power. During operation of the machine, the mover travels reciprocatingly relative to the stator poles. As a result, changes of reluctance in the magnetic circuit occur and cause changes of the flux-linkage in the stator poles. These changes induce voltage that causes the electric current to flow in the stator coils. 


\subsection{Description of MILA}

This MILA model was designed by Boldea and Nasar [6]. In this research, this model will be redesigned for using with the existing linear engine in the laboratory. Figure 2.3 and 2.4 show greater details in structure of MILA.

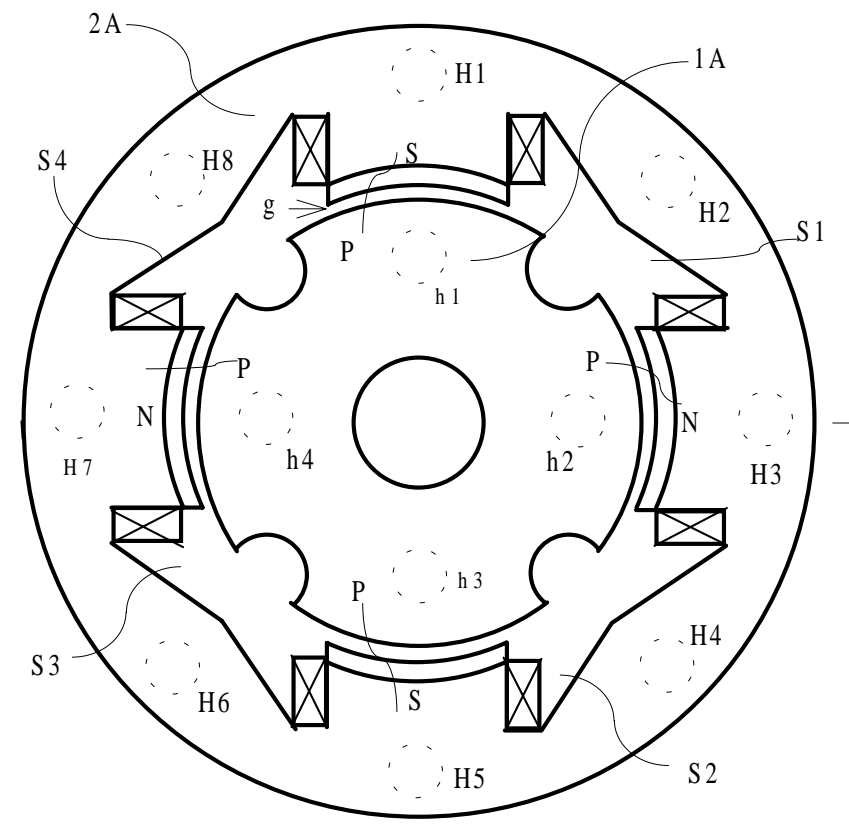

a) front view
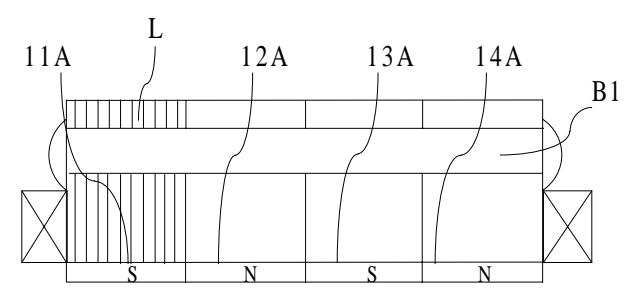

$4 \mathrm{~A}$

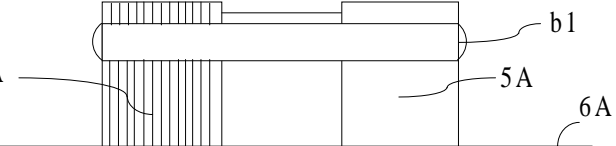

$6 \mathrm{~A}$
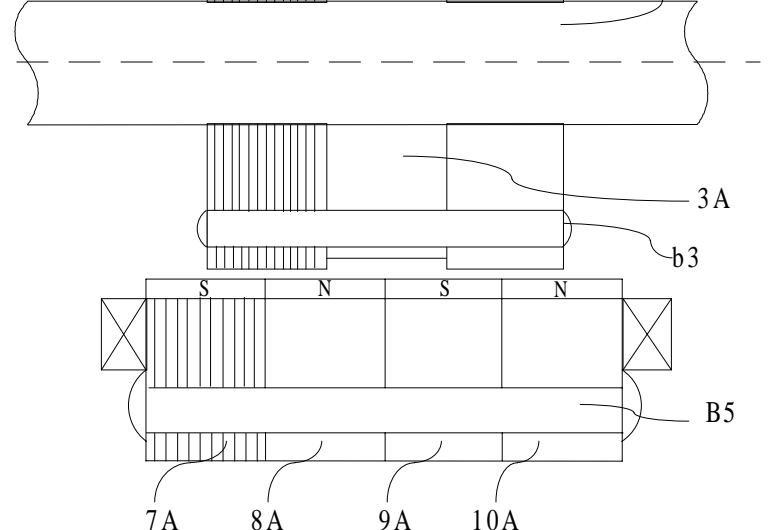

b) side view

Figure 2.3-2.4 Cross sectional views of front and side of MILA

The moving iron linear alternator (MILA) shown above is operates following the principle of operation explained in the last section. This model can function as a linear motor or linear alternator [7]. In this research, a linear alternator operation, in which converting mechanical power to electrical power, is considered and designed.

The moving iron linear alternator consists of a cylindrical-shaped mover $(1 \mathrm{~A})$ and a tubular-shaped stator (2A) which are placed in the alignment of concentricity. The Figure 2.3 and 2.4 show the cross-sectional views of the front and the side of the machine respectively. The stator has a central opening, which is sized to enclose the mover $(1 \mathrm{~A})$ 
and the airgap (g), which is between the mover and the pole faces of the stator. As a result, axial oscillations of the mover relative to the stator are free with minimal friction.

The mover part (1A) is connected to a rod (6A) connecting to the pistons of the linear engine. As the engine generates reciprocating mechanical movement, the mechanical energy is transferred through the rod to the mover, and then converts to electrical energy by change of the MMF.

As the mover part is considered, it includes two sets of laminations of iron whose shape are similar to a rotor of the salient pole machine. Two identical sets of laminations are spaced apart by one pole pitch $\left(1_{\mathrm{s}}\right)$ with a spacer $(3 \mathrm{~A})$ made of nonmagnetic and nonconductive material to help electromagnetic interaction of the mover and the stator parts proceed properly. A set of mounting bolts (b1-b4) helps fix the sets of laminations (4A and $5 \mathrm{~A}$ ) and the spacer (3A) in a proper position on the rod (6A) as shown in Figure 2.4 .

The stator assembly comprises four sets of stacked stator lamination units assigned as 7A-10A as shown in Figure 2.3-2.4. These four sets of laminations have a set of axial holes apart (H1-H8). These holes are placed for receiving a set of bolts (B1-B8), which tightens the laminations forming the stator core. This helps reduce eddy current losses.

A stator lamination unit, for example the stacked laminations $7 \mathrm{~A}$, consists of a group of annular laminations such as the lamination $\mathrm{L}$ that is a portion of the stator poles, and also a portion of plurality of elongated winding slots (S1-S4). Using this type of laminations, no casing is required in the radial direction.

Each stator lamination unit (7A-10A) has four circumferential poles (P) spaced 90 degrees apart. Each pole (P) has the permanent magnets mounted on its face in alternating polarity respective to its adjacent poles. The four units (7A-10A) are bolted together and all four poles $(\mathrm{P})$ of each lamination unit are axially gathered together and defined as pole groups. As a result, a pole group includes four magnets (11A-14A) arranged in alternating polarity axially.

The above descriptions explained the principle of operation of MILAs for a given example. However, number of poles $(\mathrm{P})$ of the stator laminations can be greater or less than the amount employed in the above example. Also a set of laminated stator units may 
include units more or less than four. These parameters depend on the designed output power and specifications of the linear engine driving the translator of MILA.

\section{$\underline{2.3 \text { Machine Analysis }}$}

To carry out the design task properly, the machine analysis part must be performed decently. From the structure and operation studies of MILA in the previous sections, a number of equations [5] that formulate the operation, and represent the performance of MILA will be developed.

Figure 2.5 shows cross-sectional views of the front and side of the machine that is redrawn with lessened details for ease of understanding in machine analysis.

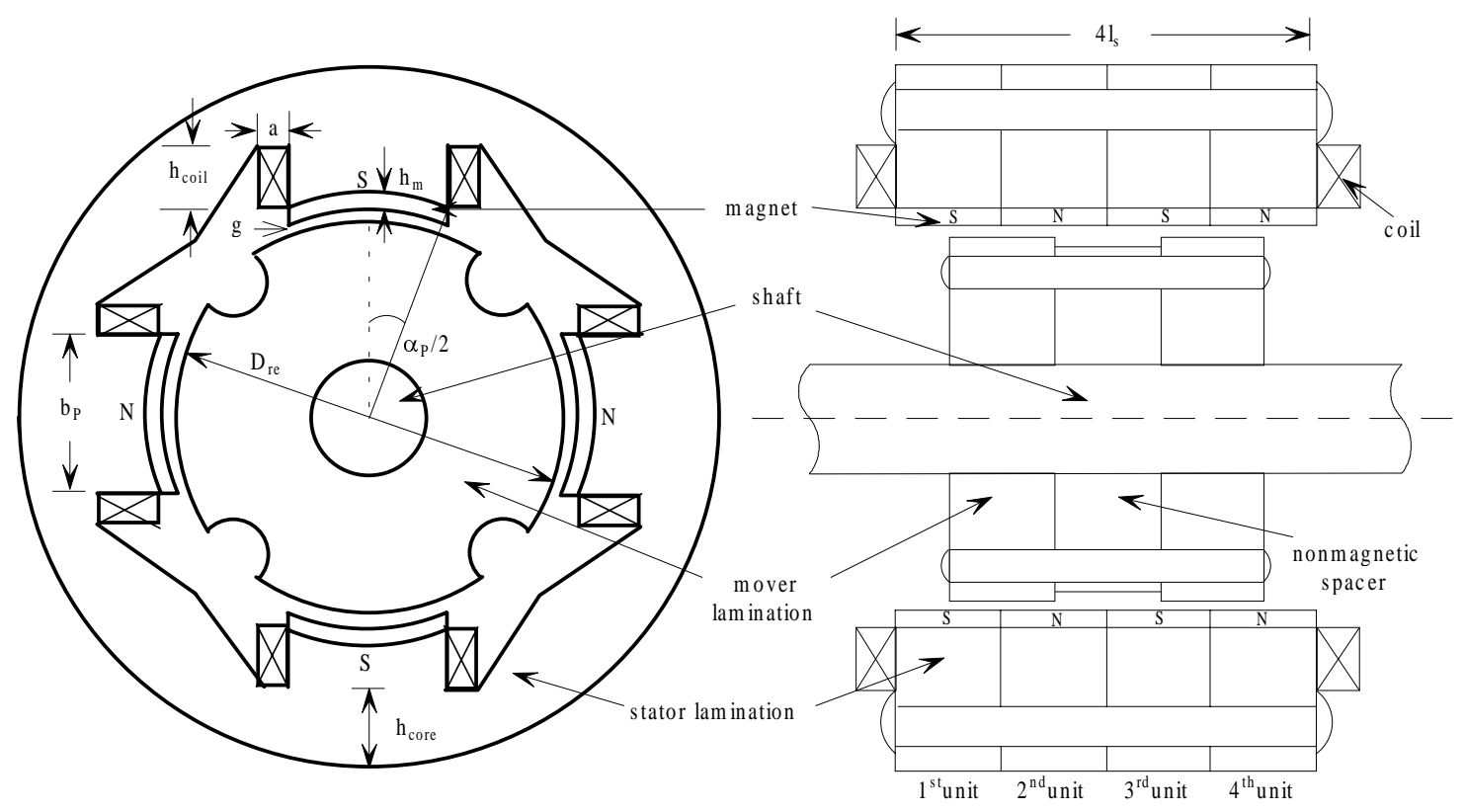

Figure 2.5 A front view and cross-sectional view of MILA

As the translator travels reciprocatingly relative to the stator poles by one pole pitch $\left(l_{s}\right)$, the magnetic flux generated by the permanent magnet in each of four laminated stator units varies between a minimum flux $\left(\phi_{\min }\right)$ and a maximum flux $\left(\phi_{\max }\right)$. From Figure 2.5, the first and third units have the S-polarity permanent magnet, whereas the second and fourth units have the N-polarity permanent magnet. When the translator travels to extreme left side, the positive maximum flux $\left(\phi_{\max }\right)$ establishes in the first and 
third unit, and the negative minimum flux $\left(\phi_{\min }\right)$ establishes in the second and fourth units. On the other hand, when the mover travels to extreme right side, the first and third unit will establish the positive minimum flux, and the other two units will establish the negative maximum flux. From this analytical concept, the variation of combination of magnetic flux from the first $\left(1^{\text {st }}\right)$ and third $\left(3^{\text {rd }}\right)$ stator units relative to the travel position of the translator is drawn in Figure 2.6. Likewise, the variation of combinative flux from the second $\left(2^{\text {nd }}\right)$ and fourth $\left(4^{\text {th }}\right)$ stator units is drawn in Figure 2.7 with negligible saturation and assumed linear variation of the magnetic flux [5].

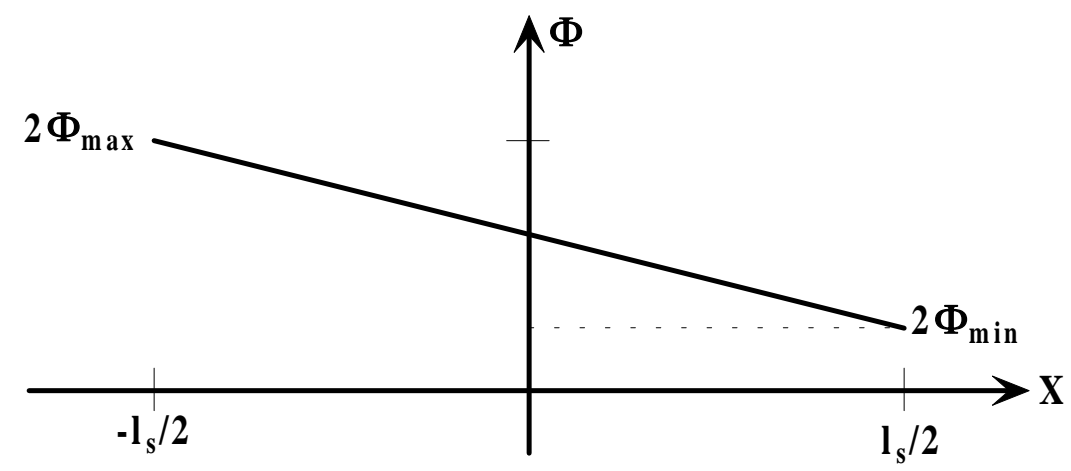

Figure 2.6 The magnetic flux in the $1^{\text {st }}$ and $3^{\text {rd }}$ units versus the translator position

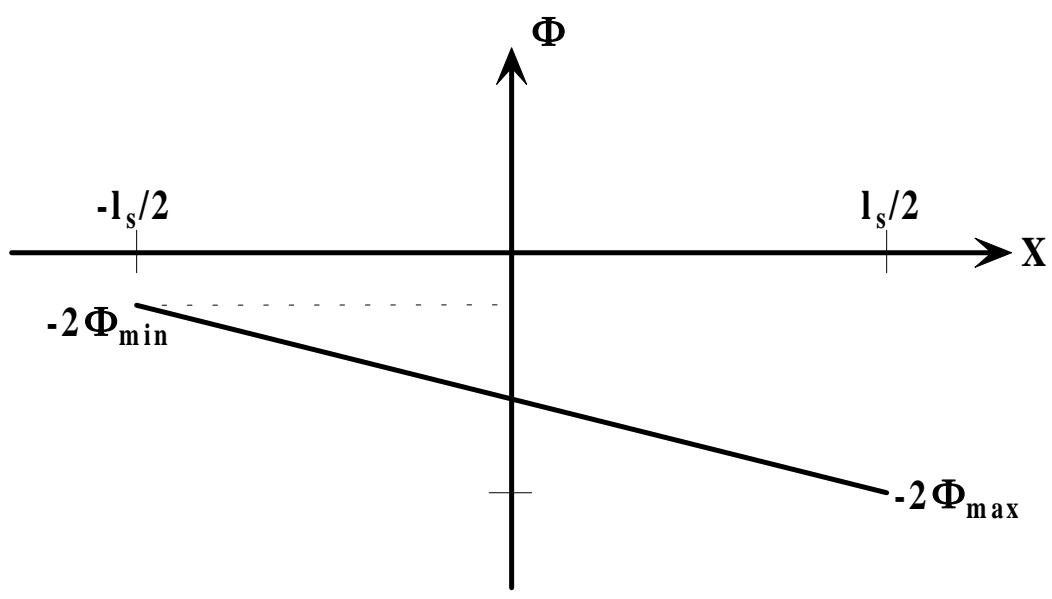

Figure 2.7 The magnetic flux in the $2^{\text {nd }}$ and $4^{\text {th }}$ units versus the translator position 
When the four stator segments are combined as a stator pole, the total flux that flows through each pole of MILA is obtained by combining the graphs in the Figure 2.6 and 2.7 together. Finally, the variation of the total magnetic flux per pole relative to the translator position is shown in Figure 2.8.

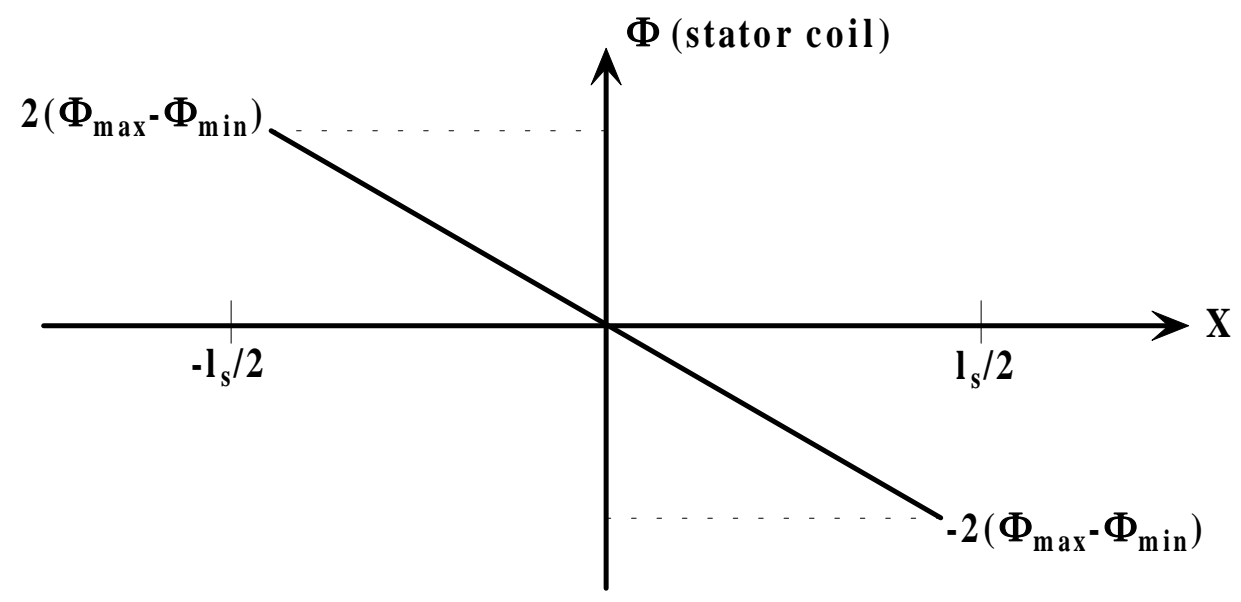

Figure 2.8 The total magnetic flux per pole versus the translator position

From Figure 2.8, the magnetic flux per pole varies between $2\left(\phi_{\max }-\phi_{\min }\right)$ at the extreme left side and $-2\left(\phi_{\max }-\phi_{\min }\right)$ at the extreme right side. In addition, when the translator reaches the middle of the travel interval, the total magnetic flux linking each coil becomes zero [5].

To start analytical procedure, a harmonic motion is applied to the translator

$$
x=\frac{1}{2} l_{s} \sin \omega t
$$

where

$1_{\mathrm{s}}$ is the stroke length or pole pitch

$\omega$ is the frequency of oscillation of the translator 
Each stator pole has a $\mathrm{N}_{\mathrm{c}}$-turn coil winding around the pole length. These coils are placed on the winding slots and connected in series shown in Figure 2.9. Therefore, the resultant induced voltage (E) is four times of the induced voltage across each coil.

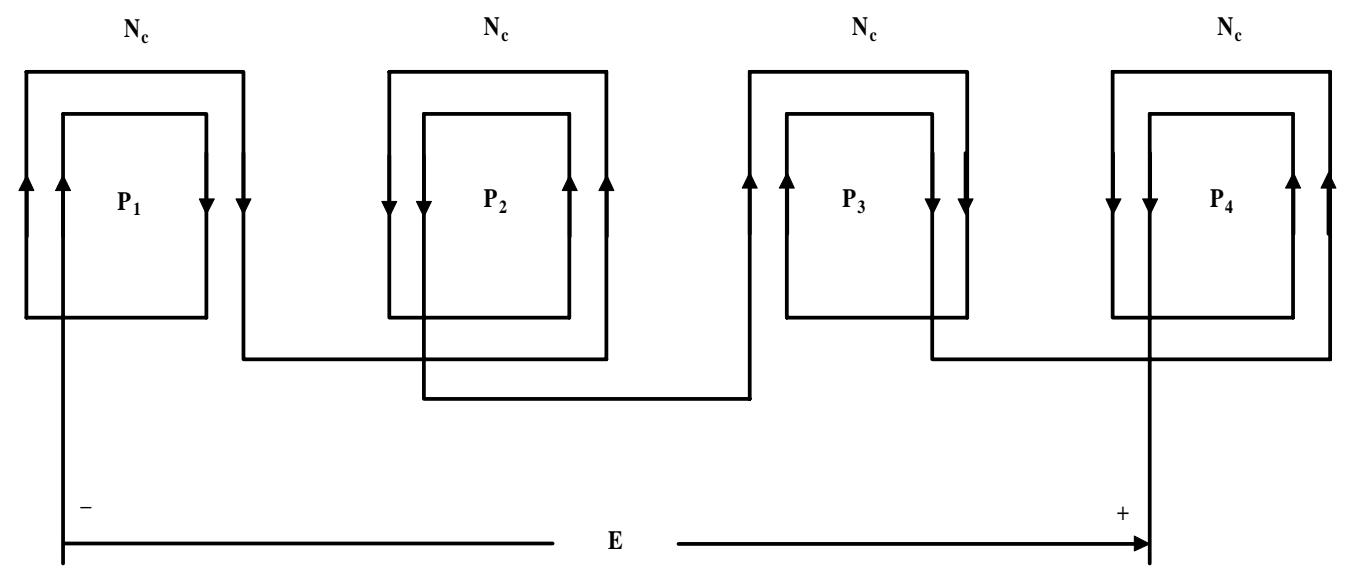

Figure 2.9 A series connection of each stator coil

Based on the electromagnetic theory, an electromotive force (emf) is induced in a closed circuit when the magnetic flux linking the circuit changes.

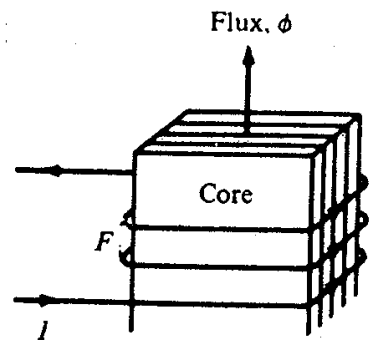

Figure 2.10 The emf induced from changes of the magnetic flux in a coil

$$
\text { emf }=-N \frac{d \phi}{d t}
$$


where

$\mathrm{N}$ is the number of turns per coil

$\phi$ is the magnetic flux linking the coil

According to the equation (2.1), the total induced voltage $(\mathrm{E})$ of the machine that has $\mathrm{P}$ coils $\left(\mathrm{N}_{\mathrm{c}}\right.$ turns each) in series connection is express as

$$
E=-P N_{c} \frac{d \phi}{d t}
$$

Technically, the derivative of the flux $\left(\frac{d \phi}{d t}\right)$ is not directly known, so the position derivative of the flux $\left(\frac{d \phi}{d x}\right)$ is introduced so that.

$$
E=-P N_{c} \frac{d \phi}{d x} \frac{d x}{d t}
$$

or

$$
E=-P N_{c} \frac{d \phi}{d x} v
$$

where $\mathrm{v}$ is the velocity of the mover

$$
v=\frac{1}{2} l_{s} \omega \cos \omega t
$$

In case of that MILA has M laminated stator units, the variation of magnetic flux per pole relative to the mover positive may be redrawn in Figure 2.11 with a defined value $\left(n=\frac{M}{2}\right)$. 
To obtain the position derivative of the flux $\left(\frac{d \phi}{d x}\right)$, the slope of the graph in the Figure 2.11 is to be determined. Fortunately, this graph is linear, so its slope is constant regardless of the translator position. Finally, the position derivative of the flux $\left(\frac{d \phi}{d x}\right)$ is obtained by using the graphical method.

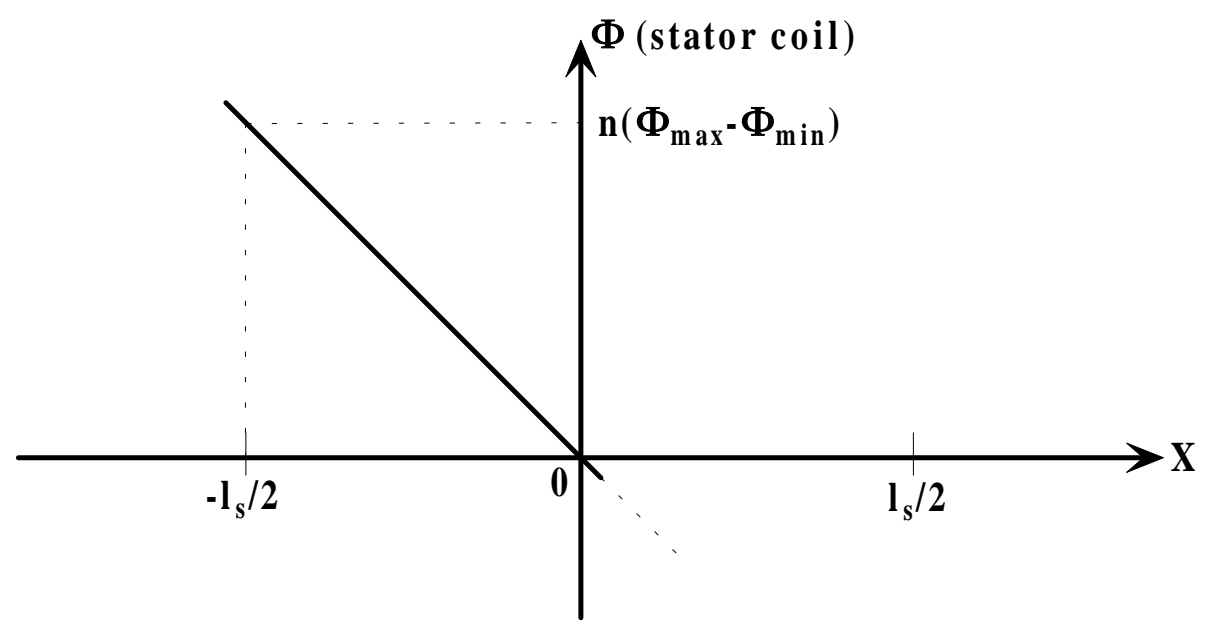

Figure 2.11 Determination of $\left(\frac{d \phi}{d x}\right)$ using a graphical method

$$
\begin{aligned}
\frac{d \phi}{d x} & =\text { slope }=\frac{\Delta Y}{\Delta X} \\
& =-\frac{n\left(\phi_{\max }-\phi_{\min }\right)}{\frac{l_{s}}{2}}
\end{aligned}
$$

Now the induced voltage generated by MILA is obtained from the expression below

$$
E=-P N_{c}\left[\frac{-n\left(\phi_{\max }-\phi_{\min }\right)}{\frac{l_{s}}{2}}\right] \frac{l_{s}}{2} \omega \cos \omega t
$$




$$
E=n P N_{c} \omega\left(\phi_{\max }-\phi_{\min }\right) \cos \omega t
$$

To obtain the maximum voltage, the minimum flux $\left(\phi_{\min }\right)$ should be minimized. For the configuration under this consideration, this goal is accomplished when [5]

$$
g+h_{m} \approx \frac{1}{2} l_{s}
$$

where $\mathrm{g}$ is the mechanical airgap

$\mathrm{h}_{\mathrm{m}}$ is the magnet thickness

Now, to determine $\phi_{\max }$ and $\phi_{\min }$, we refer to permeance function G's shown in Figure 2.12 for two mover positions. The permeance $\mathrm{G}_{4}$ is zero; and, for all practical purposes, only $\mathrm{G}_{3}$ remains for the first mover segment and $2 \mathrm{G}_{3}$ for the second. However, $\mathrm{G}_{3}$ on the left side of mover segment 1 cancels one $\mathrm{G}_{3}$ for the $\phi_{\min }$, and $\mathrm{G}_{2 \mathrm{n}}$ cancels $\mathrm{G}_{5}$. Thus, for the difference ( $\left.\phi_{\max }-\phi_{\min }\right)$ only, $\mathrm{G}_{\mathrm{g} 1}(0)$ counts for $\phi_{\max }$ and $\mathrm{G}_{3}$ for $\phi_{\min }[5]$.

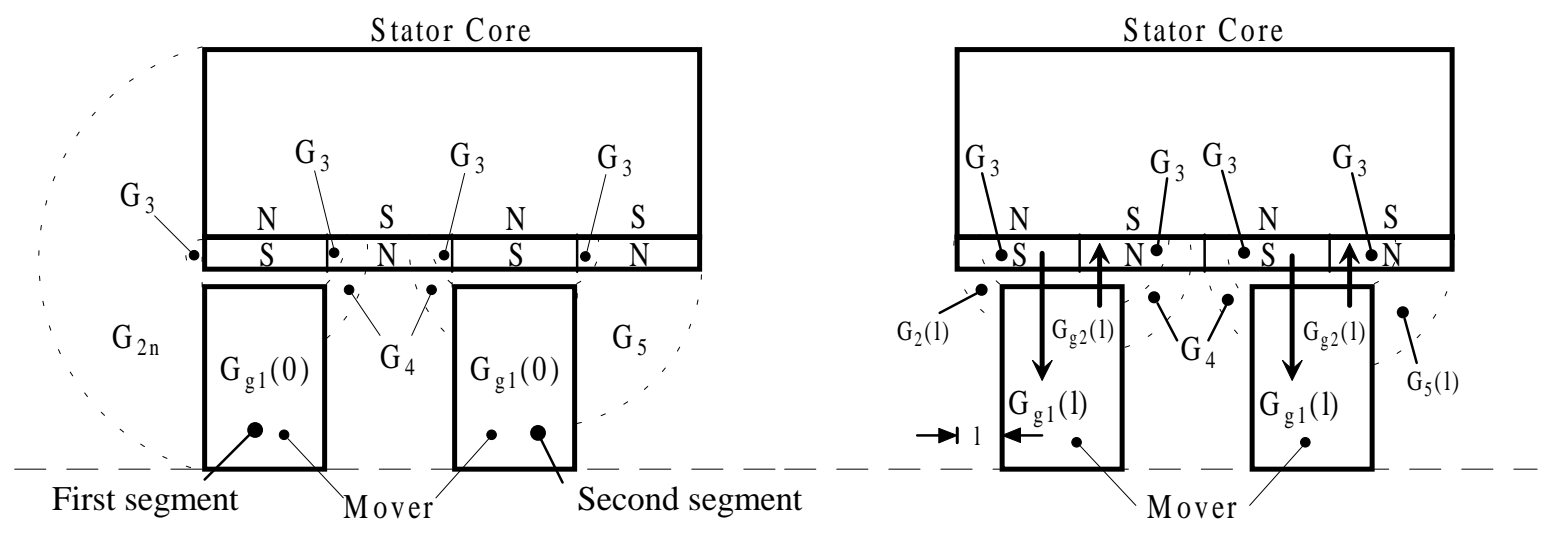

Figure 2.12 The permeance at $l=0$, and $l \neq 0$

According to Figure 2.12, magnetic circuits of MILA are drawn in Figure 2.13 to determine the minimum flux $\left(\phi_{\min }\right)$ and the maximum flux $\left(\phi_{\max }\right)$. 


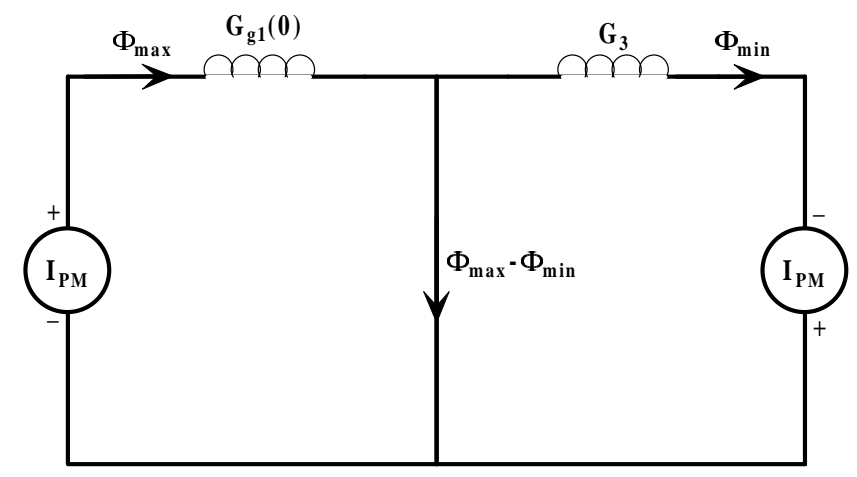

Figure 2.13 The magnetic circuit of MILA
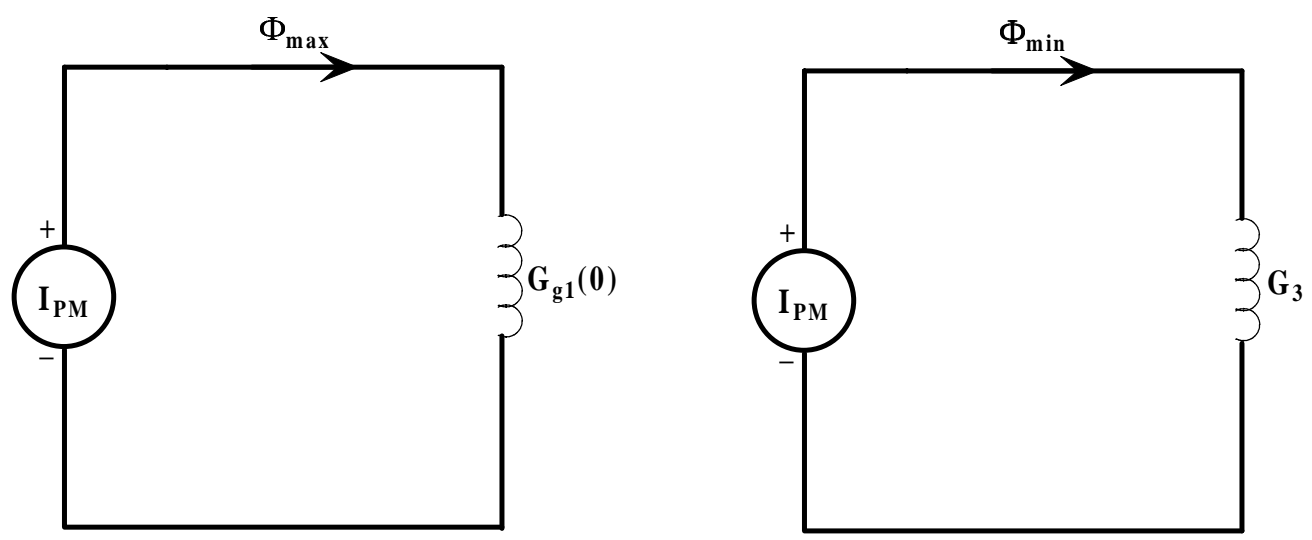

Figure 2.14 Using superposition method to determine $\Phi_{\max }$ and $\Phi_{\min }$

From the magnetic circuits above, the permanent magnets are replaced by its equivalent mmf $\mathrm{I}_{\mathrm{PM}}$ that [6]

$$
I_{P M}=\frac{B_{r} h_{m}}{\mu_{r c}}
$$

where

$\mathrm{I}_{\mathrm{PM}}$ is the permanent magnet coercive $\mathrm{mmf}$

$B_{r}$ is the remnant flux density

$\mu_{\mathrm{rc}}$ is the magnet recoil permeability 
Both permanent magnet mmf at the airgap see the permeance $G_{\mathrm{g} 1}(0)$ and $G_{3}$ in their own circuits and generates the maximum flux $\left(\phi_{\max }\right)$ and the minimum flux $\left(\phi_{\min }\right)$ respectively established in the circuit.

$$
\begin{aligned}
& \phi_{\max }=G_{g 1}(0) I_{P M} \\
& \phi_{\min }=G_{3} I_{P M}
\end{aligned}
$$

An accurate estimation of the permeance $G$ by calculating magnetic circuit with the permanent magnets is a difficult task. To facilitate this task, the magnetic flux density and magnetic field intensity are assumed to be uniform in the whole volume of the permanent magnets.

In order to determine the maximum permeance $\mathrm{G}_{\max }$, the Figure 2.15, a portion of MILA including the permanent magnets and airgap, is drawn to help permeance determination more conveniently.

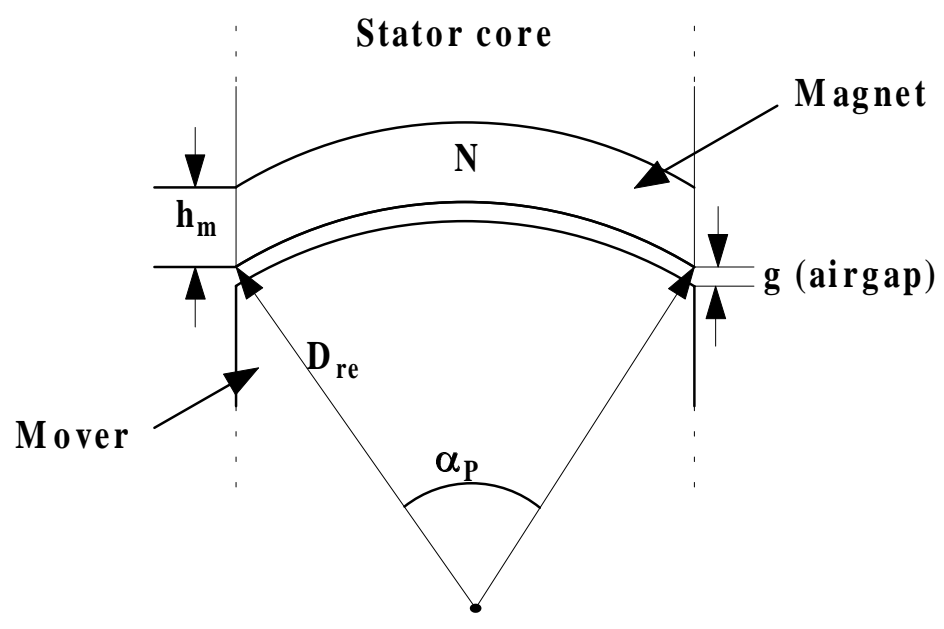

Figure 2.15(a) A portion of MILA including stator core and mover 


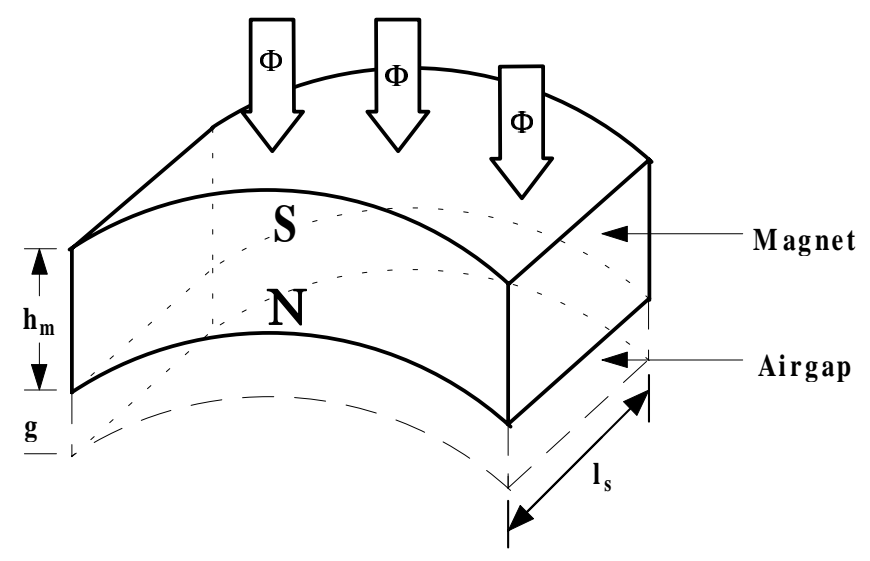

Figure 2.15(b) The permeance of the magnet and airgap

$$
\begin{gathered}
\text { averagediameter }(d)=\frac{D_{r e}+\left(D_{r e}+2\left(g+h_{m}\right)\right)}{2} \\
d=D_{r e}+\left(g+h_{m}\right) \\
G_{\max }=\frac{\mu_{0} A}{l}=\frac{\mu_{0}(\pi d) l_{s}}{g+h_{m}} \frac{\alpha_{P}}{360} \\
G_{\max }=\mu_{0} \pi\left(D_{r e}+\left(g+h_{m}\right)\right) \frac{l_{s}}{g+h_{m}} \frac{\alpha_{P}}{360}
\end{gathered}
$$

For $\mathrm{G}_{\min }$, we do the same process [8]

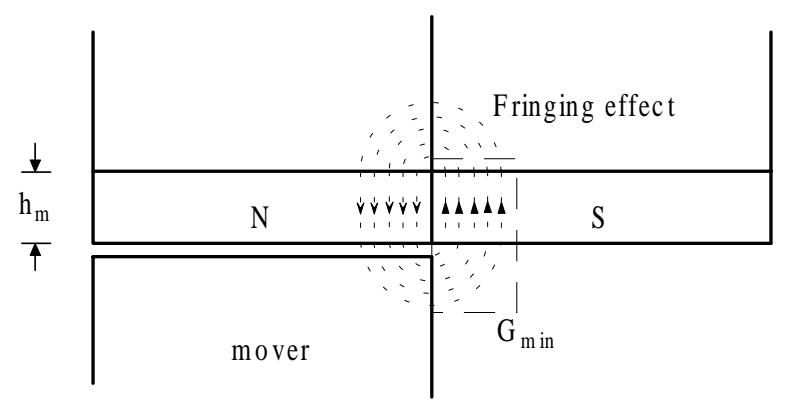

Figure 2.16 The permeance occurring at fringing area 


$$
\begin{gathered}
\text { length }(l)=h_{m}+\frac{\pi h_{m}}{4} \\
\text { Cross-section area }=h_{m} \pi\left(D_{r e}+g+h_{m}\right) \frac{\alpha_{P}}{360} \\
G_{\min }=\frac{\mu_{0} h_{m} \pi\left(D_{r e}+g+h_{m}\right)}{h_{m}+\frac{h_{m}}{4}} \frac{\alpha_{P}}{360} \\
G_{\min }=\frac{\mu_{0}\left(D_{r e}+g+h_{m}\right)}{\frac{1}{\pi}+\frac{1}{4}} \\
G_{\min }=1.7596 \mu_{0}\left[D_{r e}+\left(g+h_{m}\right)\right] \frac{\alpha_{P}}{360}
\end{gathered}
$$

The moving iron linear alternator can be represented as an equivalent circuit in Figure 2.17.

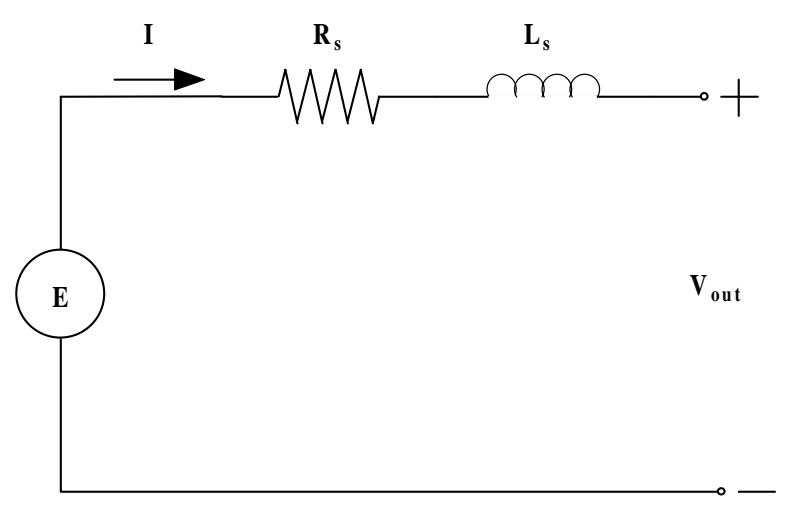

Figure 2.17 An equivalent circuit of MILA 
The parameters of this circuit are then determined. The machine resistance $R_{s}$ is achieved by the following

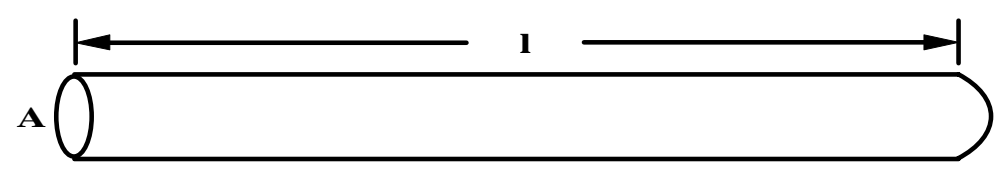

Figure 2.18 A cylindrical conductor

The resistance of a cylindrical conductor can be expressed as

$$
R=\frac{\rho l}{A}
$$

where

$\rho$ is the electrical resistivity

1 is the length of conductor

$\mathrm{A}$ is the cross-section area of conductor

We apply this expression to MILA that has four N-turn coils. The length per turn of conductor is $1_{\mathrm{s}}$ and shown in Figure 2.19.

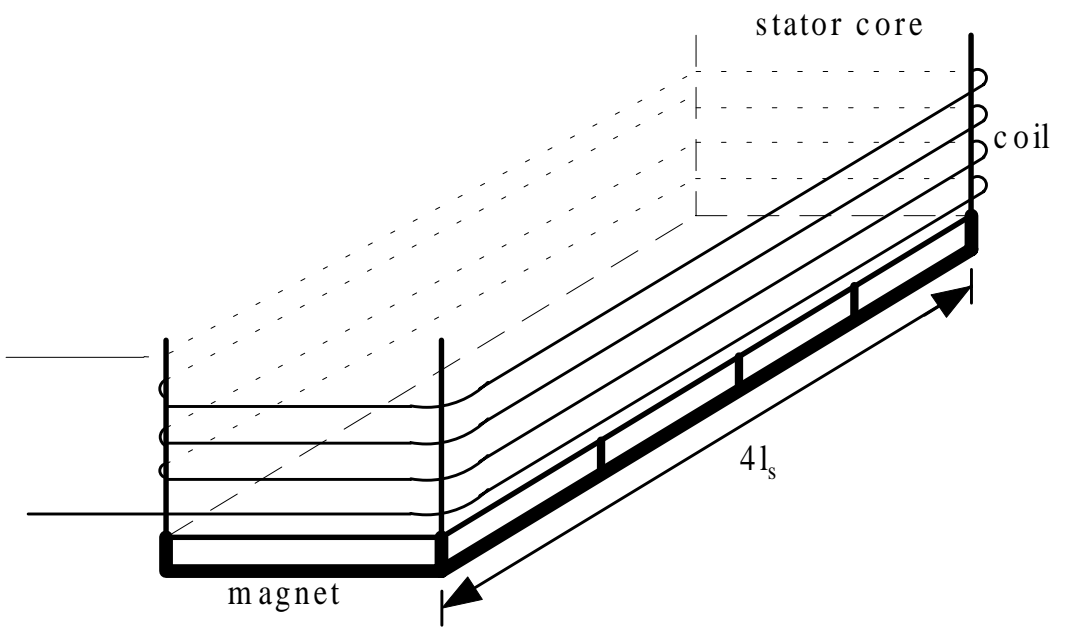

Figure 2.19 (a) A stator coil of MILA 


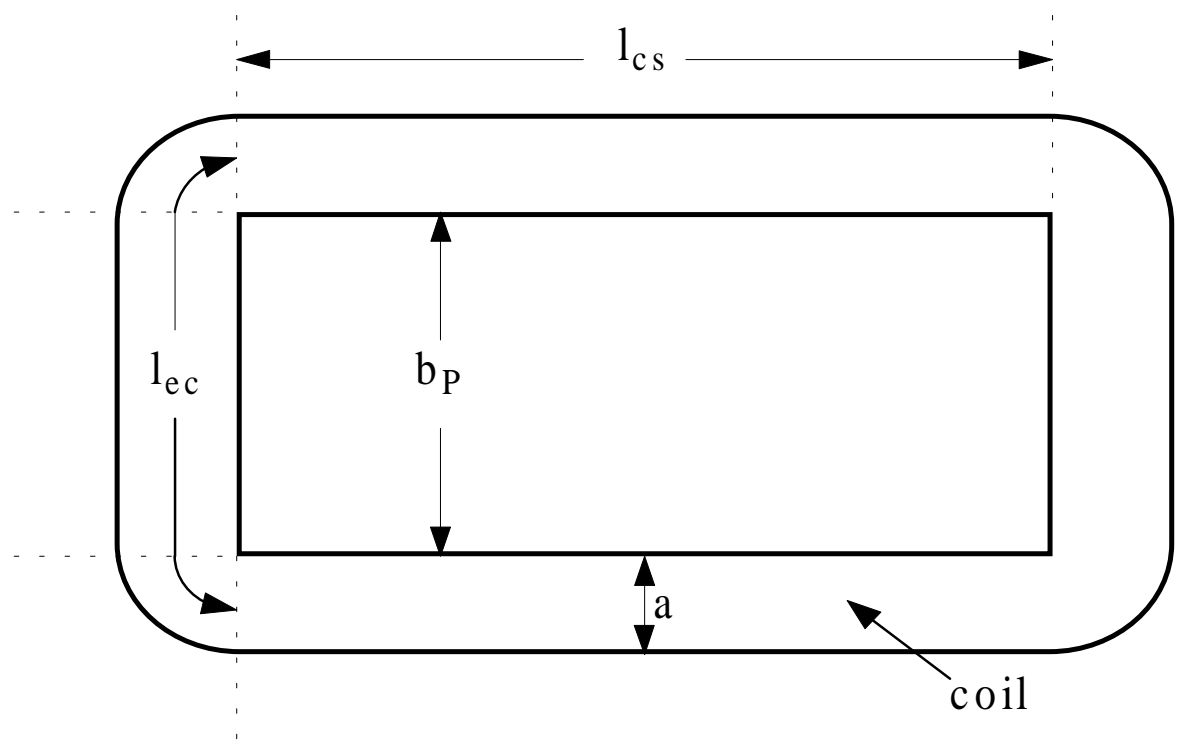

Figure 2.19 (b) A top view of the stator coil

$$
\begin{aligned}
& l_{c}=2\left(l_{c s}+l_{e c}\right) \\
& R_{s}=\frac{N_{c} P l_{c} \rho_{c o}}{A_{c}}
\end{aligned}
$$

where

$l_{c}$ is the length per turn of conductor

$l_{\text {cs }}$ is the coil length in slot

$l_{\mathrm{ec}}$ is the coil end-connection length per side

$\rho_{\mathrm{co}}$ is the copper electrical resistivity

$\mathrm{N}_{\mathrm{c}}$ is the number of turns per coil

$\mathrm{P}$ is the number of poles

$\mathrm{A}_{\mathrm{c}}$ is the cross-section area of the conductor 
We can also write the equation (2.22) as [5]

$$
\begin{aligned}
& R_{s}=\frac{N_{c}^{2} P l_{c} \rho_{c o} J_{c}}{N_{c} I_{a}} \\
& J_{c}=\frac{I_{a}}{A_{c}}
\end{aligned}
$$

where

$\mathrm{J}_{\mathrm{c}}$ is the designed current density

$I_{a}$ is the rated current

Now the machine inductance is determined regarding to the basic theory of electric circuits.

$$
L=\frac{N^{2}}{\mathfrak{R}}=N^{2} G
$$

where

$\mathrm{N}$ is the number of turns per coil

$\mathfrak{R}$ is the reluctance of the magnetic circuit

$\mathrm{G}$ is the permeance of the magnetic circuit

For the moving iron linear alternator, its inductance $\left(\mathrm{L}_{\mathrm{s}}\right)$ is regardless to the position of the mover and comprises two components: $\mathrm{L}_{\mathrm{m}}$ is the magnetizing inductance and $\mathrm{L}_{1}$ is the leakage inductance.

$$
L_{s}=L_{m}+L_{l}
$$


Now the coil permeance $\mathrm{G}_{\text {coil }}$ is defined [5]

$$
G_{\text {coil }}=n\left[G_{\max }+G_{\min }\right]
$$

(a)

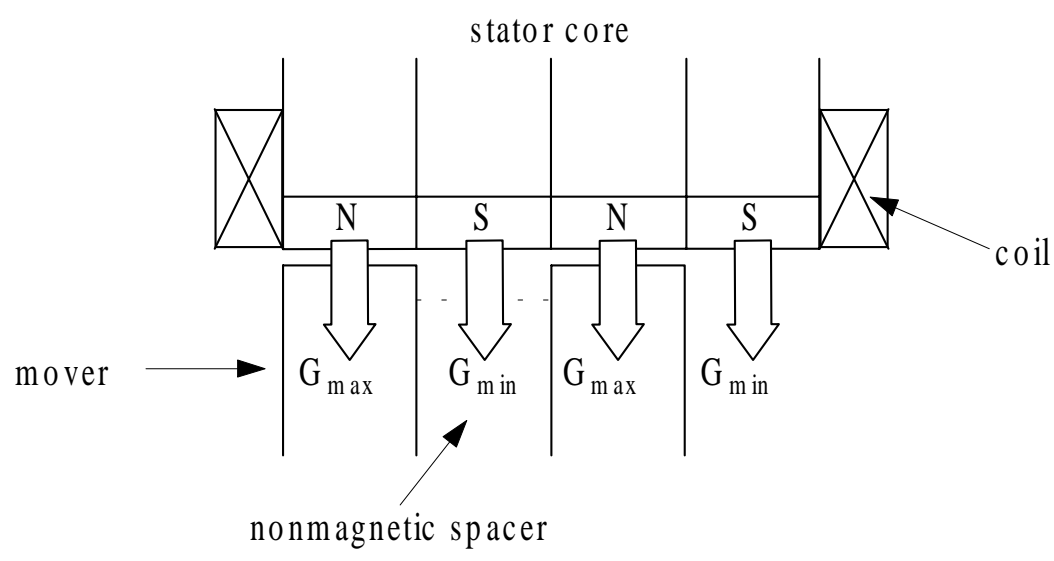

(b)

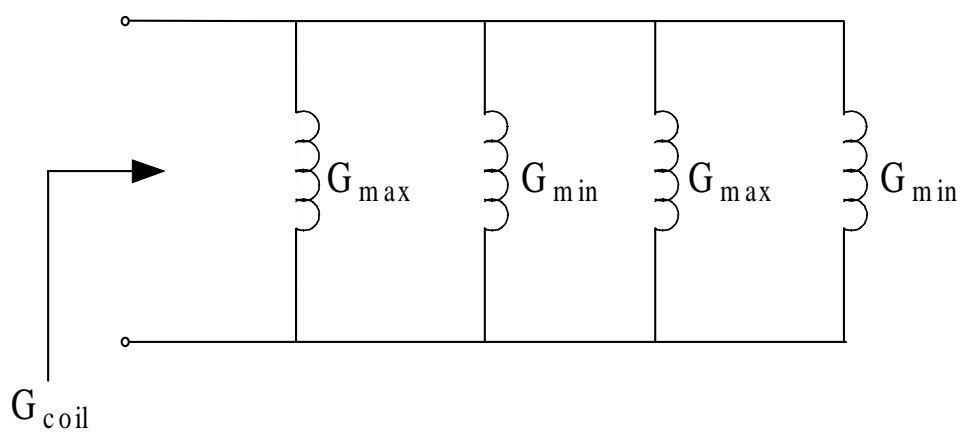

Figure 2.20 a) Permeance of a coil of MILA and b) parallel connection of these permeance

The magnetizing inductance is expressed as

$$
L_{m}=P G_{\text {coil }} N_{c}^{2}
$$

The leakage inductance consists of slot leakage and end-connection leakage inductance. The expression of the total leakage inductance can be written as [5] 


$$
L_{l}=2 P N_{c}^{2}\left(\lambda_{s} l_{c s}+\lambda_{e} l_{e c}\right)
$$

The coil length in slot is

$$
L_{c s}=2 n l_{s}
$$

The coil end-connection length per side is

$$
L_{e c}=b_{P}+\frac{\pi a}{2}
$$

(Figure 2.19 will be helpful for the above equations)

Later, the slot-specific permeance $\left(\lambda_{\mathrm{s}}\right)$ is approximated as [5]

$$
\lambda_{s} \approx \frac{h_{c o i l}}{3 a}
$$

And also, the end-connection-specific permeance $\left(\lambda_{e}\right)$ is

$$
\lambda_{e}=\frac{1}{2} \lambda_{s}
$$

This set of equations is applied for conceptual design in Chapter 3. Some equations may be modified depending on existent constraints. 


\section{CONCEPTUAL DESIGN}

Conceptual design is the first step in the machine development. Referring to the last chapter, the analytical principle of the machine is used to proceed with the design procedure. The primary goal of this thesis is to design a moving iron linear alternator (MILA) to properly cooperate with the existing linear engine in the laboratory.

\section{$\underline{\text { 3.1 Linear Internal Combustion Engine }}$}

The linear engine is an important subsystem and used as the prime mover of the generation system. In this thesis, the existing linear internal combustion engine at West Virginia University is used to be the prime mover of MILA, which will be subsequently designed. The engine concept is based on a two-stroke spark-ignited combustion cycle. The engine has two pistons mounted on each end of a shaft, which is free to oscillate within the cylinder-shaped body of linear engine. In Figure 3.1, the linear engine is illustrated in a cross-sectional view.

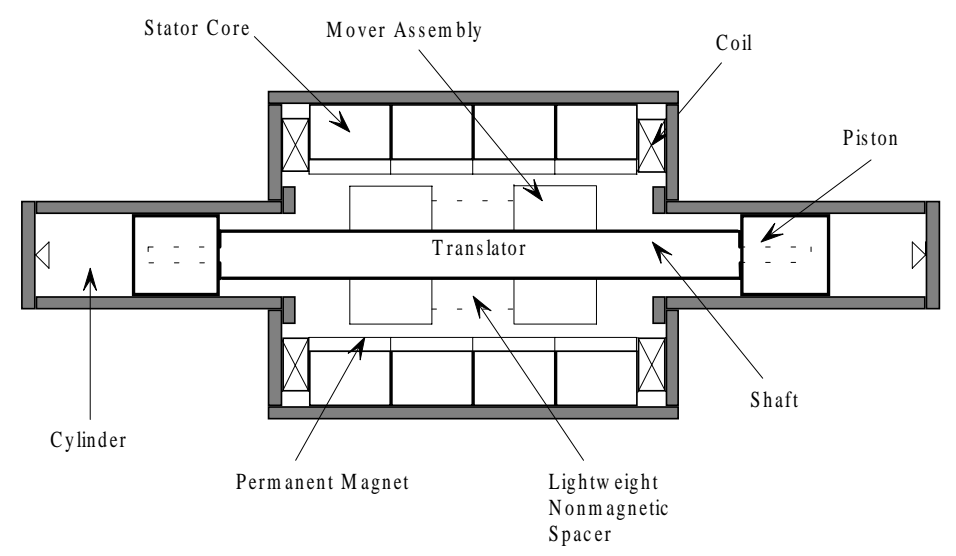

Figure 3.1 Cross-sectional view of Linear Engine with Linear Alternator 
Combustion occurs alternately at the ends in each cylinder. As one end has a combustion, internal explosion will push the piston assembly to the other end of the cylinder. Likewise, when combustion occurs at the other end of the cylinder, the other piston assembly will be pushed back to the opposite direction. Therefore, the expansion and compression processes occur alternately at both ends of the cylinder similar to behavior of a non-linear spring. This causes the shaft of the engine, which carries the mover of linear alternator that moves in back and forth. The force balance equation is obtained from the sum of the forces acting on the pistons due to internal pressure in cylinder and the electromagnetic force of the alternator. The force balance equation is then equal to the mass of the piston assembly multiplied by its acceleration [9]-[10]. The resonant frequency of oscillation can be obtained from this dynamic equation.

\subsection{MILA Design Procedure}

The design procedure of moving iron linear alternator (MILA) developed by Boldea and Nasar [5] is presented for helping readers understand the design process clearly. However, some parts of the design procedure must be modified to be suitable for using with the linear engine [10]. The following specifications are used for the design of MILA:

$\begin{array}{ll}\text { Output voltage }\left(\mathrm{V}_{\mathrm{o}}\right) & 120 \mathrm{~V} \\ \text { Input power }\left(\mathrm{P}_{\mathrm{e}}\right) & 613.78 \mathrm{~W} \text { (from the linear engine) } \\ \text { Rated frequency }(\mathrm{f}) & 25 \mathrm{~Hz} \\ \text { Stroke length }\left(\mathrm{l}_{\mathrm{s}}\right) & 0.04191 \mathrm{~m} \\ \text { Desired efficiency }(\eta) & 0.8\end{array}$

From the previous experiment, the permanent magnet linear alternator (PMLA) was tested with the linear engine and produced the reciprocating frequency at $25 \mathrm{~Hz}$. To design MILA operating at $25 \mathrm{~Hz}$, the translator mass of MILA will be designed equal to that of PMLA.

Translator mass of MILA $=$ Translator mass of PMLA $=4.1337 \mathrm{~kg}$ 
Figure 3.2 shows a cross-sectional view of the linear engine with the translator of MILA. The translator mass is the sum of the mover mass, shaft mass and piston mass.

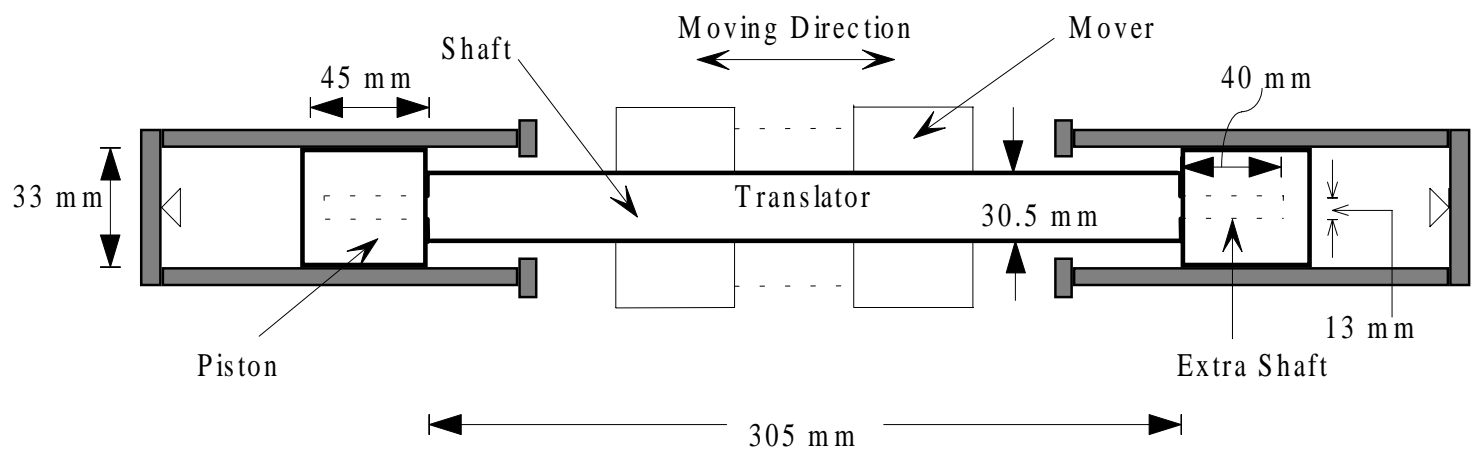

Figure 3.2 Cross-sectional view of the linear engine

Translator Mass $=$ Mover Mass + Piston Mass + Shaft Mass

To obtain the mover mass, the shaft mass and piston mass must be first determined. The volume of the shaft and piston are calculated from

$$
\begin{aligned}
\text { Shaft Volume } & =\frac{\pi D_{\text {shaft }}^{2} l_{\text {shaft }}}{4}+2 \frac{\pi D_{\text {extra shaft }}^{2} l_{\text {extra shaft }}}{4} \\
& =\frac{\pi\left(0.0305^{2}\right)(0.305)}{4}+2\left(\frac{\pi\left(0.013^{2}\right)(0.040)}{4}\right) \\
& =2.3346 \times 10^{-4} m^{3} \\
\text { Piston Volume } & =2\left(\frac{\pi D_{\text {piston }}^{2} l_{\text {piston }}}{4}-\frac{\pi D_{\text {extra shaft }}^{2} l_{\text {extra shaft }}}{4}\right)
\end{aligned}
$$




$$
\begin{aligned}
& =2\left(\frac{\pi\left(0.033^{2}\right)(0.045)}{4}-\frac{\pi\left(0.013^{2}\right)(0.040)}{4}\right) \\
& =6.6358 \times 10^{-5} \mathrm{~m}^{3}
\end{aligned}
$$

Both parts are made of Aluminum, which has density $2700 \mathrm{~kg} / \mathrm{m}^{3}$. The mass of moving parts of the engine is determined from

$$
\begin{aligned}
\text { Shaft Mass } & =\text { Shaft Volume } \text { Aluminum Density } \\
& =\left(2.3346 \times 10^{-4}\right)(2700)=0.6303 \mathrm{~kg} \\
\text { Piston Mass } & =\text { Piston Volume } \cdot \text { Aluminum Density } \\
& =\left(6.6358 \times 10^{-5}\right)(2700)=0.1792 \mathrm{~kg}
\end{aligned}
$$

Finally, the mass of mover is obtained from

$$
\begin{aligned}
\text { Mover Mass } & =\text { Translator Mass }- \text { Shaft Mass }- \text { Piston Mass } \\
& =4.1337-0.6303-0.1792=3.3242 \mathrm{~kg}
\end{aligned}
$$

The mover assembly is made of iron, which has the density $7874 \mathrm{~kg} / \mathrm{m}^{3}$. Therefore, the volume of the mover assembly is calculated from

$$
\begin{aligned}
\text { Mover Volume } & =\text { Mover Mass } / \text { Iron Density } \\
& =3.3242 /(7874) \\
& =4.2217 \times 10^{-4} \mathrm{~m}^{3}
\end{aligned}
$$


Figure 3.3 illustrates the configuration of the mover assembly that is helpful for determining the outer diameter of the mover $\left(D_{\text {re }}\right)$.

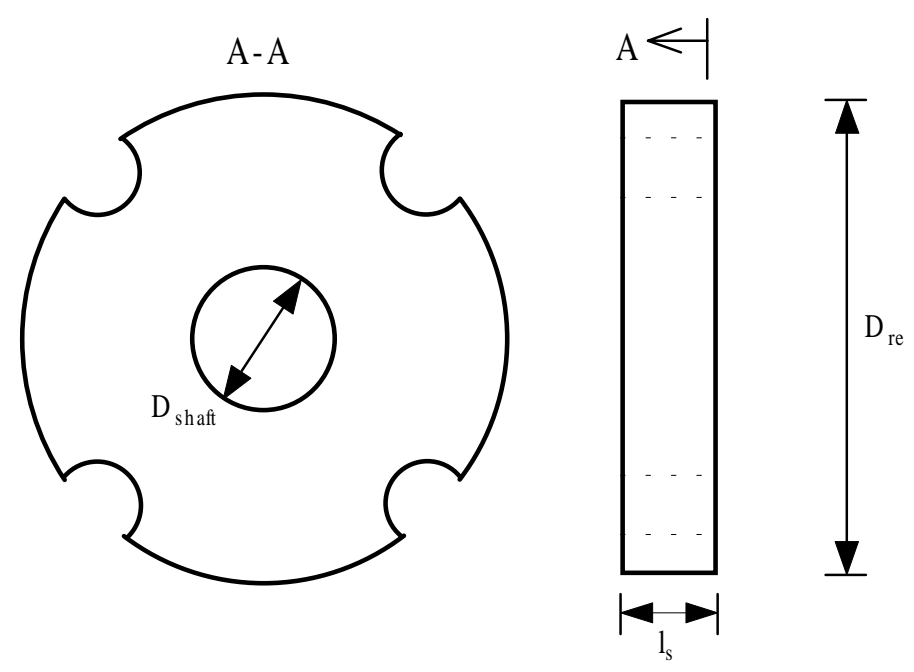

Figure 3.3 The radial cross-sectional and axial cross-sectional views of the mover assembly

$$
\text { Mover Volume }=n l_{s} \pi\left(\frac{D_{r e}^{2}}{4}-\frac{D_{\text {shaft }}^{2}}{4}-\frac{\pi^{2}}{2}\left(\frac{D_{r e}}{16}\right)^{2}\right)
$$

where

$\mathrm{n}$ is the number of mover assembly $(\mathrm{n}=2)$

$1_{\mathrm{s}}$ is the stroke length

then

$$
\text { Diameter of mover }\left(\mathrm{D}_{r e}\right)=0.0892 \mathrm{~m}
$$

Figure 3.4 shows cross-sectional views of the front and side of MILA as well as the physical dimensions of the machine [5]. 


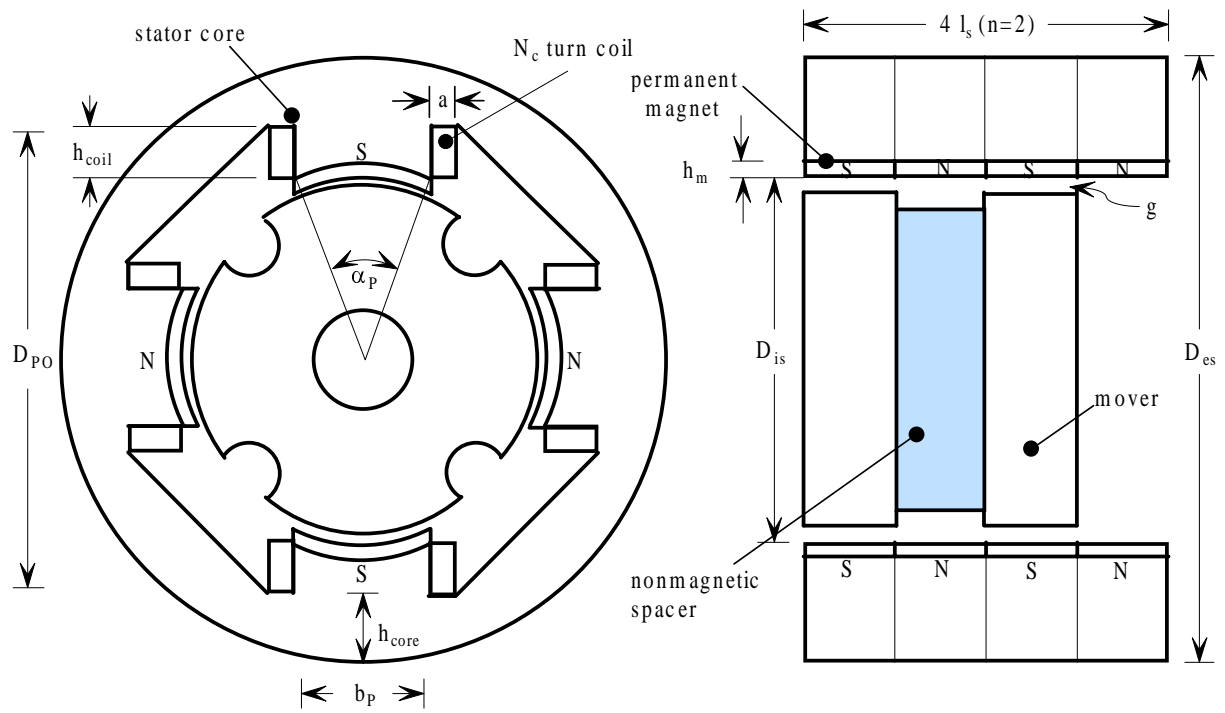

Figure 3.4 Cross sectional views showing physical dimensions of MILA

For the permanent magnets, we choose $\mathrm{NdFeB}$, which has the following properties:

Specific weight $\left(\gamma_{\mathrm{PM}}\right)$ $7600 \mathrm{~kg} / \mathrm{m}^{3}$

Residual flux density @ $20^{\circ} \mathrm{C}\left(\mathrm{B}_{\mathrm{r}}\right) \quad 1.2293 \mathrm{~T}$

Coercive force @ $20^{\circ} \mathrm{C}\left(\mathrm{H}_{\mathrm{c}}\right) \quad 0.9 \mathrm{MA} / \mathrm{m}$

Recoil permeability $\left(\mu_{\text {re }}\right) \quad 1.0446 \mu_{0}$

Temperature coefficient of $\mathrm{B}_{\mathrm{r}}\left(\mathrm{k}_{\mathrm{Br}}\right) \quad-0.12 \%$ per ${ }^{\circ} \mathrm{C}$

Temperature coefficient of $\mathrm{Hc}\left(\mathrm{k}_{\mathrm{Hc}}\right) \quad-0.6 \%$ per ${ }^{\circ} \mathrm{C}$

Operating temperature (T) $\quad 75^{\circ} \mathrm{C}$

thus

$$
\begin{aligned}
B_{r} @ 75^{\circ} \mathrm{C} & =B_{r o}\left[1+\frac{k_{B r}}{100}(T-20)\right] \\
& =1.1482 \mathrm{~T}
\end{aligned}
$$

and

$$
H_{c} @ 75^{\circ} c=H_{c o}\left[1+\frac{k_{H c}}{100}(T-20)\right]
$$




$$
=0.6030 \mathrm{MA} / \mathrm{m}
$$

Next, the airgap could be chosen between 0.4 and $1 \mathrm{~mm}$ for output power $\mathrm{P}=100$ to 1000 Watt. For the present design, we choose the airgap (g) equal to $1 \mathrm{~mm}$. In addition, the permanent magnet radial thickness can be between (4-6)g [5], we choose $h_{m}$ $=5 \mathrm{~g}=5 \mathrm{~mm}$.

The stator bore can be calculated from

$$
\begin{aligned}
D_{i s} & =D_{r e}+2 g \\
& =0.0912 \mathrm{~m}
\end{aligned}
$$

Later, the number of stator circumferential poles $(\mathrm{P})$ is designed equal to 4. Therefore, the pole span $\alpha_{P}$ is obtained from

$$
\alpha_{P}=\frac{360}{P} k_{P} \text { with } \quad k_{P}=0.5 \text { to } 0.65
$$

Selecting the pole span coefficient $\mathrm{k}_{\mathrm{p}}=0.5$ for the present design, we obtain

$$
\alpha_{P}=\frac{360}{4} \times 0.5=45^{\circ}
$$

In order to calculate the permanent magnet maximum and minimum flux, $\phi_{\max }$ and $\phi_{\min }$ respectively, per pole, the flux distribution of the machine in Figure 3.5 is considered. Determining the airgap permeance having both maximum and minimum values, $G_{\max }$ and $G_{\min }$, leads into obtaining the $\phi_{\max }$ and $\phi_{\min }$ respectively. 


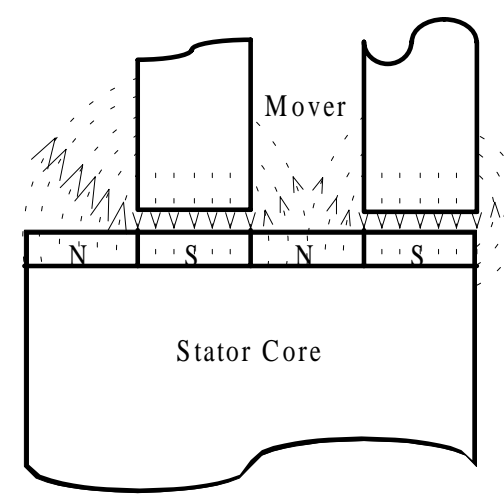

Figure 3.5 Approximate flux density distribution

From the equation (2.16)

$$
\begin{aligned}
G_{\max } & =\mu_{0} \pi\left[D_{i s}-(2 g)+\left(g+h_{m}\right)\right] \frac{l_{s}}{g+h_{m}} \frac{\alpha_{P}}{360} \\
& =4 \pi \times 10^{-7} \pi[0.0912-(2 \times 0.001)+0.006] \frac{0.04191}{0.006} \times \frac{45}{360} \\
& =3.2815 \times 10^{-7} \mathrm{H}
\end{aligned}
$$

Later,

$$
G_{\min }=\left(1+k_{\sigma}\right)\left(G_{\min 1}+G_{\min 2}\right)
$$

where the leakage coefficient $\mathrm{k}_{\sigma}$ accounts for the extreme left and extreme right position's flux lines [5].

$$
\begin{aligned}
G_{\min 1} & =1.7596 \mu_{0}\left(D_{r e}+g+h_{m}\right) \frac{\alpha_{P}}{360} \\
& =1.7596 \times 4 \pi \times 10^{-7}(0.0892+0.001+0.005) \frac{45}{360}=2.6313 \times 10^{-8} H
\end{aligned}
$$


Check if $l_{s} \leq 2\left(g+h_{m}\right)$, then $G_{\min 2}=0$. Otherwise, $G_{\min 2}$ will be determined from [5]

$$
\begin{aligned}
G_{\min 2} & =4 \mu_{0}\left(\frac{1}{2} D_{i s}-\sqrt{\frac{1}{2} l_{s}\left(g+h_{m}\right)}\right) \ln \left[\frac{l_{s}}{2\left(g+h_{m}\right)}\right] \frac{\alpha_{P}}{360} \\
& =4 \times 4 \pi \times 10^{-7}\left(\frac{0.0912}{2}-\sqrt{\frac{1}{2} \times 0.04191 \times 0.006}\right) \ln \left[\frac{0.04191}{2(0.006)}\right] \frac{45}{360} \\
& =2.7021 \times 10^{-8} \mathrm{H}
\end{aligned}
$$

Assume $\mathrm{k}_{\sigma}=0.5$, finally we obtain

$$
\begin{aligned}
G_{\min } & =(1+0.5)(2.6313+2.7021) 10^{-8} \\
& =0.08 \times 10^{-6} \quad H
\end{aligned}
$$

The permanent magnet $\mathrm{mmf} \mathrm{I}_{\mathrm{PM}}$ (per pole) is determined from

$$
I_{P M}=\frac{B_{r} h_{m}}{\mu_{r e}}=\frac{1.1482 \times 0.005}{1.0446 \times 4 \pi \times 10^{-7}}=4.3735 \times 10^{3} \mathrm{~A}
$$

Regarding to the saturation effect of the airgap, the saturation factor $\left(\mathrm{k}_{\mathrm{s}}\right)$ might be applied [5]. For the present design, we choose $\mathrm{k}_{\mathrm{s}}=0.025$.

$$
\begin{aligned}
\phi_{\max } & =\frac{G_{\max } I_{P M}}{1+k_{s}}=\frac{3.2815 \times 10^{-7} \times 4.3735 \times 10^{3}}{1+0.025} \\
& =0.0014 \quad \mathrm{~Wb} / \text { pole }
\end{aligned}
$$




$$
\begin{aligned}
\phi_{\min } & =\frac{G_{\min } I_{P M}}{1+k_{s}}=\frac{0.08 \times 10^{-6} \times 4.3735 \times 10^{3}}{1+0.025} \\
& =0.3414 \times 10^{-3} \quad \mathrm{~Wb} / \text { pole }
\end{aligned}
$$

Referring to the equation (2.9), we can determine the induced voltage $\mathrm{E}$ (rms) from

$$
E_{r m s}=\operatorname{Pn}\left(\phi_{\max }-\phi_{\min }\right) \cdot \frac{\text { velocity }_{r m s}}{l_{s} / 2} k_{r e} N_{c}=C_{e} N_{c}
$$

where

$\mathrm{k}_{\mathrm{re}}$ is a reduction factor owing to waveform distortion (0.9-0.95)

velocity $_{\mathrm{rms}}$ is the RMS value of the velocity of the mover obtained from differentiating the position data from the experiment @ $\mathrm{f}=25 \mathrm{~Hz}$

From the above equation, we obtain

$$
\begin{aligned}
C_{e} & =\operatorname{Pn}\left(\phi_{\max }-\phi_{\min }\right) \cdot \frac{\text { velocity }_{r m s}}{l_{s} / 2} k_{r e} \\
& =(4)(2)\left(0.0014-0.3414 \times 10^{-3}\right) \frac{2.102}{0.04191 / 2}(0.95) \\
& =0.8072 \mathrm{~V}
\end{aligned}
$$

The mmf or ampere-turns per pole is

$$
N_{c} I_{n}=\frac{P_{e}}{C_{e}}=\frac{613.78}{0.8072}=760.39 \text { At/ pole }
$$


The rated current density $\mathrm{J}_{\mathrm{co}}$ can be between 2 to $4.5 \times 10^{6} \mathrm{~A} / \mathrm{m}^{2}$ and a window fill factor $\mathrm{k}_{\text {fill }}$ can be between 0.55 to 0.7 [5]. In this design, we choose $\mathrm{J}_{\text {co }}$ equal to $3.0 \times 10^{6} \mathrm{~A} / \mathrm{m}^{2}$ and $\mathrm{k}_{\text {fill }}$ equal to 0.65 . The active (copper) area of a coil can be determined from

$$
\begin{aligned}
A_{c o} & =a \times h_{\text {coil }}=\frac{N_{c} I_{n}}{J_{c o}} \\
& =\frac{760.39}{3.0 \times 10^{6}}=253.46 \mathrm{~mm}^{2}
\end{aligned}
$$

Therefore, the actual window area is

$$
A_{w}=\frac{A_{c o}}{k_{\text {fill }}}=\frac{253.46}{0.65}=389.95 \mathrm{~mm}^{2}
$$

Referring to Figure 3.4, the coil width (a) in the window area is determined from

$$
\begin{aligned}
a & \approx \frac{1}{2} D_{i s}\left(\sin \frac{90^{\circ}}{2}-\sin \frac{\alpha_{P}}{2}\right) \\
& =\frac{0.0912}{2}\left(\sin 45^{\circ}-\sin \frac{45^{\circ}}{2}\right)=0.0148 \mathrm{~m}
\end{aligned}
$$

Then the coil height can be calculated by

$$
h_{\text {coil }}=\frac{A_{w}}{a}=\frac{389.95 \times 10^{-6}}{14.8 \times 10^{-3}}=0.0264 \mathrm{~m}
$$

Next, the outer diameter $\mathrm{D}_{\mathrm{PO}}$ is obtained from

$$
D_{P O}=D_{i s}+2 h_{\text {coil }}+h_{m} / 2
$$




$$
=0.0912+2(0.0264)+0.0025=0.1464 \mathrm{~m}
$$

The pole width $b_{P}$ can be calculated from

$$
b_{P}=D_{i s} \sin \frac{\alpha_{P}}{2}=0.0912 \sin \frac{45^{\circ}}{2}=0.0349 \mathrm{~m}
$$

In order to find the core depth, a core flux density $\mathrm{B}_{\text {core }}$ that can be between 1.1 to $1.35 \mathrm{~T}$ may be chosen [5]. We choose $\mathrm{B}_{\text {core }}$ equal to $1.1 \mathrm{~T}$.

$$
h_{\text {core }} \approx \frac{\phi_{\max }}{2 B_{\text {core }} l_{s}}=\frac{0.0014}{2(1.1)(0.04191)}=0.0152 \mathrm{~m}
$$

Finally, the external diameter of the stator $\mathrm{D}_{\mathrm{es}}$ is obtained

$$
D_{e s}=D_{P O}+2 h_{\text {core }}=0.1464+2(0.0152)=0.1768 \mathrm{~m}
$$

Later, the parameters of the equivalent circuit in Figure 2.17 are determined. The inductance, which consists of two components, is expressed as [7]

$$
L_{m}=C_{m} N_{c}^{2} \quad \text { and } \quad L_{\sigma}=C_{\sigma} N_{c}^{2}
$$

where

$$
\begin{aligned}
C_{m} & =n\left(G_{\max }+G_{\min }\right) P \\
& =2(3.2815+0.800) \times 10^{-7} \times 4 \\
& =3.2652 \times 10^{-6} \mathrm{H}
\end{aligned}
$$


and

$$
C_{\sigma}=2 P\left(\lambda_{s} l_{c s}+\lambda_{e} l_{e c}\right) \mu_{0}
$$

where

$$
\begin{aligned}
& l_{c s}=\text { coil length in a slot }=2 n l_{s} \\
& =2 \times 2 \times 0.04191=0.1676 \mathrm{~m} \\
& l_{e s}=\text { length of the end connection }=b_{P}+\frac{\pi a}{2} \\
& =0.0349+\frac{\pi \times 0.0148}{2}=0.0581 \mathrm{~m} \\
& \lambda_{s}=\text { slot permeance }=\frac{h_{\text {coil }}}{3 a} \\
& =\frac{0.0264}{3(0.0148)}=0.5939 H \\
& \lambda_{e}=\text { end-connection permeance }=\frac{1}{2} \lambda_{s} \\
& =0.2970 \mathrm{H}
\end{aligned}
$$

Finally, the $C_{\sigma}$ can be calculated

$$
\begin{aligned}
C_{\sigma} & =2 \times 4 \times(0.5939 \times 0.1676+0.2970 \times 0.0581) \times 4 \pi \times 10^{-7} \\
& =1.1745 \times 10^{-6} \mathrm{H}
\end{aligned}
$$


Define $C_{L}=C_{m}+C_{\sigma}$, where the inductance of the machine $L_{s}=C_{L} N_{c}^{2}$, so

$$
C_{L}=(3.2652+1.1745) \times 10^{-6}=4.4397 \times 10^{-6} \quad H
$$

There are $\mathrm{P}$ stator coils connecting in series. Each coil has $\mathrm{N}_{\mathrm{c}}$ turns. In other to determine the resistance of the machine $R_{s}=C_{R} N_{c}^{2}$, the resistance coefficient is defined as [5]

$$
C_{R}=\frac{P \rho_{c o} l_{c} J_{c o}}{N_{c} I_{n}}
$$

where

$1_{\mathrm{c}}=$ the length of the copper wire per turn $=2\left(\mathrm{l}_{\mathrm{cs}}+\mathrm{l}_{\mathrm{es}}\right)=0.4516 \mathrm{~m}$

$\rho_{c o}=$ the electrical resistivity of copper $=2.1 \times 10^{-8} \Omega \cdot \mathrm{m}$

Substituting numerical values, then $C_{R}$ is calculated

$$
\begin{aligned}
C_{R} & =\frac{4 \times 2.1 \times 10^{-8} \times 0.4516 \times 3.0 \times 10^{6}}{760.3931} \\
& =1.4965 \times 10^{-4} \Omega
\end{aligned}
$$

The copper loss $\mathrm{P}_{\mathrm{co}}$ can be calculated from

$$
\begin{aligned}
P_{c o}=I_{n}^{2} R_{s}=C_{R}\left(N_{c} I_{n}\right)^{2} & =1.4965 \times 10^{-4}(760.39)^{2} \\
& =86.53 \mathrm{~W}
\end{aligned}
$$


The core losses are assumed to be $10 \%$ of the copper loss, so we obtain [5]

$$
P_{\text {core }}=0.1 \times 86.53=8.653 \mathrm{~W}
$$

Now the mechanical losses are determined

$$
\begin{aligned}
P_{\text {mech }} & =P_{e}-P_{o}-P_{c o}-P_{\text {core }} \\
& =613.78-(0.8 \times 613.78)-86.53-8.65 \\
& =27.58 \mathrm{~W}
\end{aligned}
$$

A tuning capacitor $(\mathrm{C})$ is added in the circuit to keep the phase of the current same as that of the voltage [7] as shown in Figure 3.6.

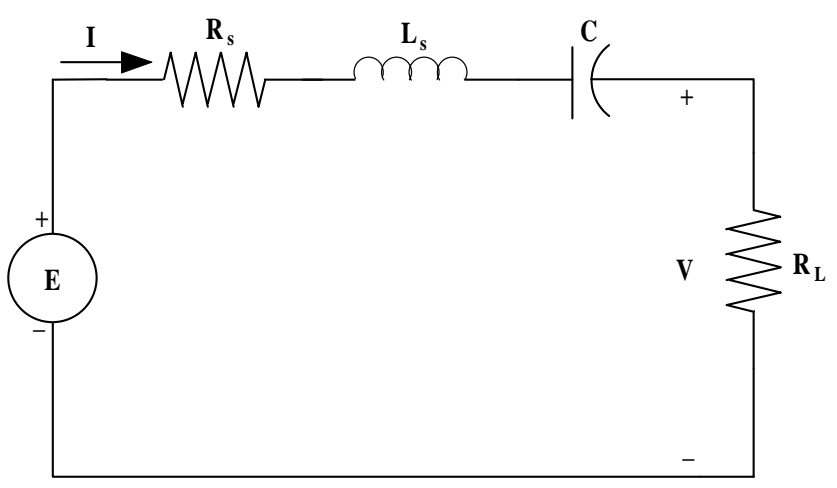

Figure 3.6 A MILA circuit with a tuning capacitor

The voltage equation can be written in phasor form as

$$
\bar{E}=\bar{V}+R_{s} \bar{I}+j \omega L_{s} \bar{I}-j \frac{1}{\omega C} \bar{I}
$$


where

$$
C=\frac{1}{\omega^{2} L_{s}}
$$

then

$$
\bar{E}=\bar{V}+R_{s} \bar{I}
$$

Later, the number of turns per coil $\mathrm{N}_{\mathrm{c}}$ is determined

$$
\begin{aligned}
N_{c} & =\frac{V_{o}}{C_{e}-C_{R}\left(N_{c} I_{n}\right)} \\
& =\frac{120}{0.8072-1.4965(760.39) \times 10^{-4}} \\
& =173.06 \text { turns }
\end{aligned}
$$

Then the resistance $\left(R_{s}\right)$ and inductance $\left(L_{s}\right)$ of the machine are calculated below

$$
\begin{aligned}
R_{s} & =C_{R} N_{c}^{2}=1.4965 \times 10^{-4} \times(173.06)^{2} \\
& =4.4820 \Omega \\
L_{s} & =C_{L} N_{c}^{2}=4.4397 \times 10^{-6} \times(173.06)^{2} \\
& =0.1330 \mathrm{H}
\end{aligned}
$$


Finally, the resultant design variables and other parameters are given in Table 3.1

Table 3.1 Design parameters obtained from the conceptual design

\begin{tabular}{|l|l|}
\hline Magnet Height & $0.005 \mathrm{~m}$ \\
\hline Current Density & $3.0 \mathrm{MA} / \mathrm{m}^{2}$ \\
\hline Core Density & $1.1 \mathrm{~T}$ \\
\hline Fill Factor of Coil & 0.65 \\
\hline Airgap Dimension & $0.001 \mathrm{~m}$ \\
\hline Coil Width & $0.0148 \mathrm{~m}$ \\
\hline Coil Height & $0.0264 \mathrm{~m}$ \\
\hline Core Thickness & $0.0152 \mathrm{~m}$ \\
\hline Pole Width & $0.0349 \mathrm{~m}$ \\
\hline Stator Length & $0.1676 \mathrm{~m}$ \\
\hline
\end{tabular}

\begin{tabular}{|l|l|}
\hline Stator Diameter & $0.1768 \mathrm{~m}$ \\
\hline Mover Diameter & $0.0892 \mathrm{~m}$ \\
\hline Number of Turns per Coil & 173 \\
\hline Conductor Diameter & $1.4 \mathrm{~mm}$ \\
\hline Stator Resistance & $4.482 \Omega$ \\
\hline Stator Inductance & $0.1330 \mathrm{H}$ \\
\hline Input Power (Engine) & $613.78 \mathrm{~W}$ \\
\hline Rated Output Power & $491.02 \mathrm{~W}$ \\
\hline Stator Mass & $19.30 \mathrm{~kg}$ \\
\hline Alternator Mass & $23.44 \mathrm{~kg}$ \\
\hline
\end{tabular}

This is a combination of designed parameters for developing a MILA with the desired output voltage and output power. To obtain an ideal combination, an optimization methodology may be applied to the design routine. This work will be performed in the next chapter. 


\section{OPTIMIZATION DESIGN}

In the previous chapter, conceptual design provided a combination of geometry parameters for the linear alternator that met a specified output voltage and power. However, an ideal design that generates the machine having maximum efficiency with lowest mass is indeed desired for developing the prototype. Consequently, an optimization method must be used to select a design that serves this demand.

The optimization toolbox in MATLAB provides a function that is able to perform optimization on constrained problems. The algorithm of this function will be explained in the first section. Subsequently, the design criterion will be developed with defined constraints. After the optimization routine is completed, the optimal results will be presented and discussed.

\section{$\underline{4.1 \text { Overview of the MATLAB constrained optimization routine }}$}

In this study, constrained optimization technique is applied to the existing design routine to determine the optimal parameter $(x)$ that minimizes the objective function $f(x)$ with the given constraints $G_{i}(x)$ and maintains in the defined boundaries [11]. A general form of the optimization problem can be expressed as

$$
\begin{array}{ccc} 
& \min _{x} f(x) \\
\text { subject to } & G_{i}(x)=0 \quad i=1, \ldots, n_{e} \\
& G_{i}(x) \leq 0 \quad i=n_{e}+1, \ldots, n \\
x_{l} \leq x \leq x_{u} & &
\end{array}
$$


In this chapter, the MATLAB function, CONSTR, using the Sequential Quadratic Programming (SQP) method, is used to perform the optimization for the alternator design. This method consists of three major phases:

1) Developing the Hessian matrix of the Lagrangian function to form QP subproblem

2) Formulating the QP subproblem approximated as the Quadratic form

3) Solving the QP subproblem to obtain the line search direction $\left(d_{k}\right)$ for updating the system parameter $(x)$ for the next iteration

The first Hessian matrix can be any positive definite symmetric matrix such as the identity matrix I. Subsequently, a QP subproblem will be formulated based on a quadratic approximation of the Lagrangian function that states as

$$
L(x, \lambda)=f(x)+\sum_{i=1}^{n} \lambda_{i} G_{i}(x)
$$

From the above equation, the upper and lower bounds of the optimization parameter (x) are assumed that have been expressed as inequality constraints. Then the QP subproblem is constructed as the quadratic form as

$$
\begin{aligned}
& \min _{d \in \Re^{m}} \frac{1}{2} d^{T} H_{k} d+\nabla f\left(x_{k}\right)^{T} d \\
& \nabla G_{i}\left(x_{k}\right)^{T} d+G_{i}\left(x_{k}\right)=0 \quad i=1, \ldots, n_{e} \\
& \nabla G_{i}\left(x_{k}\right)^{T} d+G_{i}\left(x_{k}\right) \leq 0 \quad i=n_{e}, \ldots ., n
\end{aligned}
$$

The QP subproblem can be solved using the Quadratic Programming technique, and its solution will present the line search direction $\left(d_{k}\right)$ to form the new optimization parameter $\left(x_{k+1}\right)$ for the next iteration.

$$
x_{k+1}=x_{k}+\alpha_{k} d_{k}
$$


When $x_{k+1}$ is obtained, the Hessain matrix will be updated. To do this, the BFGS method developed by Broyden, Fletcher, Golfarb and Shanno [12]-[15] is used to calculate the new Hessain matrix where $\lambda_{i}(i=1, \ldots, n)$ is an estimate of the Lagrange multipliers.

$$
H_{k+1}=H_{k}+\frac{q_{k} q_{k}^{T}}{q_{k}^{T} S_{k}}-\frac{H_{k}^{T} H_{k}}{S_{k}^{T} H_{k} S_{k}}
$$

where

$$
\begin{aligned}
& S_{k}=x_{k+1}-x_{k} \\
& q_{k}=\nabla f\left(x_{k+1}\right)+\sum_{i=1}^{n} \lambda_{i} \cdot \nabla G_{i}\left(x_{k+1}\right)-\left[\nabla f\left(x_{k}\right)+\sum_{i=1}^{n} \lambda_{i} \cdot \nabla G_{i}\left(x_{k}\right)\right]
\end{aligned}
$$

Subsequently, solving the Quadratic Programmin problem is illustrated. From equation (4.3), at each iteration of the SQP method, a QP problem is solved in the form where $A_{i}$ represents the $i^{\text {th }}$ row of the $n$ by m matrix $A$.

$$
\begin{array}{rl}
\min _{d \in \Re^{m}} \frac{1}{2} d^{T} H d+c^{T} d & \\
A_{i} d=b_{i} & i=1, \ldots, n_{e} \\
A_{i} d \leq b_{i} & i=n_{e}+1, \ldots ., n
\end{array}
$$

The solution procedure involves two parts. The first part involves the calculation of a feasible point, and the second part involves generation of an iterative sequence of feasible points that converges to the solution.

In this method, an active set, $\mathrm{Ak}$, which is an estimate of active constraints at the solution point, is maintained. Later, $\overline{A_{k}}$ is updated at each iteration $\mathrm{k}$, and it is used to form a basis for a search direction $d_{k}$. The feasible subspace of $d_{k}$ is formed from a basis $\mathrm{Z}_{\mathrm{k}}$, whose columns are orthogonal to the estimate of the active set $\overline{A_{k}}$. Therefore, a search direction, which is formed from a linear summation of any combination of the columns of $Z_{k}$, certainly remains on the boundaries of the active constraints. The matrix $\mathrm{Z}_{\mathrm{k}}$ can be formed from the last $n-l$ columns of the $\mathrm{QR}$ decomposition of the matrix $A_{k}$ where $l$ is the number of active constraints and $l<n$. Finally, $\mathrm{Z}_{\mathrm{k}}$ is expressed 


$$
\begin{aligned}
& Z_{k}=Q[:, l+1: n] \\
& \text { where } \quad Q^{T} \bar{A}_{k}^{T}=\left[\begin{array}{c}
R \\
0
\end{array}\right]
\end{aligned}
$$

Again, since the basis represent the feasible subspace for the search direction $d_{k}$, if $\mathrm{P}$ is a vector of constraints, the search direction $d_{k}$ can be found as

$$
d_{k}=Z_{k}^{T} P
$$

Then the new parameter is obtained

$$
x_{k+1}=x_{k}+\alpha d_{k}
$$

The step length $(\alpha)$ of the search direction at each iteration can be determined from

$$
\alpha=\min _{i}\left\{\frac{-\left(A_{i} x_{k}-b_{i}\right)}{A_{i} d_{k}}\right\} \quad(i=1, \ldots, n)
$$

The algorithm of SQP method is briefly stated from the above expressions. In the next section, the function, CONSTR, based on this method will be used in the design routine to determine the optimal design.

\subsection{Optimization Design Development}

The objective of this chapter is to optimize a moving iron linear alternator with respect to the efficiency and mass for the given linear engine. Since the existing experimental data of the mover position were obtained at $25 \mathrm{~Hz}$ frequency, the translator mass obtained from the previous chapter is fixed to keep the mover oscillating at the same frequency. Consequently, only the stator mass and efficiency will be optimized in the routine. 
The MATLAB function, CONSTR, is used to perform this task. The input of this function includes the function that returns the value to be minimized, and lower and upper bounds of the design variables. In this design, the design variables and their lower and upper bounds are assigned in the table below.

Table 4.1 Design parameters and their lower and upper bounds

\begin{tabular}{|c|c|c|}
\hline Design Parameters & Lower Bound & Upper Bound \\
\hline $\mathrm{J}_{\mathrm{co}}$ & $2 \mathrm{MA} / \mathrm{m}^{2}$ & $4 \mathrm{MA} / \mathrm{m}^{2}$ \\
\hline $\mathrm{B}_{\text {core }}$ & $1.1 \mathrm{~T}$ & $1.3 \mathrm{~T}$ \\
\hline $\mathrm{h}_{\mathrm{m}}$ & $0.001 \mathrm{~m}$ & $0.008 \mathrm{~m}$ \\
\hline $\mathrm{k}_{\text {fill }}$ & 0.55 & 0.65 \\
\hline
\end{tabular}

The above parameters are selected since their changes greatly effect the efficiency and stator mass. In this design, the dimension of airgap is not selected as a design parameter since it is assigned at the smallest value where manufacturing capabilities are allowed and the clearance is sufficient for vibration of translator to obtain the highest flux at the same size of permanent magnets.

Subsequently, two constraints are defined in the design routine to maintain the design results in the proper dimensions such that

$$
\begin{aligned}
& G_{1}(x)=a-0.6 h_{\text {coil }} \leq 0 \\
& G_{2}(x)=0.015-h_{\text {core }} \leq 0
\end{aligned}
$$

where

$G_{i}$ is the design constraint

$x$ is the design variable

$a$ is the coil width (should be less than 0.6 times of $\mathrm{h}_{\text {coil }}$ )

$h_{\text {coil }}$ is the coil height

$h_{\text {core }}$ is the thickness of stator core (should be greater than $0.015 \mathrm{~m}$ ) 
Figure 4.1 shows a portion of MILA including the stator pole, stator core, coil and slots. The first constraint is assigned to obtain a good dimension of stator poles and slots. The other constraint is applied to allow an adequate core thickness without saturation.

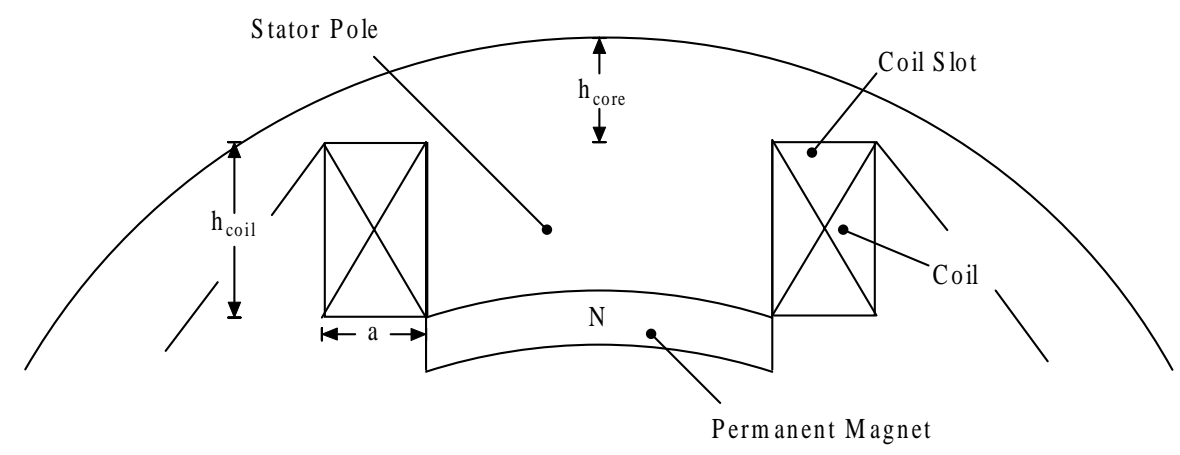

Figure 4.1 A portion of MILA showing dimensions of stator core and slots.

Since the MATLAB optimization routine is written to minimize the objective function, the reciprocal of the efficiency is used in the objective function to indicate the routine to maximize the efficiency. Finally, the objective function that minimizes the stator mass and maximize the efficiency can be expressed as [9]

$$
f(x)=\text { objective function }=c \cdot \text { mass }+(1-c) \frac{1}{\text { efficiency }}
$$

where

$c$ is the weighing coefficient between $[0,1]$

Then the routine will determine the optimal design variable $(x)$ that minimize the objective function with respect to the constraints such that

$$
\min _{x} f(x)
$$

subject to

$$
\begin{aligned}
& G_{1}(x) \leq 0 \\
& G_{2}(x) \leq 0
\end{aligned}
$$




\subsection{Optimization Results}

From the optimization routine, the optimal results are found in 27 iterations at $\mathrm{c}=$ 0.5 . The number of iterations may be larger or smaller depending on the initial design parameter $(\mathrm{x})$ inserted as an input of the routine. The track of the stator mass and efficiency are plotted in Figure 4.2. The weighing coefficient can be chosen as other numbers depending on the demand of designer. However, MILA can present the efficiency up to $88 \%$ when the weighing coefficient is chosen to be zero.

Track of Stator Mass at $\mathrm{c}=0.5$

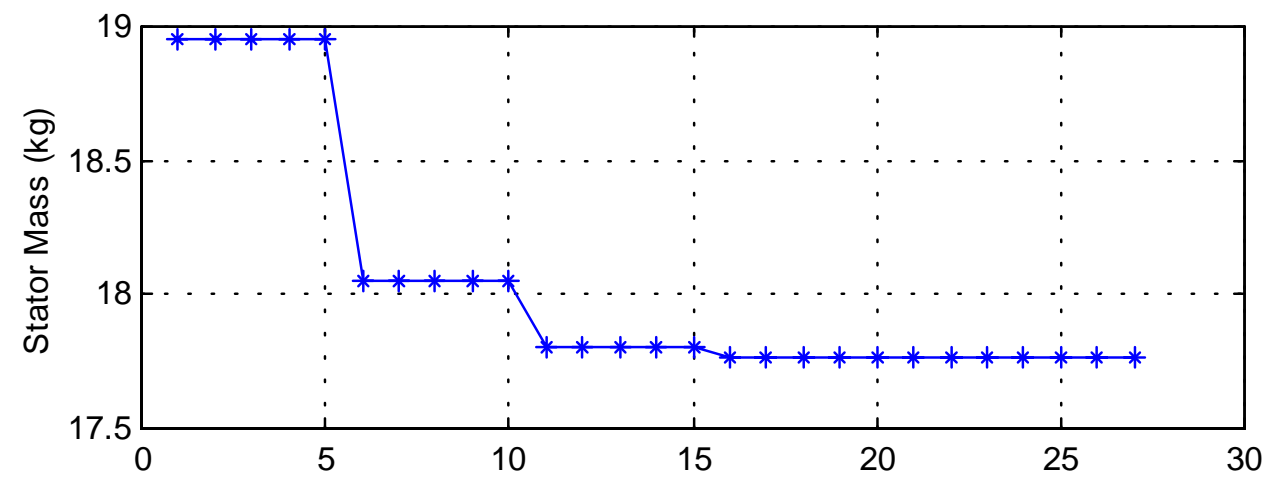

Track of Efficiency at $\mathrm{c}=0.5$

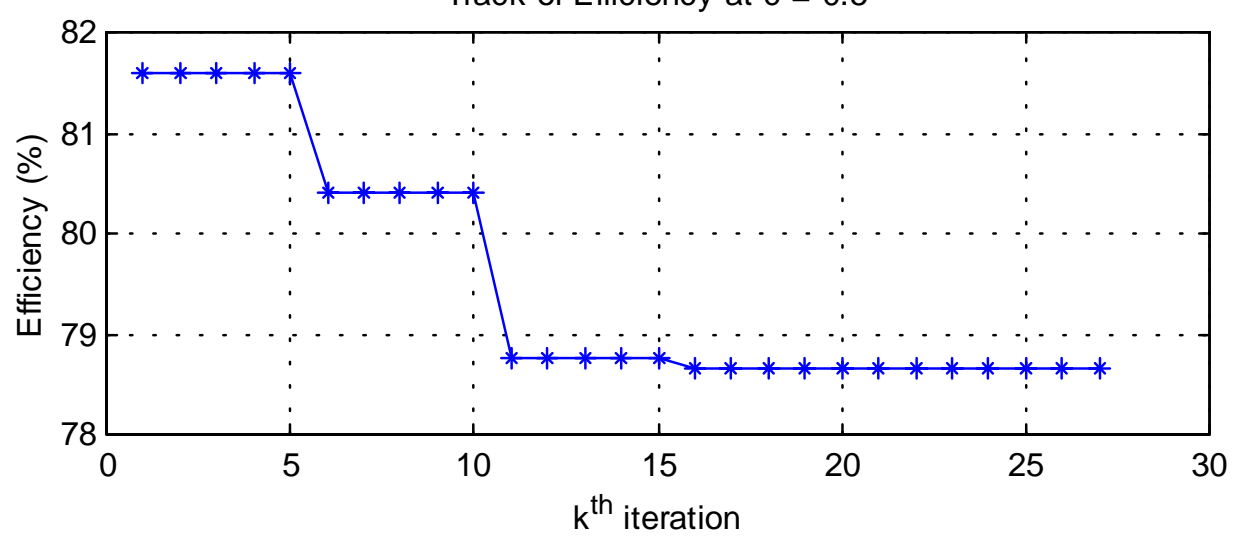

Figure 4.2 Track of stator mass and efficiency

The resultant design variables and other parameters are given in Table 4.2 
Table 4.2 Design parameters obtained from the optimization routine

\begin{tabular}{|l|l|}
\hline Magnet Height & $0.0047 \mathrm{~m}$ \\
\hline Current Density & $3.78 \mathrm{MA} / \mathrm{m}^{2}$ \\
\hline Core Density & $1.1 \mathrm{~T}$ \\
\hline Fill Factor of Coil & 0.55 \\
\hline Airgap Dimension & $0.001 \mathrm{~m}$ \\
\hline Coil Width & $0.0148 \mathrm{~m}$ \\
\hline Coil Height & $0.0247 \mathrm{~m}$ \\
\hline Core Thickness & $0.0150 \mathrm{~m}$ \\
\hline Pole Width & $0.0349 \mathrm{~m}$ \\
\hline Stator Length & $0.1676 \mathrm{~m}$ \\
\hline
\end{tabular}

\begin{tabular}{|l|l|}
\hline Stator Diameter & $0.1729 \mathrm{~m}$ \\
\hline Mover Diameter & $0.0892 \mathrm{~m}$ \\
\hline Number of Turns per Coil & 182 \\
\hline Conductor Diameter & $1.2 \mathrm{~mm}$ \\
\hline Stator Resistance & $6.26 \Omega$ \\
\hline Stator Inductance & $0.1488 \mathrm{H}$ \\
\hline Rated Output Power & $482.78 \mathrm{~W}$ \\
\hline Efficiency & $78.65 \%$ \\
\hline Stator Mass & $17.77 \mathrm{~kg}$ \\
\hline Alternator Mass & $21.90 \mathrm{~kg}$ \\
\hline
\end{tabular}

The above parameters are transferred to the next chapter to develop an alternator model in a field analysis software package to perform field analysis later on. From the above results, there is the trade off between the efficiency and stator mass. To obtain higher efficiency, having low mass must be sacrificed. Consequently, there is no unique optimal design for this optimization. 


\section{FIELD ANALYSIS}

Due to novelty of MILA magnetic structure, the conventional magnetic circuit approach is not suitable for determining the magnetic flux. To explore in-depth performance of MILA, a field analysis software package based on the Finite Element Method is required to serve this purpose.

\subsection{Magnetostatic Finite Element Method}

The finite element method is a numerical technique for obtaining approximate solutions for various engineering problems. The basic concept of the finite element method is that the behavior of a complex structure under certain excitations and restraining conditions will be the sum of the behaviors of its smaller components. Therefore, a large complex structure can be subdivided into many relatively small, simple-shape components for which the known equations can be applied. These components are called elements. Using numerical techniques, the equation sets are solved, and the solutions provide results for the entire structure [16].

In magnetostatic static analysis, the set of Maxwell's equations is applied.

$$
\begin{aligned}
& \nabla \times B=0 \\
& \nabla \times H=J
\end{aligned}
$$

where

$\mathrm{H}$ is the magnetic intensity vector

$\mathrm{B}$ is the magnetic flux density vector

$\mathrm{J}$ is the current density vector 
In addition to Maxwell's equations, the constitutive equation that describes the behavior of the magnetic material is

$$
B=\mu H
$$

where

$\mu$ is the magnetic permeability

Subsequently, the magnetic vector potential is introduced as

$$
B=\nabla \times A
$$

From the equation (5.1), (5.2) and (5.4), they can be rewritten as

$$
\begin{aligned}
& \nabla \times \nabla \times A=\mu J \\
& \nabla \cdot \nabla \times A=0
\end{aligned}
$$

Referring to the vector identical $\nabla \times \nabla \times X=\nabla(\nabla \cdot X)-\nabla^{2} X$, the equation (5.5) and (5.6) can be combined as

$$
\nabla^{2} A=-\mu J
$$

The above partial differential equations are solved first by discretising these equations in their space dimensions [17]. The discretisation is performed locally over small regions of simple but arbitrary shape. The results in matrix equations relate the input ( $\mathrm{J})$ at specified points in the elements (the nodes) to output (A) at these same points. To solve equations over large regions, the matrix equations for these small sub-regions can be summed node by node. Then the results for global matrix equations are obtained. 


\subsection{Overview of EMAS field Analysis Software}

EMAS, a field analysis software package developed by Ansoft Corporation, is a powerful tool, and extensively used in this chapter. With high computing capability, EMAS can deal with three-dimensional structure problems or complicated models quite well. In addition, it has the ability to quantify design parameters and visualize electromagnetic fields, which helps to understand performance variations and to obtain repeatable and accurate characterization data. EMAS uses the techniques of the Finite Element Analysis (FEA) method to calculate magnetic and electric field properties for devices.

There are three major parts involved in the analysis of a model when using EMAS [18].

- Describing the model and defining the problem

- Solving the problem (automatically or manually)

- Viewing the results of the analysis

The first part consists of creation of the model and definition of the problem. Usually, a user will spend most of his/her time in this part involving building geometry, applying the excitations and boundary conditions, and creating the finite element model.

Later, the solution part offers users two options for running automatic analysis mode or manual analysis mode. In automatic analysis mode, no user interaction is needed. At this step, the software will take over and calculate all of the results that were requested. By the way, manual analysis mode may be used by an experienced user who wants to modify or extract some data during processing an analysis task.

Finally, the results-viewing part occurs after the solver has finished the calculations. The result can be viewed if they are acceptable for the submitted model. However, design modification can be made, based on information gleaned from the analysis. The algorithm of a complete process is illustrated as the below flow chart. 


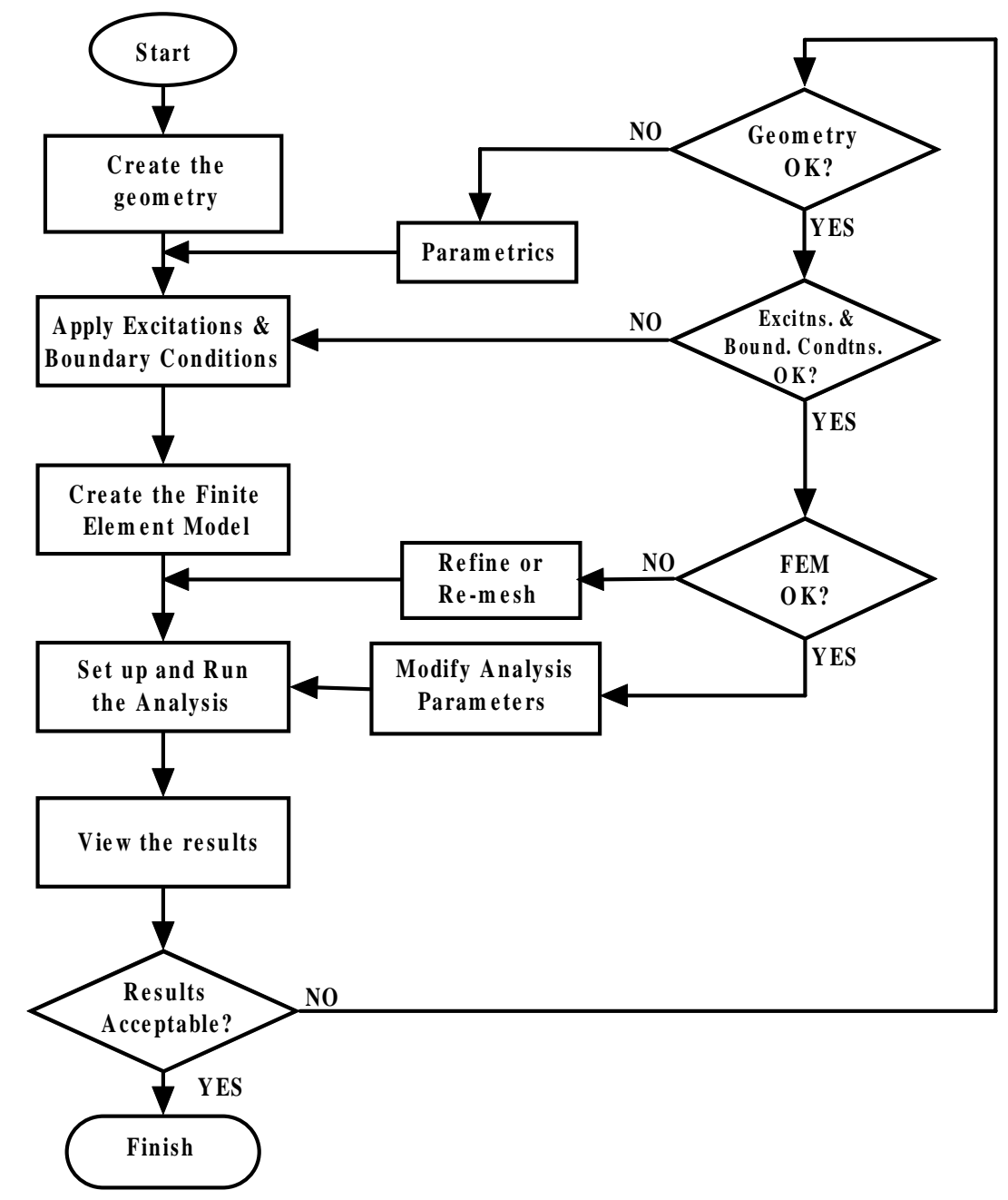

Figure 5.1 Flow chart for field analysis in EMAS

\subsection{Approach to MILA Model Using EMAS}

To start performing field analysis, the set of geometry data, designed from the chapter 4, was utilized in the geometry part of EMAS. For this application, the EMAS package was operated in the GUI (Graphical User Interface) mode that allows users to create or manage their models graphically [18].

In geometry menu, geometric models of projects can be created by three types of entities: 1) Wireframe 2) Surface and 3) Solid. Creating the MILA models utilized the solid geometry type providing an ambiguous mathematical and visual definition of a physical object. In fact, the MILA structure contains complex objects. This may need the 
construction operations in EMAS that can combine, cut resolve or otherwise shape lower dimensional geometry into more complicated objects, based on Boolean Operations for example, union, subtraction, and intersection. Therefore, only the box and cylinder shaped solids were used to create the complete model of MILA shown in Figure 5.2. To complete the geometry task, a cylinder-shaped air box was created to cover the MILA model and regioned as isolated object later on.
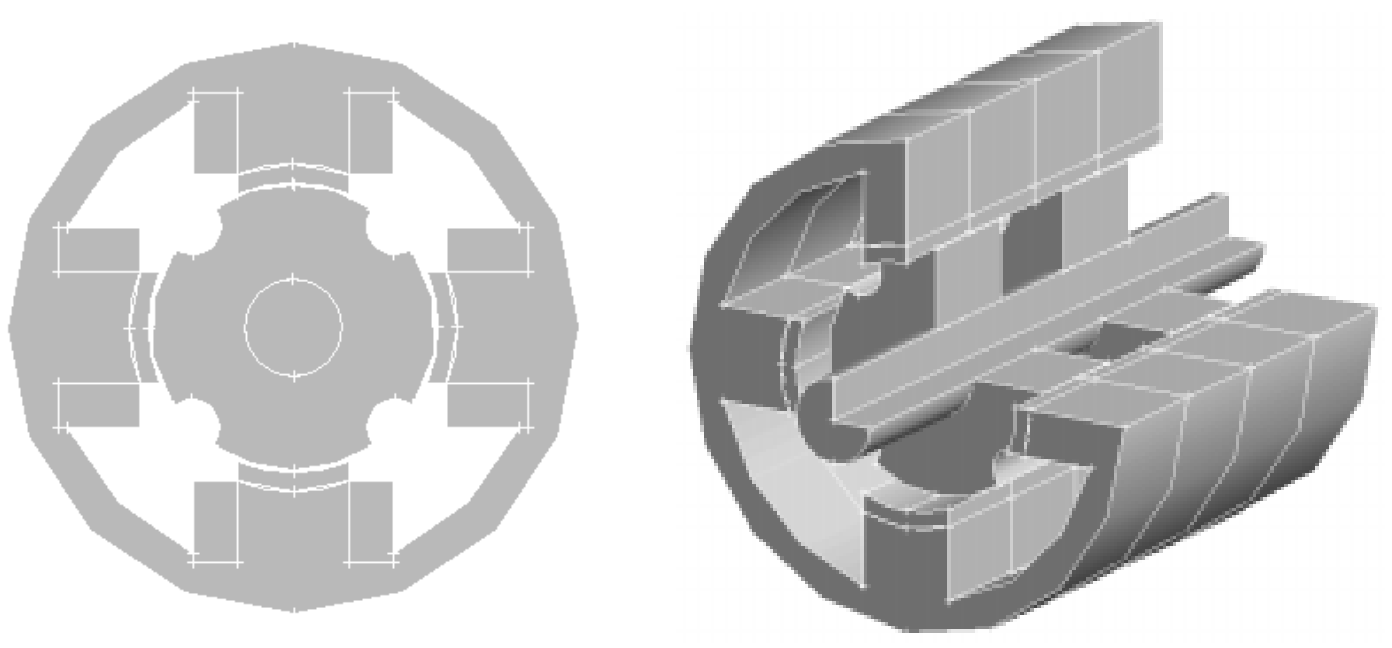

Figure 5.2 MILA model in front view and trimetric view

After finishing creation of geometry, the next important step is applying the excitations and boundary conditions to the geometry. EMAS provides several analysis types that users can use to solve different types of electromagnetic problems. In this study, the magnetostatic analysis type, which calculates static fields and derived quantities in permeable media, was applied with below assumptions:

- Conducting and dielectric media is ignored

- There are no electric fields

- Magnetic fields are constant in time

- Static magnetic fields are described by the magnetic vector potential alone

- Magnetic materials can be linear or non-linear 
To reduce computation time in analysis, one quarter of the above model was analyzed. In Figure 5.3, permanent magnetization was assigned to the permanent magnet objects. Each group of arrows shows its magnetizing direction. NdFeB (NeodymiumIron-Boron) magnet with $\mathrm{H}_{\mathrm{c}}=603 \mathrm{~A} / \mathrm{mm}$ was used for this design. $\mathrm{NdFeB}$ has high remanent flux density $\left(\mathrm{B}_{\mathrm{r}}\right)$, high coercive force $\left(\mathrm{H}_{\mathrm{c}}\right)$, linear demagnetization curve as well as low cost [8].

Later, magnetic flux tangent was assigned to any faces of model as the boundary conditions. Magnetic Flux Tangent is used to constraint the magnetic flux density vectors to be tangent to the selected edge or face. As a result, the machine flux is kept within the stator core and there is no leakage to the surrounding air. Using this boundary condition does not sacrifice much in accuracy of the results since the permeability of the steel material used as the stator core is much larger than that of the air, and leakage is negligible. This favors reducing computation time, rather than having to add more airsurrounding objects for obtaining high accuracy. A triangle-symbol frame represents a boundary of magnetic flux tangent.

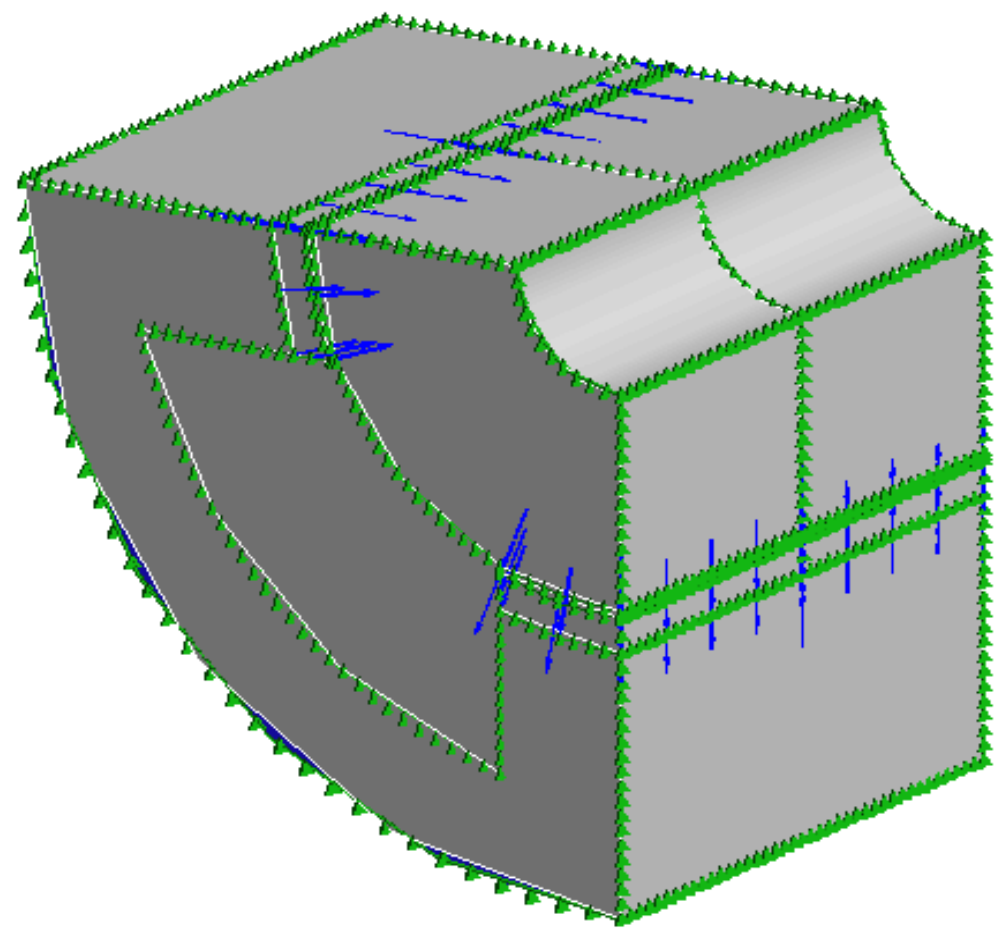

Figure 5.3 MILA model with excitations and boundary conditions 
In analysis application, the finite element model was created. Meshing and material assignment were applied to all objects. The list of materials assigned to the objects is shown in Table 5.1.

Table 5.1 List of materials used in the model

\begin{tabular}{|c|c|c|}
\hline Materials & Objects & Relative Permeability \\
\hline Iron & Translator & 5286 \\
\hline Steel & Stator core & 4421 \\
\hline NdFeB & Permanent magnet & 1.05 \\
\hline Copper & Coil & 1 \\
\hline Air & $\begin{array}{c}\text { Airgap and air } \\
\text { surrounding }\end{array}$ & 1 \\
\hline
\end{tabular}

Meshing model is a difficult task in three-dimensional analysis. There are several different element shapes for two-dimensional and three-dimensional models shown in Figure 5.4.

Three-Dimensional

Linear
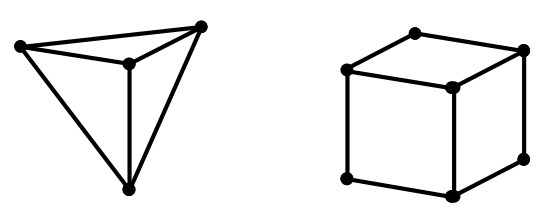

Quadratic

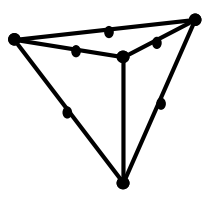

tetrahed ron

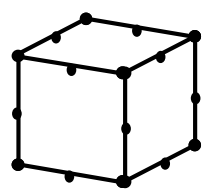

brick
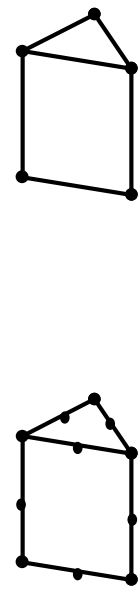

wedge
Two-Dimensional

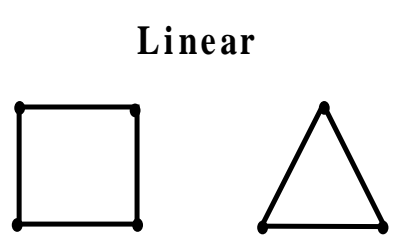

Quadratic
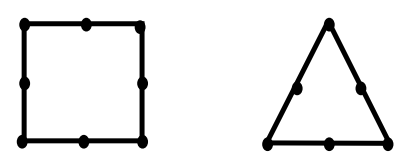

quadrilateral

triangle

Figure 5.4 Two-dimensional and three-dimensional elements 
Using automeshing option is usually the fastest way to produce a mesh for regions of complex geometry, but it cannot complete its task in case of the model containing a number of regions, which are different in size. Basically, using automesher requires users to specify the region to be meshed as well as a Default Element Size. Automesher tries to use this value to make elements of approximate size whenever possible. Care must be taken for selecting this value because large difference of meshing size of neighboring regions may cause unacceptable meshing for the field solver. Finally, the finite element model was generated as shown in Figure 5.5.

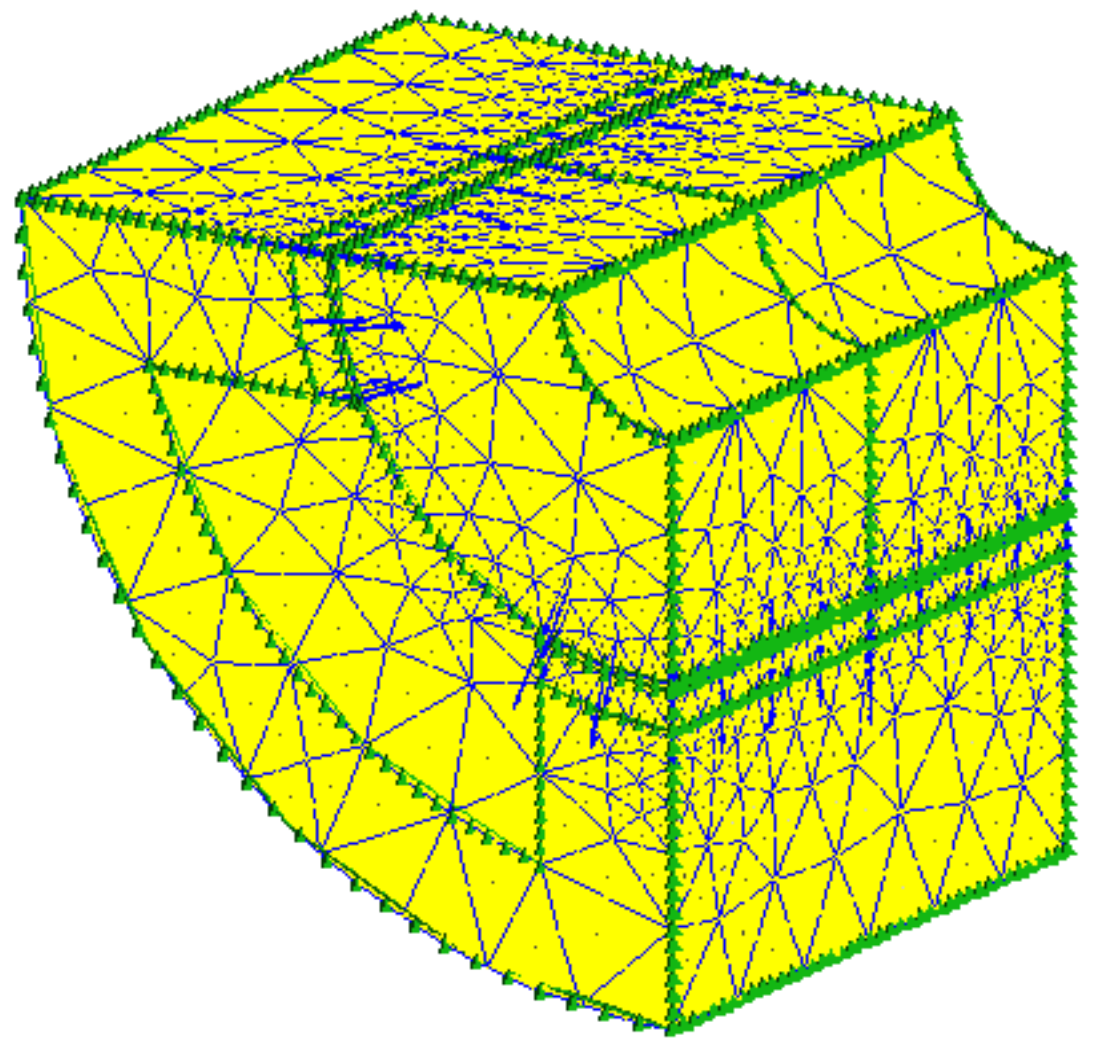

Figure 5.5 Finite Element Model of MILA

In this research, the manual analysis was used for solving the magnetic field of MILA because a few inherent problems of the software prevented using automatic analysis. As a result, the computation time was approximately 3 hours for Pentium II, 300 MHz with 128 MB RAM. 
After the analysis was completed, the magnetic field outputs can be viewed as either color contours or vectors. Figure 5.6 displays the magnetic flux density of MILA at the left-end mover position as color contours and vectors.
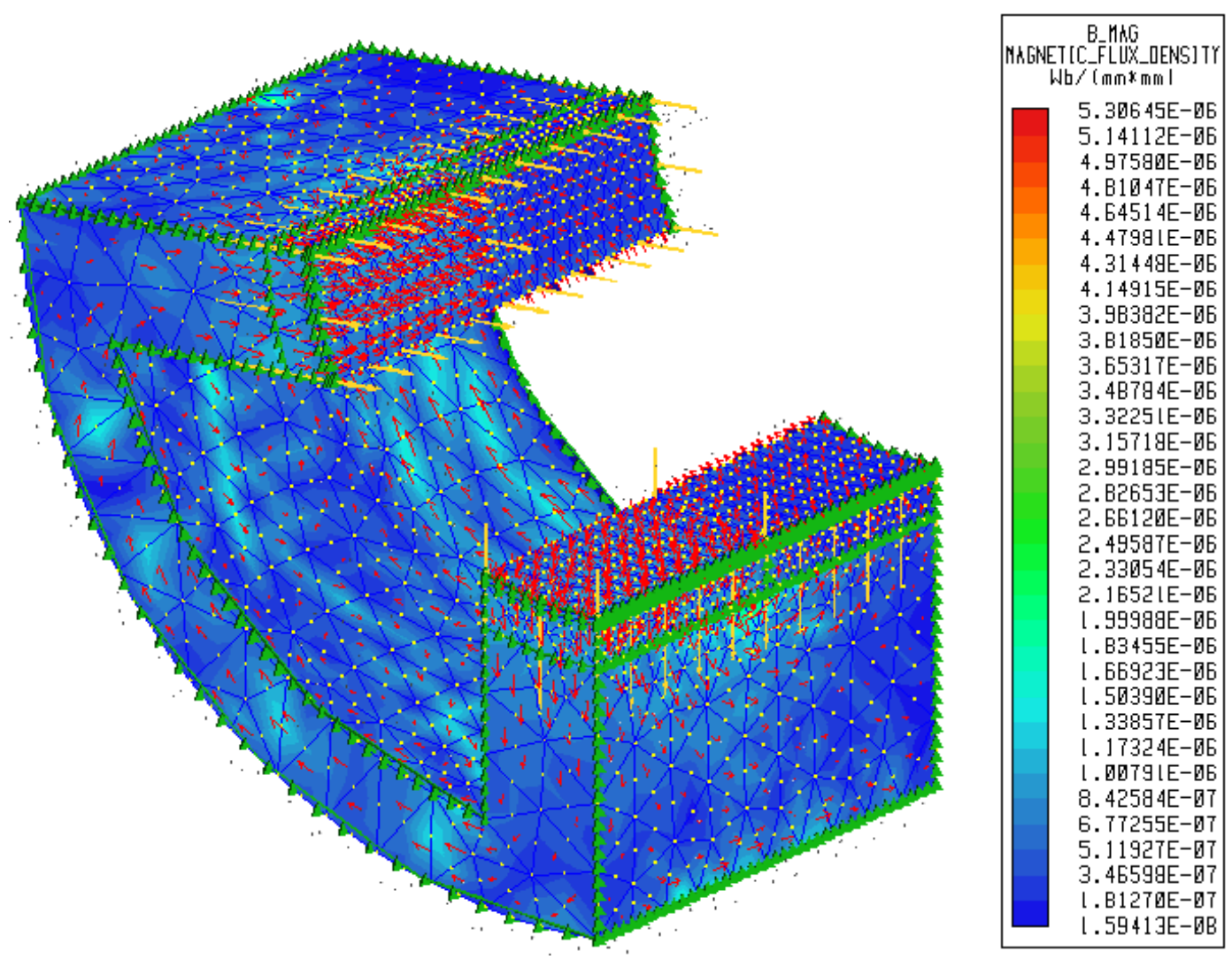

Figure 5.6 Color contours and vectors of magnetic flux density

In Figure 5.6, the mover and the air surroundings are blank for ease of viewing the fields. There are three different flux paths in the stator core. Obviously, the north and south poles are side-by-side. At the location where they meet, a lot of fringing flux that occurs is one of the flux paths in the core. By the way, there are interesting events of the other flux paths. As the mover stands at the left-end position, majority of magnetic flux produced from the permanent magnets at the left-side poles goes out into the right wing of the stator core, and the rest of the flux keeps flowing in the left wing. That is because the most of flux from the left pole is being pulled toward the pole of opposite polarity. Reviewing the results in Figure 5.6, the flux path goes from the left pole then down 
through the mover and into the left wing at the bottom of the picture. Immediately, the flux is bent and pulled strongly towards to the pole in the right wing. However, some cancellation of this flux would be expected due to the opposite flux from the poles in the right side, and the most cancellation would occur in the left side of the stator core.

\subsection{Simplified Model}

To obtain the induced voltage that occurs from changes of the flux within the coils while the mover is moving, the magnetic flux at each different mover position has to be determined. From the experimental data, the mover position related to time is illustrated as the curve below.

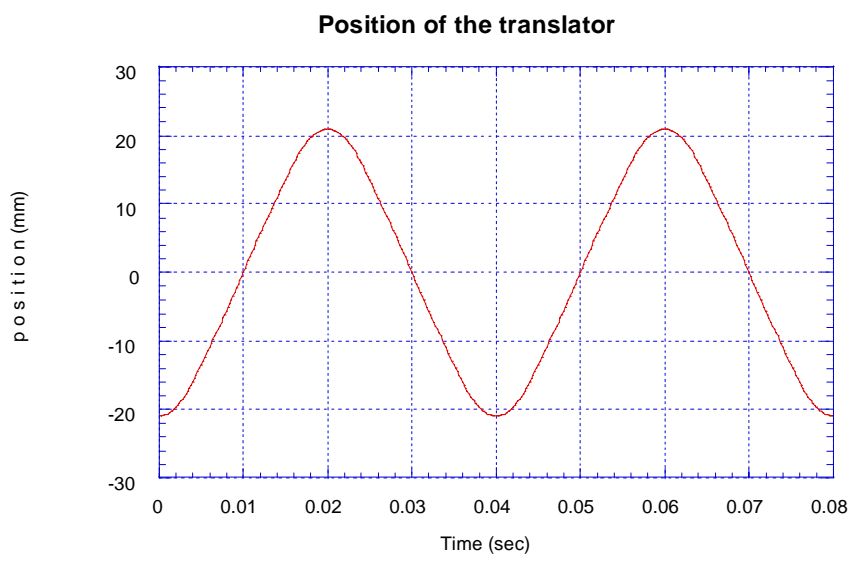

Figure 5.7 Position of the translator

A number of analyses have to be performed to calculate the magnetic flux at each translator position. Due to extremely long computation time and difficulty of meshing, the initial attempt to use the three-dimensional model for solving the fields should be discarded. The good solution fixing the computation time problem is developing a twodimensional model that can represent major characteristic of the magnetic flux in 3-D model. This two-dimensional model will be called simplified model. To verify the simplified model that will be developed later, analysis of the 3-D model will be performed at four different translator positions among the left-half stroke. The results obtained from the analyses are flipped to right-half plane with negative sign, and are displayed as a curve shown in Figure 5.8. 


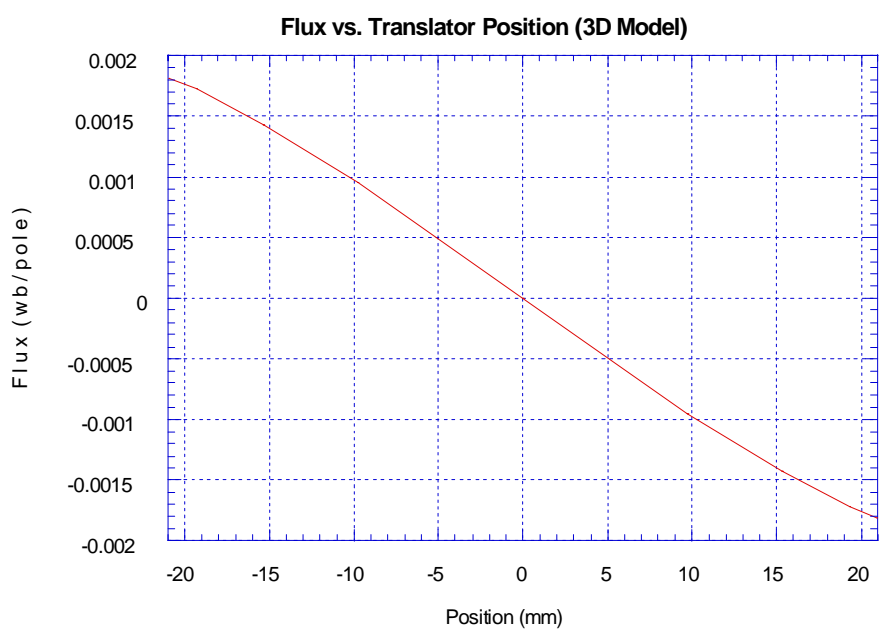

Figure 5.8 Magnetic flux versus translator position

As the magnetic flux paths of the 3-D model have been analyzed, there are indeed flux established in both radial and axial planes. Making field analysis of MILA in a twodimensional model in the axial cross-section without regarding to the flux in the radial plane would be incorrect. To make the 2-D analysis possible, two fictitious cores, which will be called wings, are added to the axial cross-section of MILA as Figure 5.9. These wings play the role of the missing core [19], which conducts the radial magnetic flux, in the axial cross-section view.

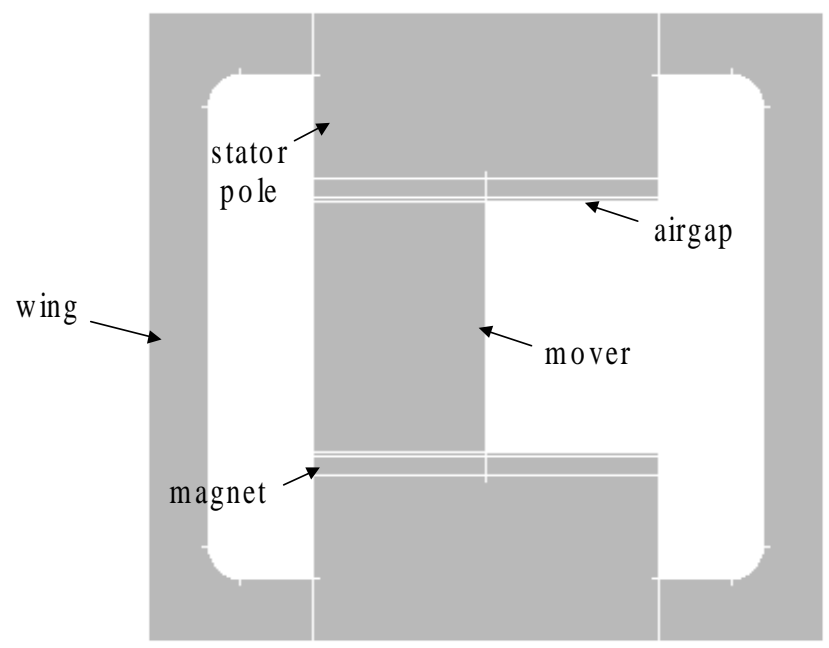

Figure 5.9 Simplified model 
The same process producing 3-D analysis was repeated for the simplified model. In addition, the current excitation was added to the model under load conditions for armature reaction effects. To be convenient for the verification of the simplified model, no load condition was assumed in this chapter. The results from the two-dimensional analysis are displayed in Figure 5.10.
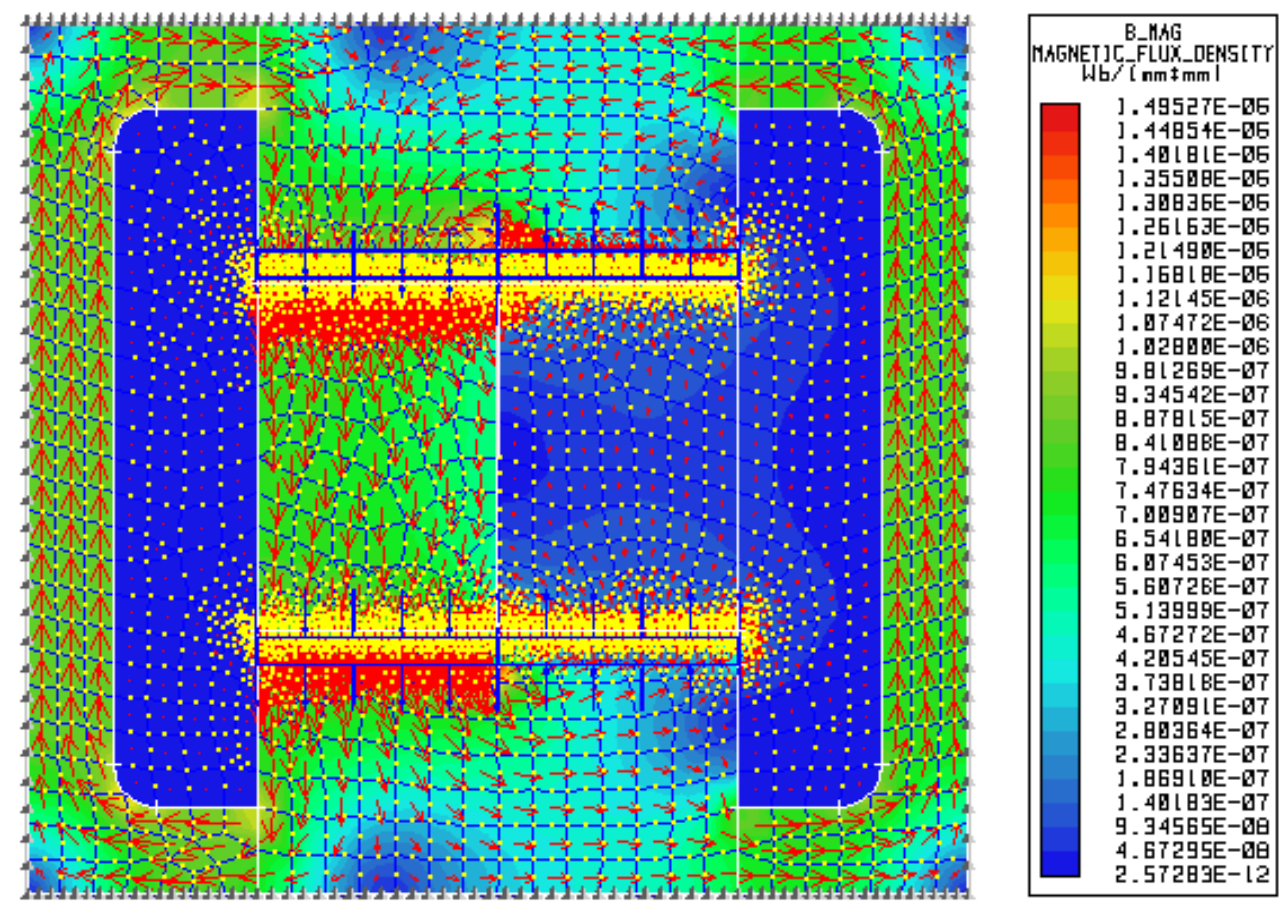

Figure 5.10 Magnetic Flux Density in the Simplified Model

The flux obtained from the analysis of the simplified model is very similar to that of the three-dimensional model. There are still three different flux paths in the stator core. They play the same roles as the flux paths in the 3-D model. This confirms that the simplified model can represent the 3-D model properly. Moreover, much shorter computation time was given in analyzing the simplified model (ten minutes for completing an analysis). Based on the experimental data of the translator position related to time, fifteen different positions were selected for repeating the above analysis until the magnetic flux at any translator positions was obtained. After completing fifteen analyses, the relationship of the magnetic flux linking the coil and position of the mover is finally illustrated in Figure 5.11. 


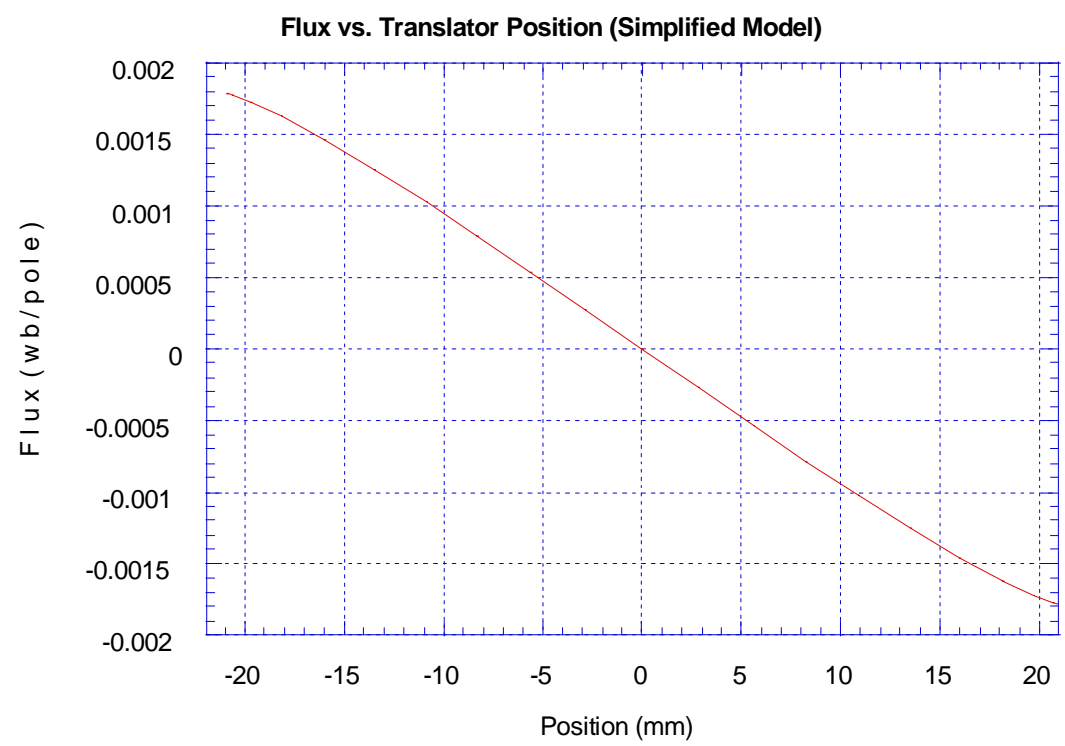

Figure 5.11 Magnetic Flux vs Position in the Simplified Model

A comparison of magnetic flux between the simplified and 3-D model is shown in Figure 5.12

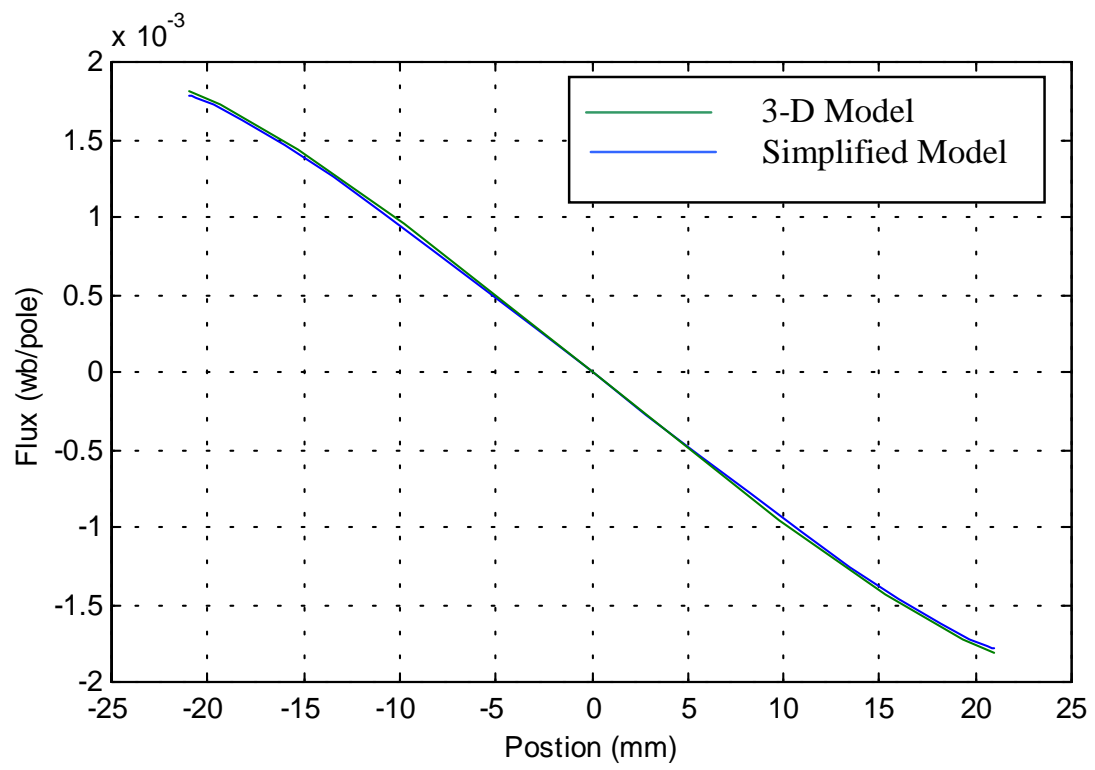

Figure 5.12 Comparison of the magnetic Flux in Simplified and 3-D model 
Obviously, both curves are very similar. In addition, the curves of the magnetic flux versus translator position obtained from both models are almost linear. This result supports the assumption made in Chapter 2 where change of magnetic flux with respect to translator position $\left(\frac{d \phi}{d x}\right)$ is assumed constant. With short computation time and ease of generating finite element models, the simplified model will be used for the output results in the next chapter. 


\section{SIMULATION AND RESULTS}

The simplified model developed in the previous chapter was explored to obtain the magnetic flux as a function of translator position at no load. In this chapter, this task will be continued to obtain the back emf (Electromotive Force) of the alternator. To demonstrate the practicability of MILA, a resistive load will be applied to the alternator, and the output results will be discussed.

\subsection{Simulation Preparation}

Referring to Faraday's Law, the induced voltage of the linear alternator is obtained from

$$
E=-N_{c} \frac{d \phi}{d t}=-N_{c} \frac{d \phi}{d x} \cdot \frac{d x}{d t}
$$

Consequently, of the translator position versus time data is required. From the experiment where the linear engine was used as a prime mover for driving the moving magnet linear alternator, the set of data of the translator position versus time will be used in this chapter as plotted in Figure 6.1. 


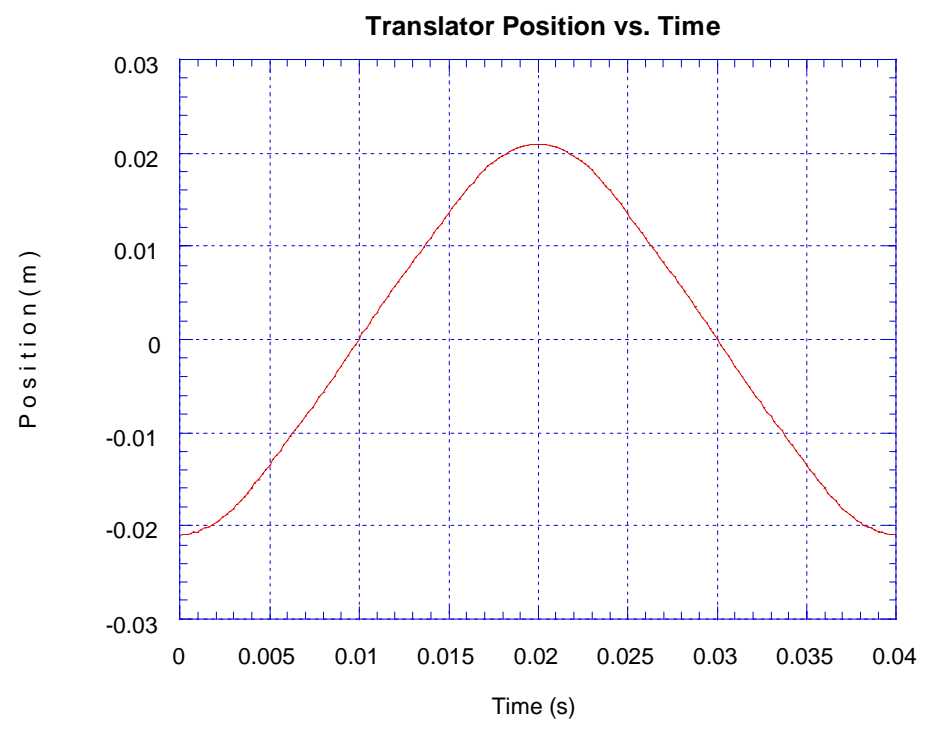

Figure 6.1 Plot of Translator Position in one period

This curve presents the frequency of oscillation at $25 \mathrm{~Hz}$ with the magnitude equal to a half stroke length of the linear alternator. To obtain the translator velocity, the translator position is differentiated with respect to time. The plot of the translator velocity versus time is shown in Figure 6.2.

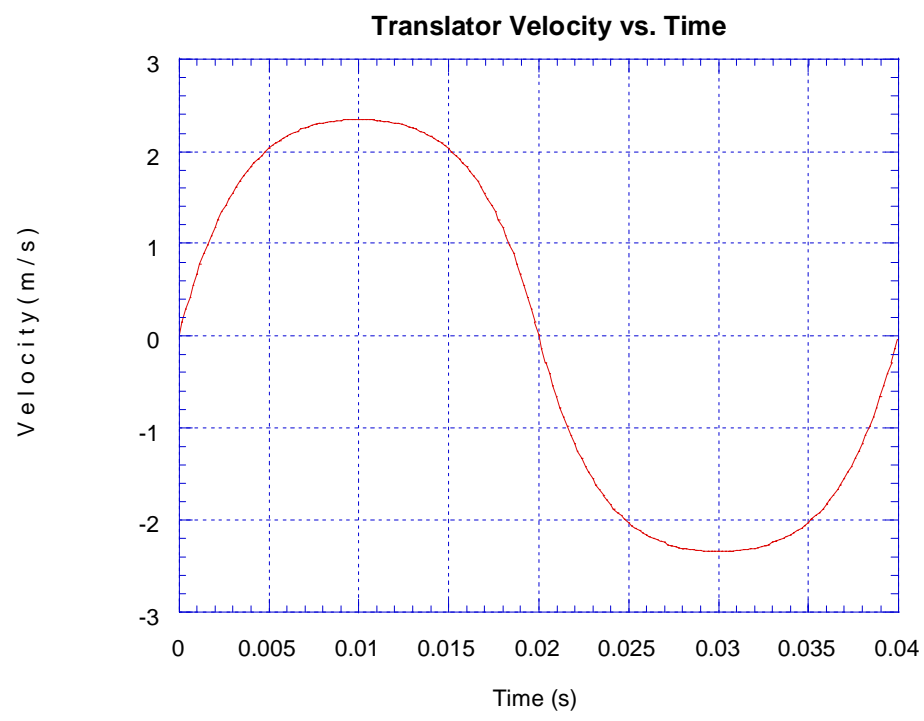

Figure 6.2 Plot of Translator Velocity in one period 


\subsection{MILA Simulation at No Load}

With the known data of the no-load flux versus translator position from the previous chapter, determining the back emf is straightforward. This flux versus time is shown in Figure 6.3. The equation (6.1) is rewritten to express the induced voltage of MILA.

$$
E=-P N_{c} \frac{d \phi}{d t}
$$

where

$\mathrm{P}$ is the number of poles

$\mathrm{N}_{\mathrm{c}}$ is the number of turns per coil

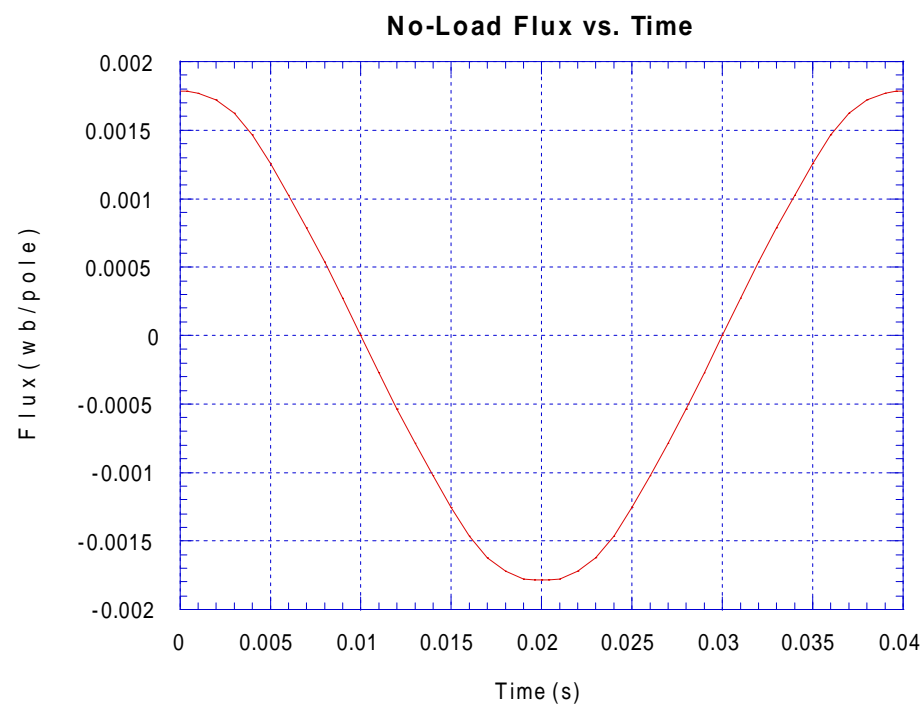

Figure 6.3 Plot of No-Load Flux vs. Time

In Figure 6.4, the back emf is obtained from differentiating the above curve. The back emf is decomposed to determine the magnitude of each harmonic using Fast Fourier Transform (FFT) technique. The magnitude of each harmonic is shown in Figure 6.5. 


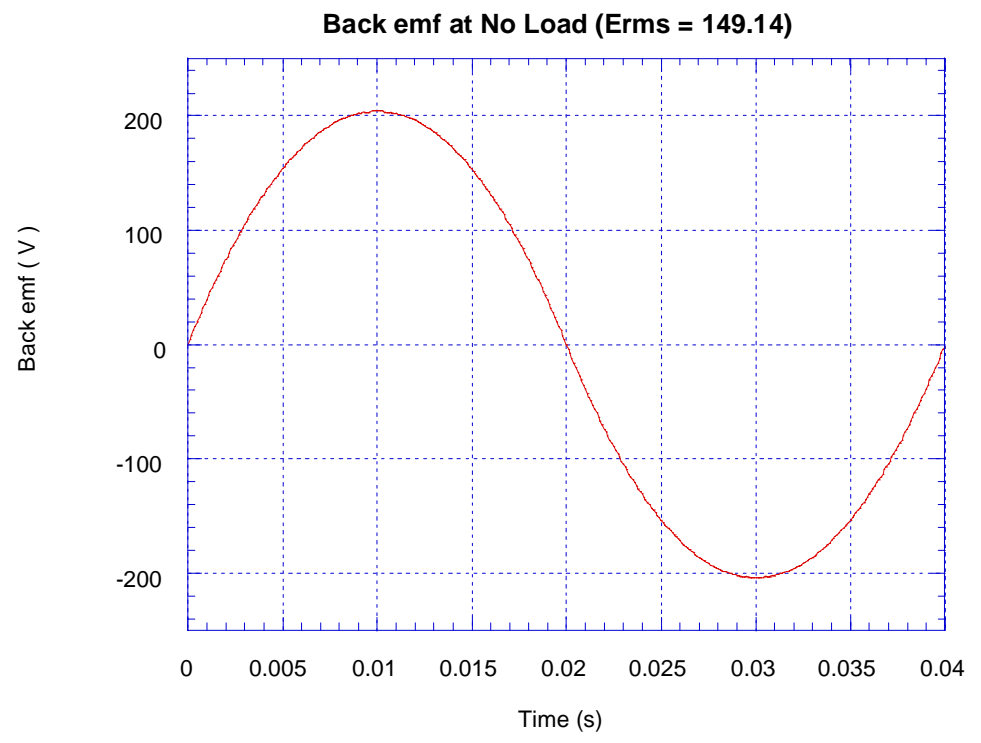

Figure 6.4 Back emf vs. Time at No Load

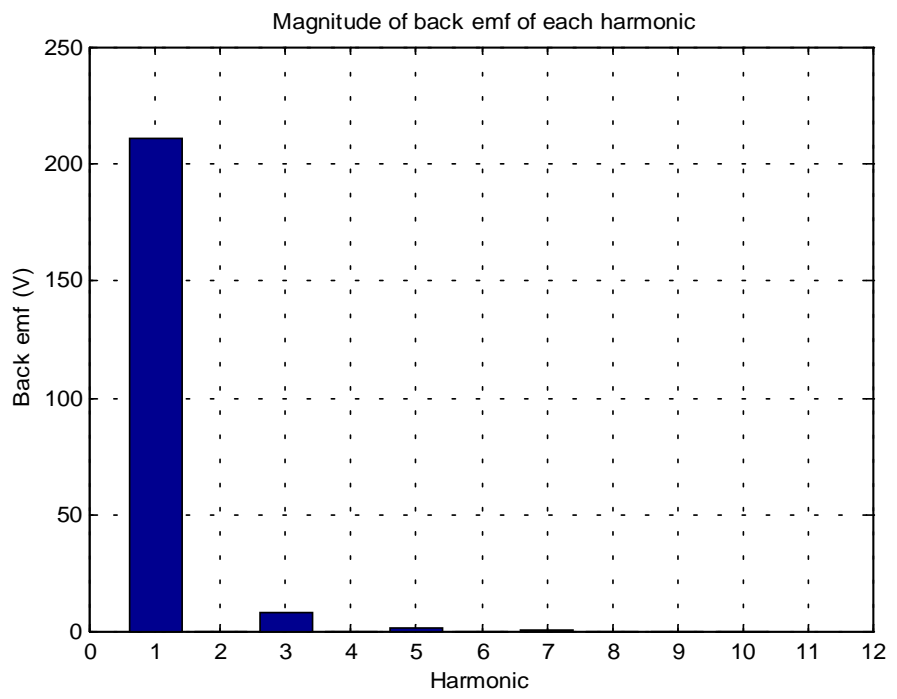

Figure 6.5 Magnitude of each harmonic

Figure 6.5 shows that the back emf is very close to the sinusoidal form. Later, the RMS value of the back emf is obtained at 149.16 Volts. In the next section, a resistive load will be applied to MILA, and an algorithm will be developed to determine the back emf and electric current of MILA. 


\section{$\underline{\text { 6.3 MILA Simulation under Load Conditions }}$}

In this section, a resistive load is connected to the output terminal of MILA. The magnetic flux established in the stator core not only comes from the permanent magnets, but also from the electric current in the coils. When the flux established from the current is considered, of course, the simulation process has to be more complicated. An electric circuit that illustrates the linear alternator with the resistive load is depicted in Figure 6.6.

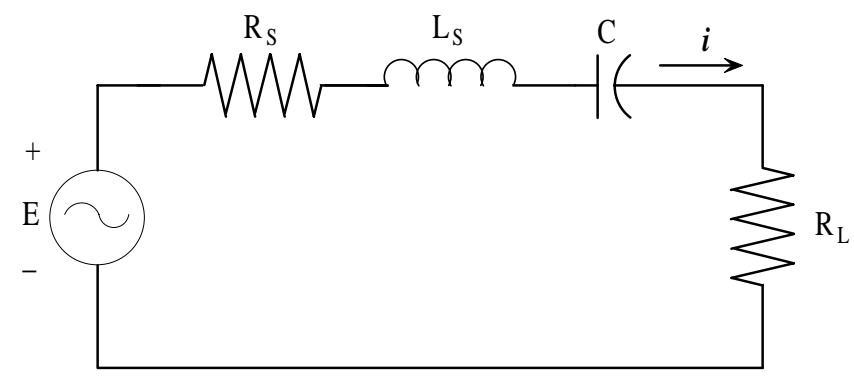

Figure 6.6 An Electric Circuit illustrating MILA with Resistive Load

From the above circuit, a tuning capacitor [7] is added to keep the phase of the current same as that of the back emf. Then back emf can be expressed as

$$
E=R_{s} i+L_{s} \frac{d i}{d t}+\frac{1}{C} \int i d t+R_{L} i
$$

when

$$
R=R_{s}+R_{L}
$$

then

$$
E=R i+L_{s} \frac{d i}{d t}+\frac{1}{C} \int i d t
$$

The above differential equation must be solved for obtaining the circuit current. This work can be achieved by using the ODE45 function in MATLAB. Howver, the back emf, which is the input of the equation, has to be determined first from the equation (6.2). 
For the load consideration in EMAS, the excitation coil cross-sections will be added to the simplified model with the value $N_{c} i$ amperes. This value is certainly not fixed. Whenever the translator is shifted to the new position, the new value of the induced voltage is calculated. Then the new current is obtained. Consequently, the value of $N_{c} i$ will be reentered before a field analysis starts. The algorithm of the simulation can be illustrated as the below flowchart.

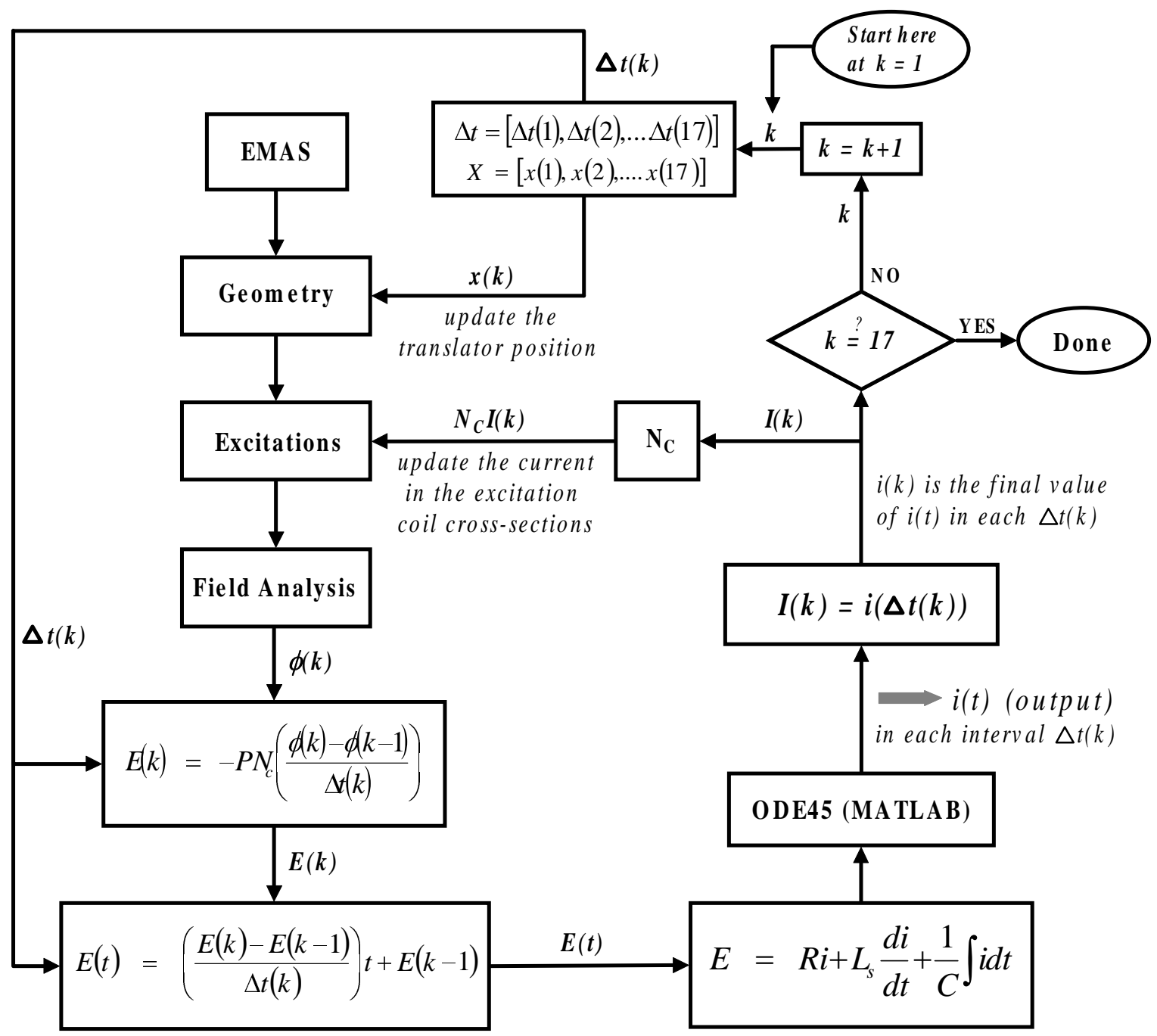

Figure 6.7 A Flowchart showing the algorithm of the simulation for 17 different translator positions 


\subsection{Simulation Results}

In the simulation, the linear engine is assumed the driving force for the linear alternator with a certain velocity profile regardless of load variations. Later, fifteen different translator positions are defined, and then the analyses are proceeded following the above algorithm. Later the results are presented in Figure 6.8.

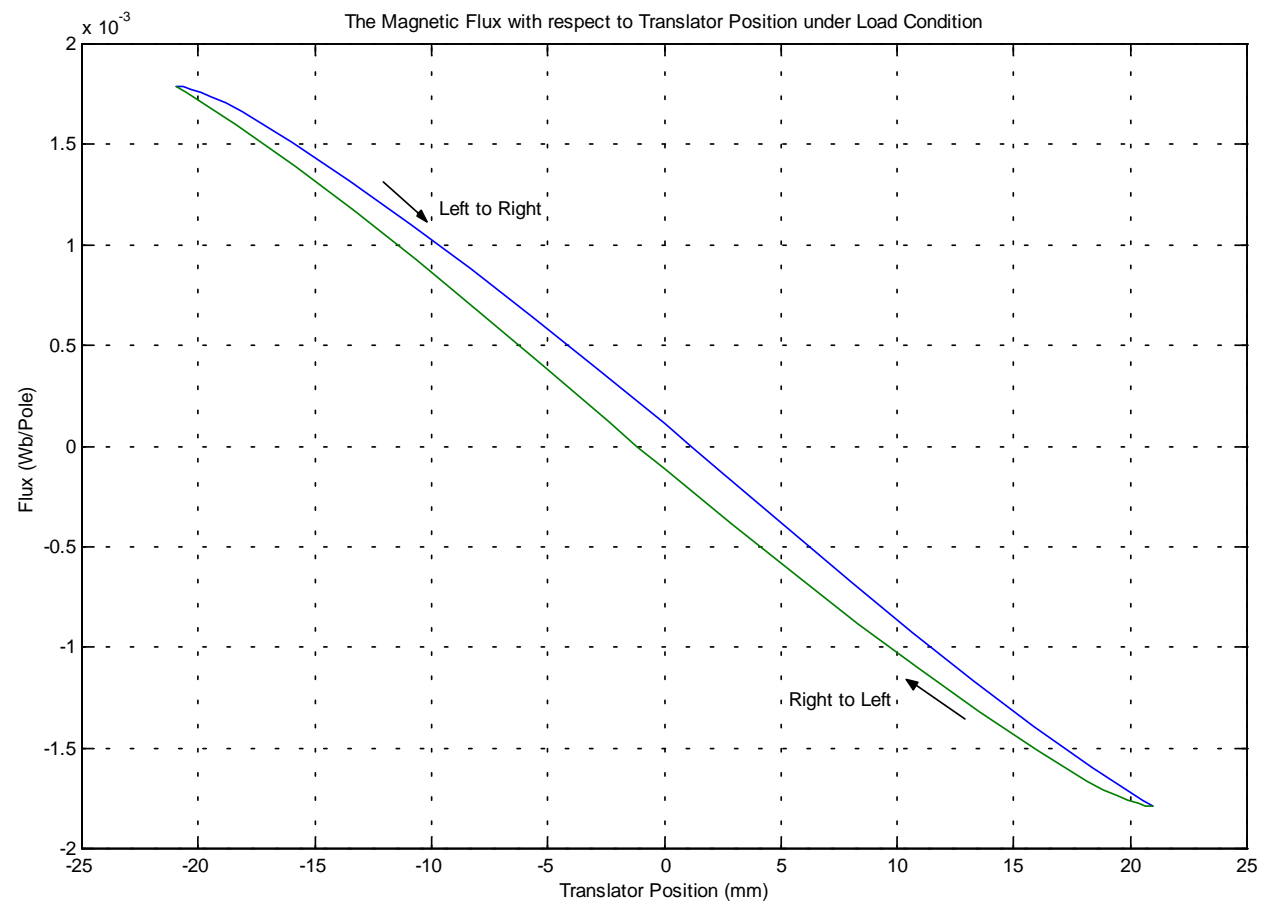

Figure 6.8 Plot of Flux vs. Translator Position

From viewing Figure 6.8, there are two curves that represent changes of magnetic flux related to translator position. They do not cross the zero point because these flux curves are created from adding amount of flux established from the current in the coils to the no-load flux curve. The upper curve occurs when the translator is pushed from the left end to the right end. Due to no current in the coils at the beginning, this curve starts at the same point as the no-load flux curve. Later, the translator starts moving, the current starts flowing in the coils. When the translator reaches the middle of stroke length, the resultant flux does not become zero yet. That is because the current still establishes an amount of 
flux in the core. The current will reach the highest value around this area, and then it will start decreasing when the translator moves beyond. Finally, the current becomes zero when the translator reaches the right end.

Subsequently, the bottom curve is created when the translator is pushed back to the left end. As a result, the induced current flows in the other direction. This makes this curve placed below the first curve.

Later, the back emf and electric current obtained from the simulation are shown in Figure 6.9 and 6.10 .

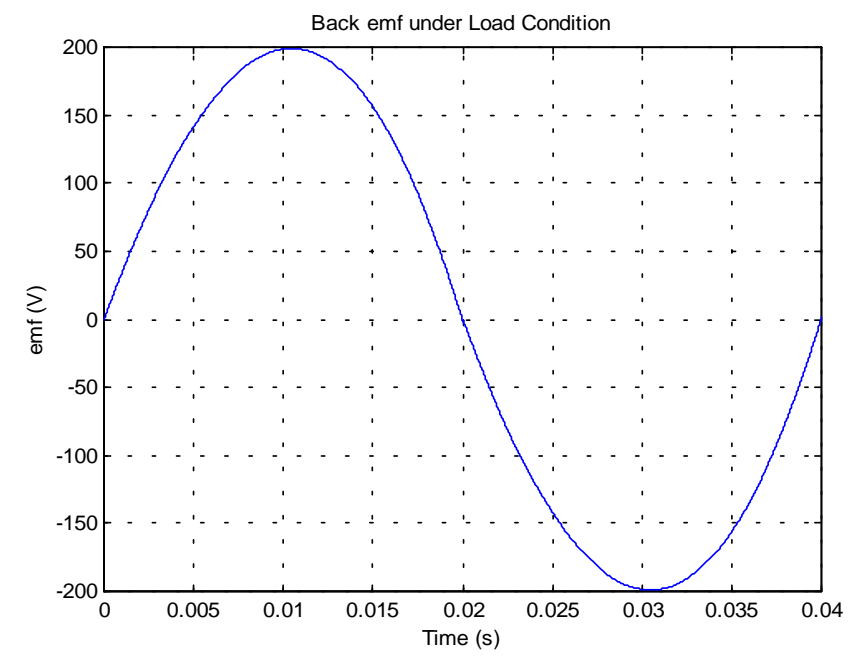

Figure 6.9 Plot of Back emf vs. Time $\left(E_{R M S}=145.03 \mathrm{~V}\right)$

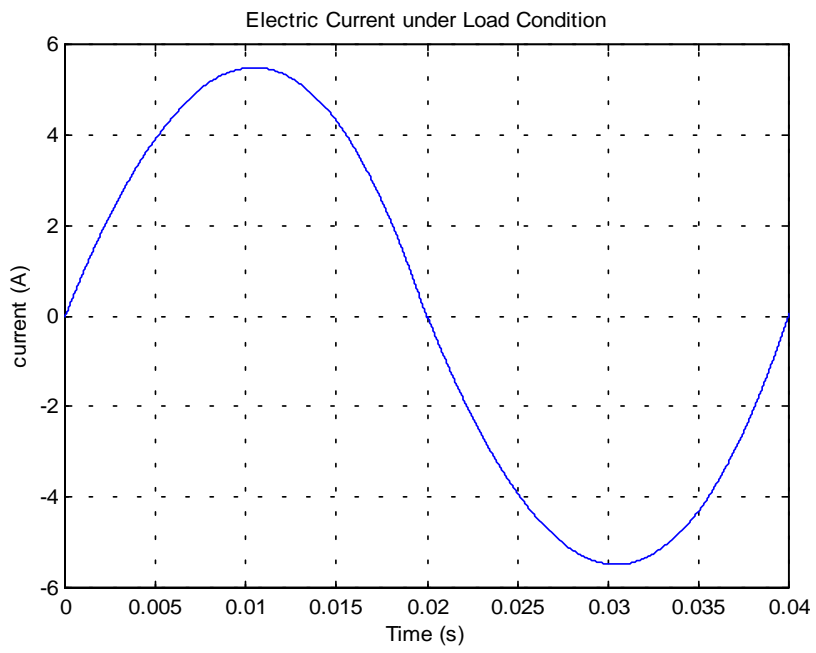

Figure 6.10 Plot of Load Current vs. Time ( $\left.I_{R M S}=4.0 \mathrm{~A}\right)$ 
Due to adding the tuning capacitor, the electric current is in phase with the back emf. Subsequently, the current waveform is decomposed to determine the magnitude of harmonics as shown in Figure 6.11.

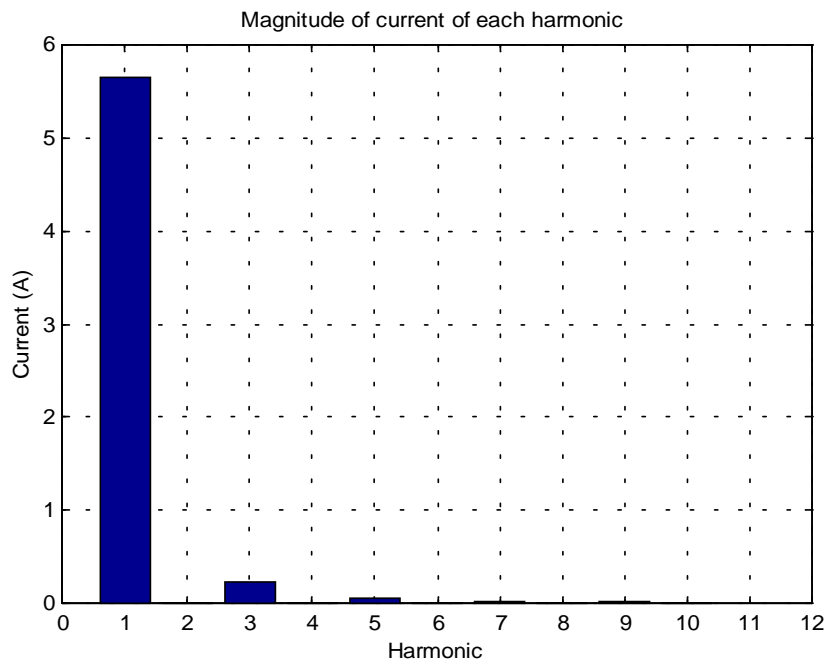

Figure 6.11 Plot of the Magnitude of current of each harmonic

From Figure 6.11, the third harmonic is very small. This indicates that the output voltage is very similar to the sinusoidal waveform. Later, the system efficiency can be calculated from

$$
\eta=\frac{P_{\text {out }}}{P_{\text {engine }}} \times 100 \%
$$

The engine power $\left(\mathrm{P}_{\text {engine }}\right)$ can be obtained from the average value of the instantaneous power $\left(\mathrm{P}_{\text {inst }}\right)$ expressed as

$$
P_{\text {inst }}=F_{e}(t) \cdot v(t)
$$

then

$$
P_{\text {engine }}=\operatorname{average}\left(P_{\text {inst }}\right)
$$


where

$F_{e}(t)$ is the engine force versus time

$\mathrm{v}(\mathrm{t})$ is the translator velocity versus time

From the previous experiment, the engine force and velocity data are used to determine the instantaneous engine power as plotted in Figure 6.12.

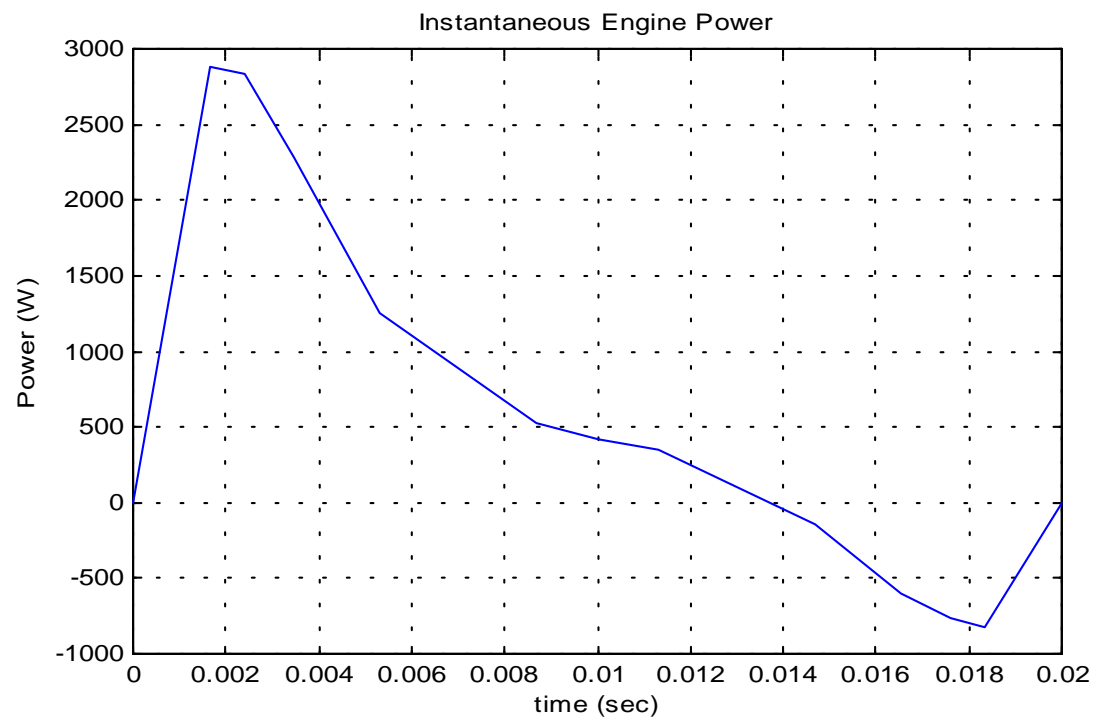

Figure 6.12 Instantaneous power of linear engine

Later, the engine power $\left(\mathrm{P}_{\text {engine }}\right)$ is obtained from averaging the instantaneous power $\mathrm{P}_{\text {inst }}(\mathrm{t})$.

$$
\begin{aligned}
P_{\text {engine }} & =\frac{1}{T} \int_{0}^{T} P_{\text {inst }}(t) d t \\
& =613.78 \mathrm{~W}
\end{aligned}
$$

From the optimization design results, whereas MILA was designed for the rated output voltage $\left(\mathrm{V}_{\mathrm{o}}\right)=120 \mathrm{~V}$, the output power $\left(\mathrm{P}_{\mathrm{o}}\right)$ equal to $482.78 \mathrm{~W}$ was obtained. These values represent the resistive load as 


$$
\begin{aligned}
R_{L} & =\frac{V_{o}^{2}}{P_{0}} \\
& =\frac{120^{2}}{482.78}=30 \Omega
\end{aligned}
$$

Later, this resistance is used in the simulation. When the load current is obtained, the output power can be calculated from

$$
\begin{aligned}
P_{o} & =I_{r m s}^{2} R_{L} \\
& =(4.0)^{2}(30) \\
& =480 \mathrm{~W}
\end{aligned}
$$

Finally, the efficiency is obtained from the equation (6.6)

$$
\begin{aligned}
\eta & =\frac{480}{613.78} \times 100 \% \\
& =78.2 \%
\end{aligned}
$$

The specifications of MILA are presented in Table 6.1

Table 6.1 Specifications of MILA at rated (4 amps)

\begin{tabular}{|l|c|}
\hline Rated Voltage & $120 \mathrm{~V}$ \\
\hline Rated Power & $480 \mathrm{~W}$ \\
\hline Efficiency & $78.2 \%$ \\
\hline Weight & $21.9 \mathrm{~kg}$ \\
\hline Volume & $2.92 \mathrm{Liters}$ \\
\hline
\end{tabular}


Finally, the results obtained from the simulation present the desired output voltage. The efficiency is rather high and close to the value obtained from the design routine. The alternator weight is moderate. The structure similar to its rotary counterpart makes MILA ideal for mass production. These advantages demonstrate that MILA is practical and is a good candidate for the existing linear engine. 


\section{CONCLUSION}

The main objective of this research was to design, analyze and simulate a new type of linear alternator called Moving Iron Linear Alternator (MILA), for the developed linear engine at West Virginia University for auxiliary power unit applications. Due to novelty of the machine structure, first, machine configuration was to be clarified. Next, operation of alternator was explored and a number of analytical equations were applied. Subsequently, an optimization methodology was used to maximize the efficiency with minimum mass. Then, a field analysis software package was used to simulate the machine flux. Finally, the machine simulation was performed to obtain the alternator output voltage. The quality of the output voltage was analyzed.

\subsection{MILA Structure and Design}

Moving Iron Linear Alternator has simple configuration, but its operation is complicated. Consequently, the first task of this work was to design the machine structure. The magnetic circuit analysis of MILA presented in Chapter 2 was applied to the design routine. Basically, the magnetic circuit does not present high accuracy, but it was the best tool to design the machine.

Conceptual design was proceeded in Chapter 3. The goal of this chapter was to design the alternator to be able to cooperate with the existing linear engine properly. The in-depth design process was explained step by step. The design results were obtained and discussed in the final section of the chapter.

To obtain an ideal design before the model was developed in the field analysis software, an optimization method using the Sequential Quadratic Programming (SQP) method was applied to the design routine in Chapter 4. In this routine, the translator mass was fixed due to requirement of oscillation frequency to remain at $25 \mathrm{~Hz}$. Consequently, 
only the stator mass was minimized. Finally, the optimum model was obtained with maximum efficiency and minimum mass.

\subsection{Field Analysis and Simulation}

Once the optimum design was found, the machine model was developed using EMAS, a field analysis software package based on the finite element method. Then the three-dimensional (3D) machine model was analyzed to obtain the magnetic flux. Unfortunately, the extremely long computational time was given in 3D analysis. Moreover, serious difficulty of meshing 3D finite element model tended to make complicated models unmeshable. However, to present the flux distribution of 3D model, a number of days were sacrificed to determine the flux at four different translator positions. Then the results were plotted as a function of translator position.

To facilitate the work, the actual 3D model was simplified as a two-dimensional model. Much shorter computation time was found for analyzing the simplified model. Later, the flux was determined at a number of different translator positions. These flux results were then compared with the flux curve from 3D model, and very little discrepancies were observed. Consequently, the simplified model was validated and was used as a representative of MILA.

With the simplified model, the simulation was performed at no load and under load conditions in Chapter 6. With the flux distribution curve alone, the back emf could be determined straightforward at no load. Subsequently, the simulation was more complicated when a load was applied to the alternator. The flux due to the effect of the armature reaction was added with the flux established by the field. Consequently, the current was solved in an iterative process from the differential equation and then applied to the excitation processor of EMAS. The interaction of EMAS and MATLAB was required in this work. Finally, the results of the simulation were presented and discussed in details. Due to heavier structure, MILA would be a good candidate to be used in conjunction with linear engine for stationary power applications. Since the lamination shape is similar to rotary type, the infrastructure can easily support mass production of this type of alternator for auxiliary or distributed power generation. 


\section{$\underline{7.3 \text { Future Work }}$}

Further work of this research was to identify other possible ways to improve design techniques and simulation results.

1) In this research, only alternator model was considered. It is recommended that an integrated model including the linear engine and alternator model would be developed to represent the overall system.

2) Since long computational time was required for the finite element solutions, the, the simplified model was used in this research to fix this problem. In the future, with more powerful processors, the full three-dimensional model may be used to obtain more accurate results.

3) Due to good performance of MILA obtained from the simulation, the prototype may be built to test and investigate the performance. 


\section{References}

[1] White, M. A., Colenbrander, K., Olan, R. W., and Penswick, L. B., "Commercially Viable, Long Life, High Efficiency stirling Generators For Remote Power Applications," American Society of Mechanical Engineers Proceedings of the 1995 ASME International Mechanical Engineering Congress \& Exposition Nov 12-17 1995.

[2] Ross, B. A. and Ritter, D. C., "Performance Of A Second Generation 10 Watt Stirling Generator Set," Proceedings, $29^{\text {th }}$ Intersociety Energy Conversion Engineering Conference, Monterey CA, Paper No. AIAA-94-3803-CP, Vol. 4, pp. 1917-1921.

[3] Famouri, P., Cawthorne, W. R., Clark, N., Nandkumar, S., Atkinson, C., Atkinson, R., McDaniel, T., and Petreanu, S., "Design And Testing Of A Novel Linear Alternator And Engine System For Remote Electrical Power Generation," Proceedings of the 1999 Winter Meeting of IEEE Power Engineering Society, Part 1 (of 2) Jan 31-Feb 41999 v1 New York, NY, USA, p 108-112.

[4] White, M. A., Colenbrander, K., Olan, R. W., and Penswick, L. B., "Generators That Won't Wear Out," Mechanical Engineering v118 n2 Feb 1996 ASME New York, NY, USA, p 92-96.

[5] Boldea, I., and Nasar, S. A., "Linear Electric Actuators And Generators," Cambridge University Press, 1997.

[6] Nasar, S. A., and Boldea, I., "Linear Electrodynamic Machine And Method Of Making And Using SAME," United States Patent, Patent Number: 5,654,596, August 5, 1997.

[7] Boldea, I., and Nasar, S. A., "New Linear Reciprocating Machine With Stationary Permanent Magnets," IAS'96: Conference Record of the 1996 IEEE Industry Applications, October 6-10, 1996, San Diego, California.

[8] Gieras, J. F., and Wing, M., "Permanent Magnet Motor Technology: Design and Applications,” Marcel Dekker, Inc., 1997.

[9] Cawthorne, W. R., "Optimization Of A Brushless Permanent Magnet Linear Alternator For Use With A Linear Internal Combustion Engine," Thesis Collection, West Virginia University. 
[10] Clark, N., Nandkumar, S., Atkinson, C., Atkinson, R., McDaniel, T., Petreanu, S., Famouri, P., and Cawthorne, W. R., "Operation Of A Small Bore Two-Stroke Linear Engine," Proceedings of the 1998 Fall Technical Conference of the ASME Internal Combustion Engine Division, Part 1 (of 3) Sep 27-30 1998 v31 n1 Clymer, NY, USA, p 33-42.

[11] “Optimization Toolbox User's Guide,” The MathWorks, Inc., 1997.

[12] Broyden, C. G., "The Convergence Of A Class Of Double-Rank Minimization Algorithm,” J. Inst. Mathematics. Applications, Vol.6, p 76-90, 1997.

[13] Fletcher, R., "A New Approach To Variable Metric Algorithm," Computer Journal, Vol. 13, p 317-322, 1970.

[14] Golfarb, D., "A Family Of Variable Metric Updates Derived By Variational Means," Mathematics of Computing, Vol. 24, p 23-26, 1970.

[15] Shanno, D. F., "Conditioning of Quasi-Newton Methods for Function Minimization," Mathematics of Computing, Vol. 24, p 647-656, 1970.

[16] Huebner, K. H., Thornton, E. A., and Byrom, T. G., "The Finite Element Method For Engineers," John Wiley \& Sons, Inc., 1995.

[17] Smith, I. M., and Griffiths, D. V., "Programming The Finite Element Method," John Wiley \& Sons, Ltd., 1998.

[18] “EMAS Seminar Notes Version 4,” Ansoft Corporation, June 1997.

[19] Boldea, I., Wang, C., Yang, B., and Nasar, S. A., "Analysis And Design Of FluxReversal Linear Permanent Magnet Oscillating Machine," Proceedings of the 1998 IEEE Industry Applications Conference. Part 1 of 3) Oct 12-15 1998 v1, St. Louis, MO, USA. 


\section{APPENDIX}

\section{$\underline{\text { A Program Code }}$}

\section{optimize.m}

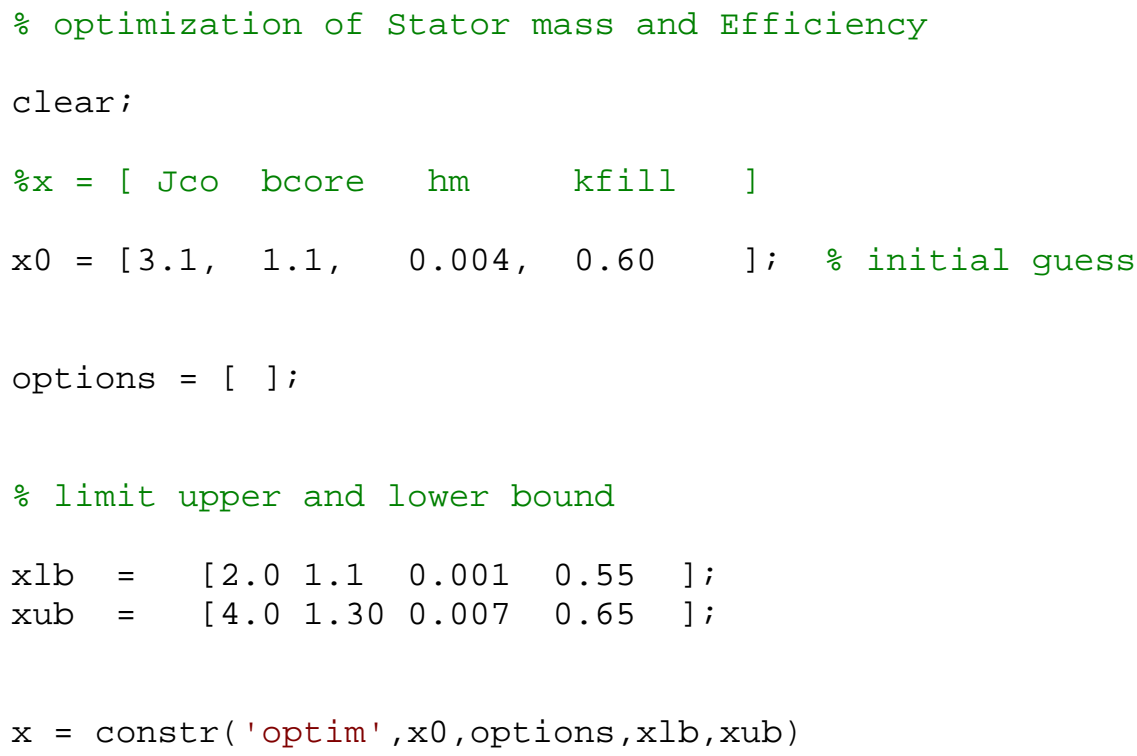

\section{optim.m}

function [object, constraint, eff_new, Nc, Rs, Ls, Pout_new, Mstator] = optim(x)

\% design moving iron linear alternator

Data

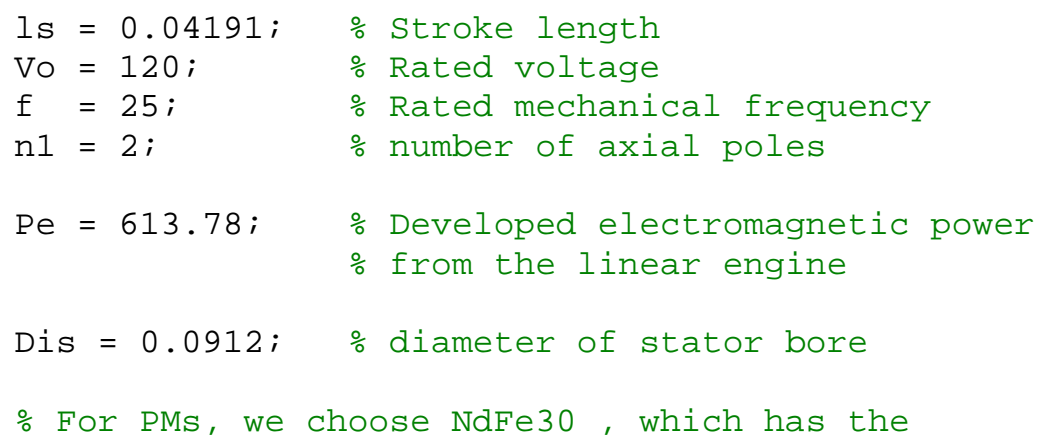


\% Magnet properties:

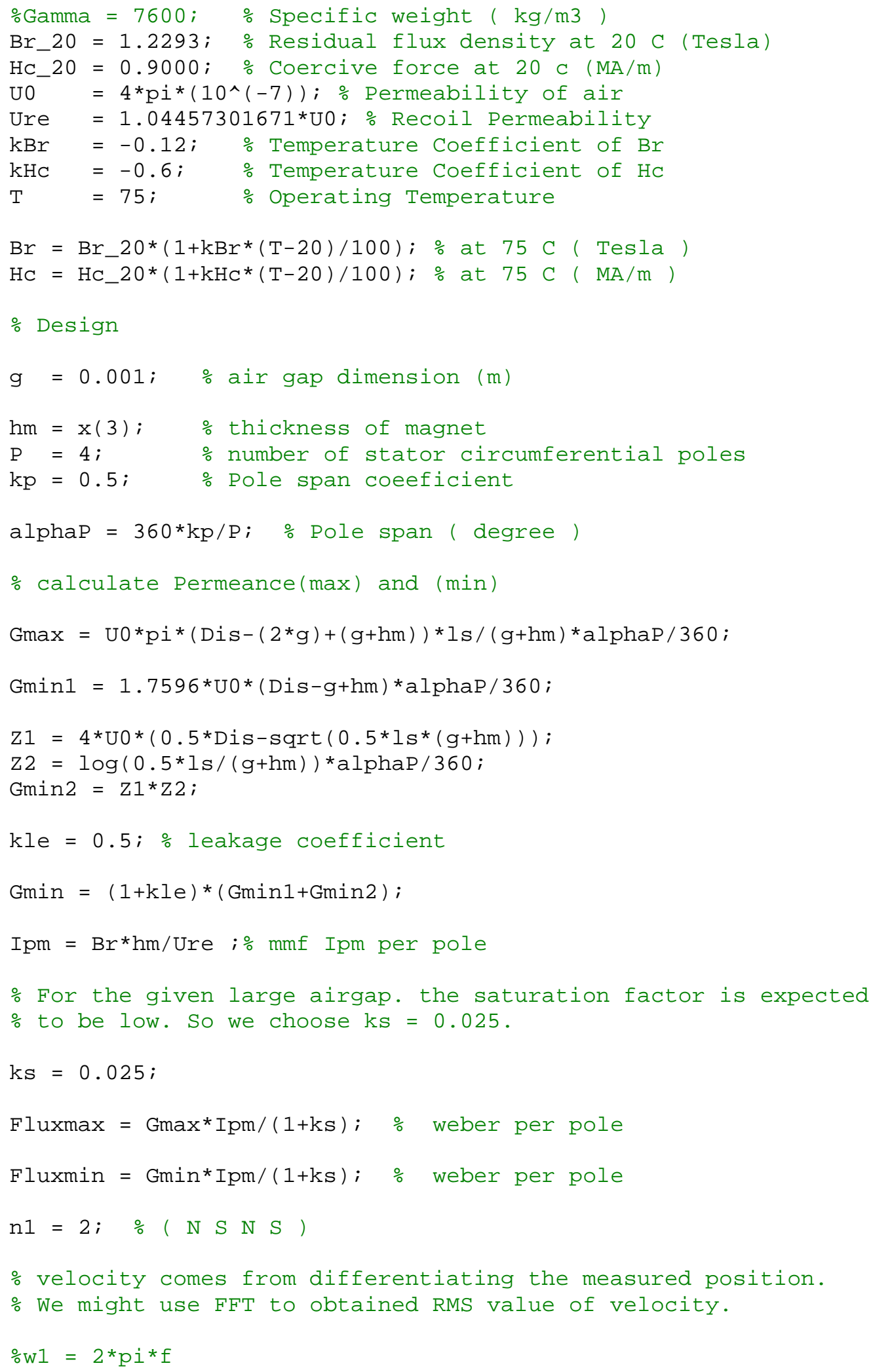




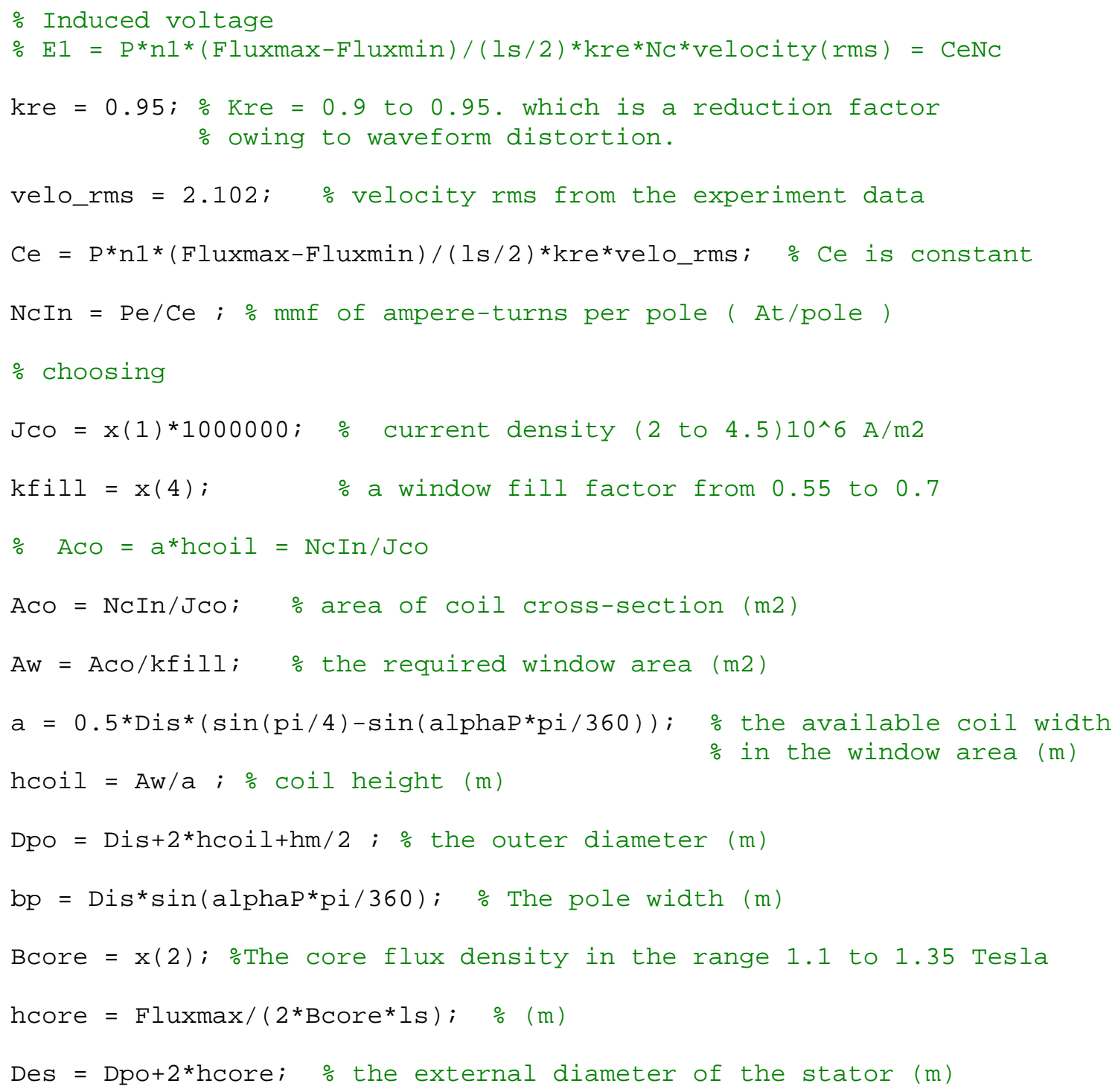




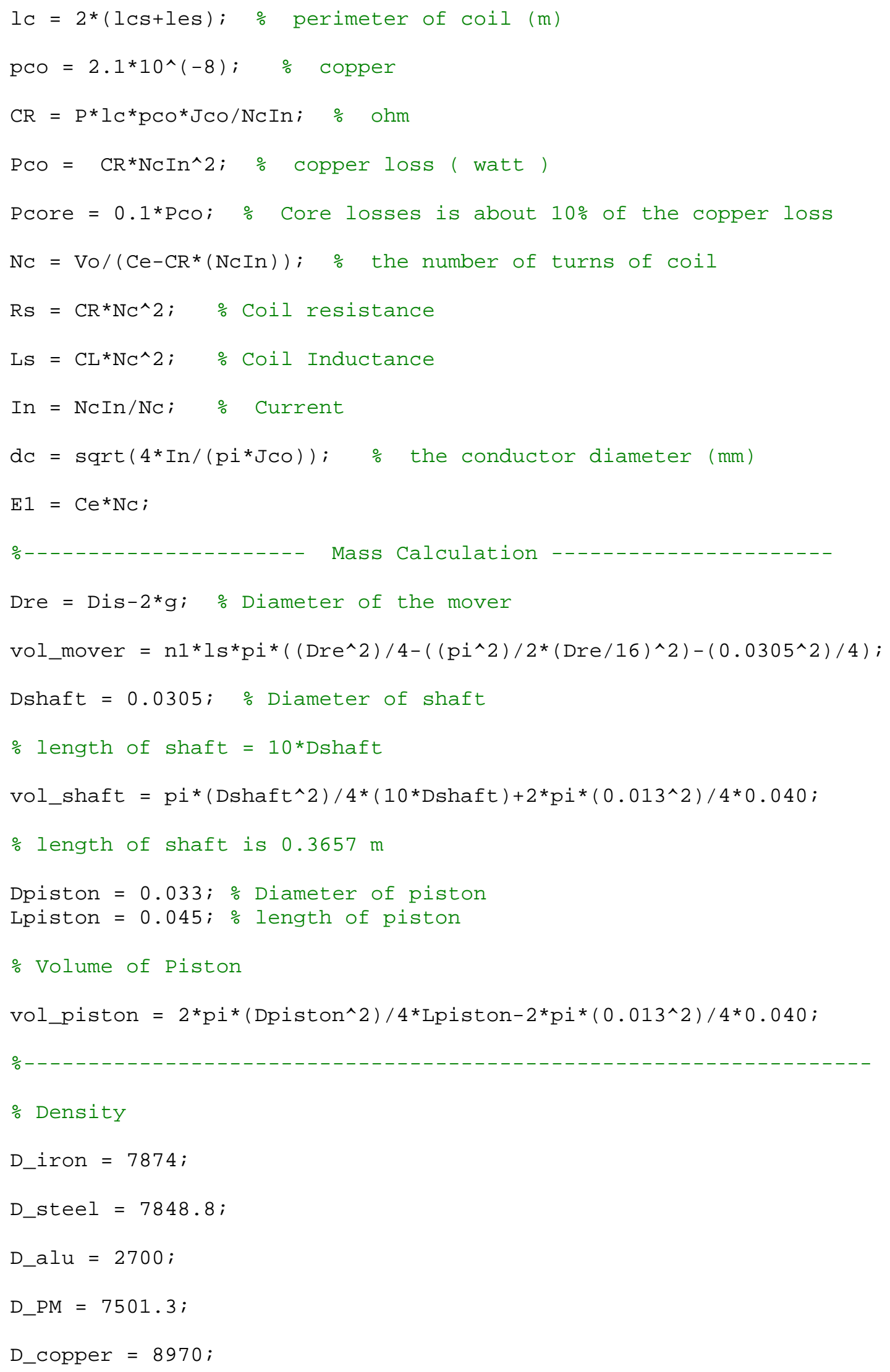




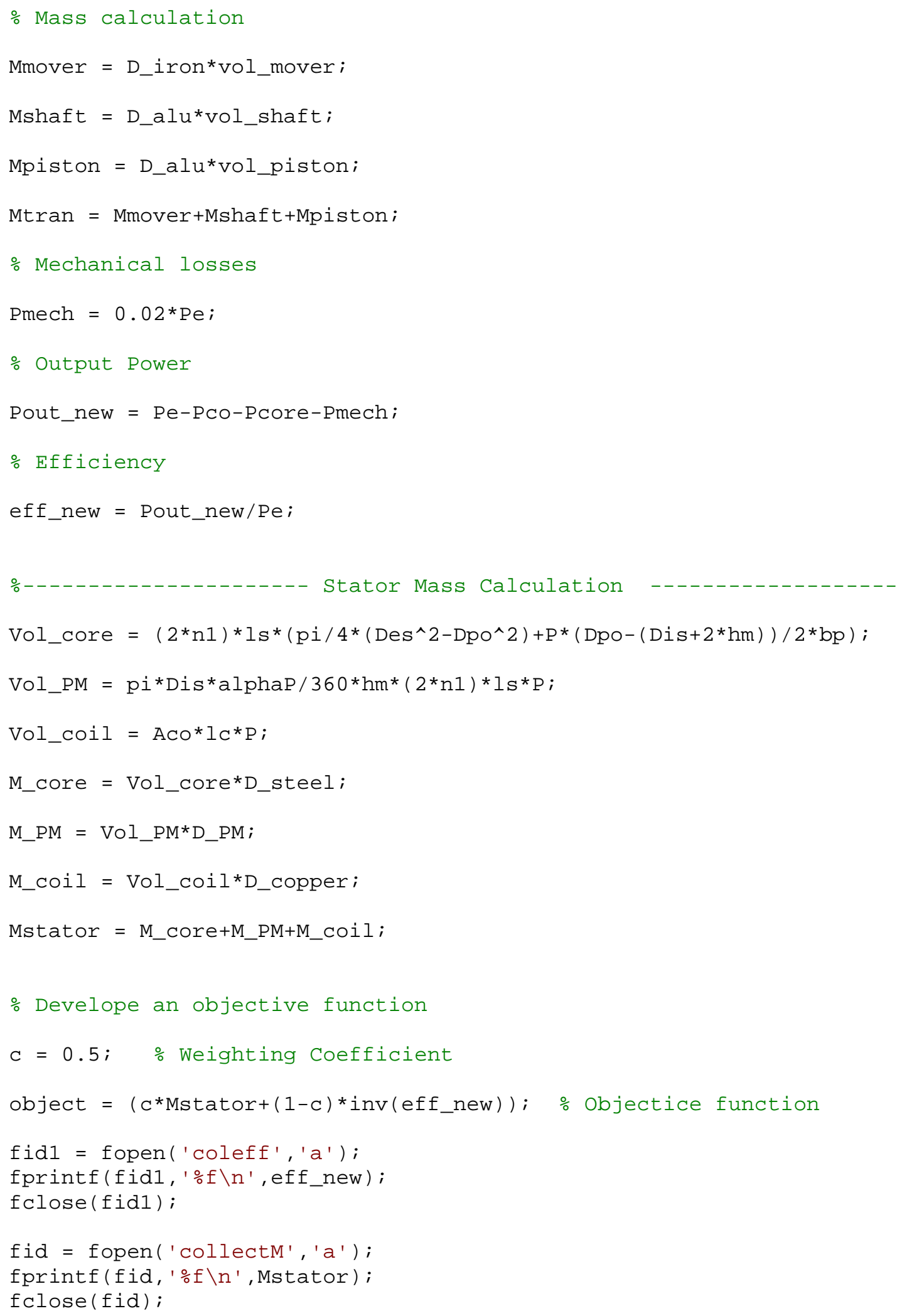


\% Constraints

constraint $(1)=a-0.6 *$ hcoil;

constraint $(2)=0.015$-hcore;

\section{cal_i.m}

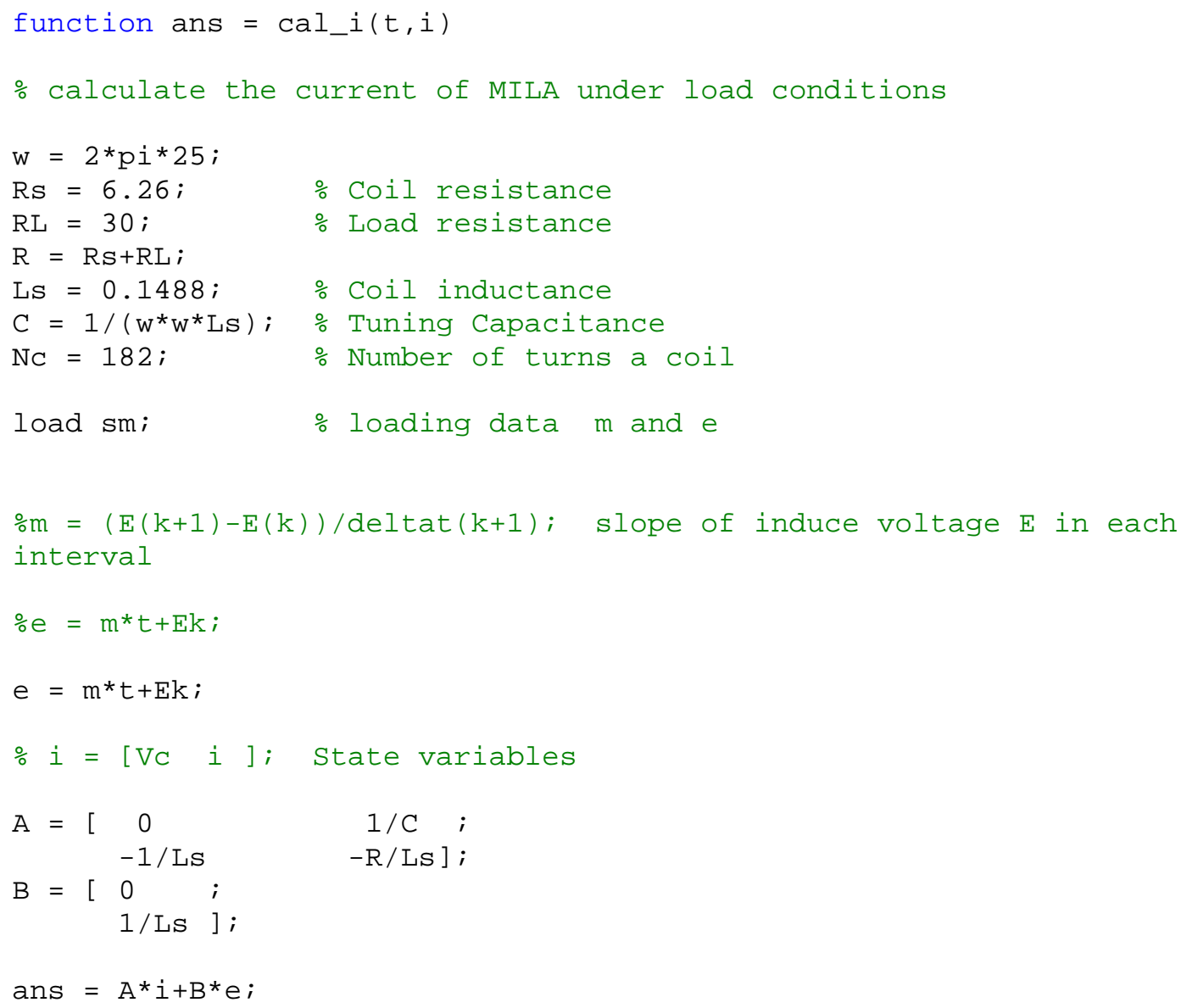

\section{iem.m}

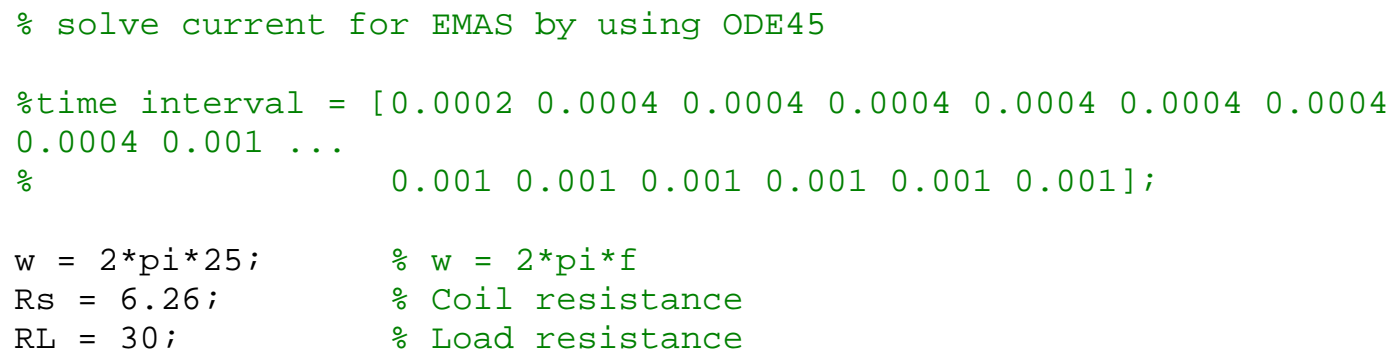




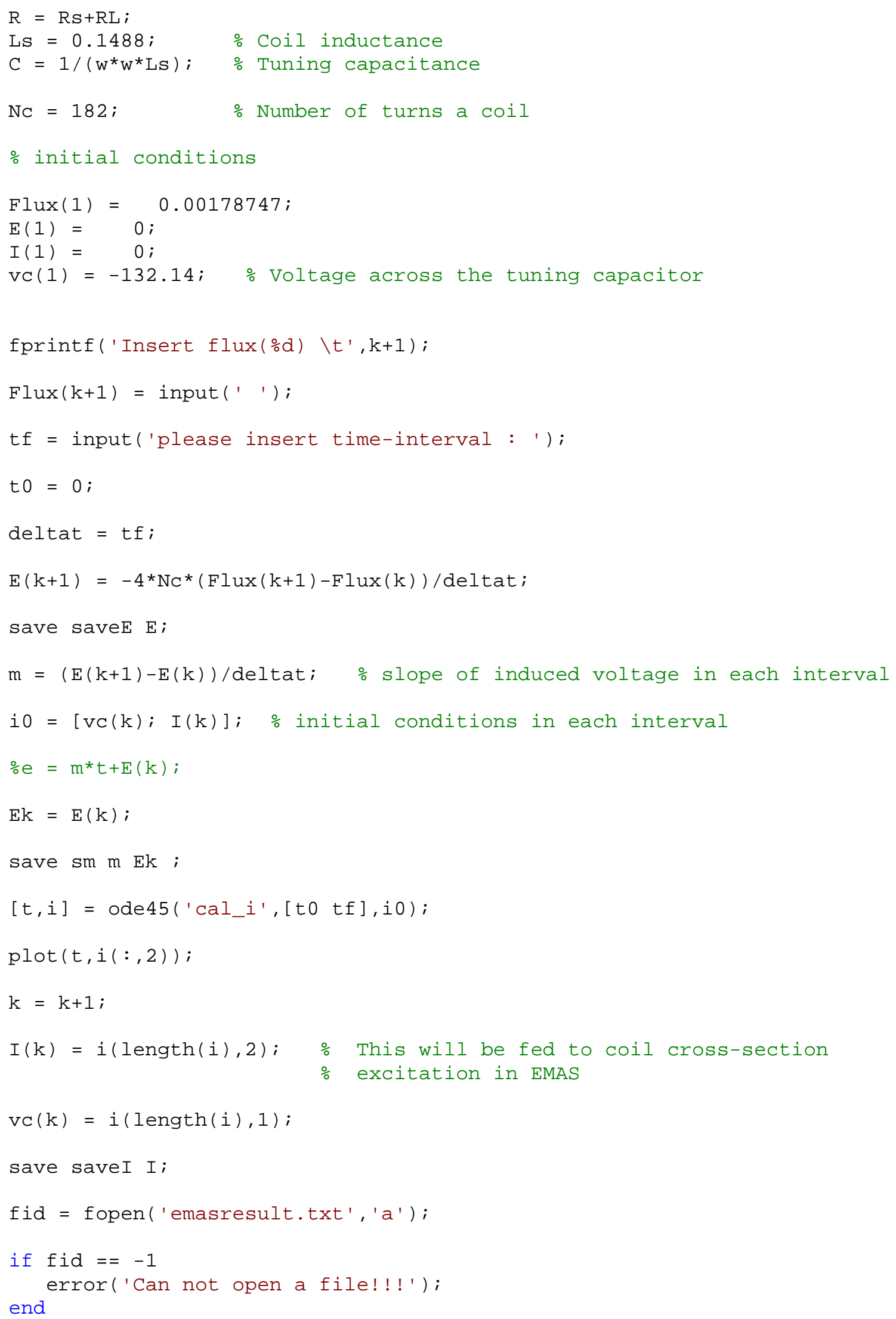




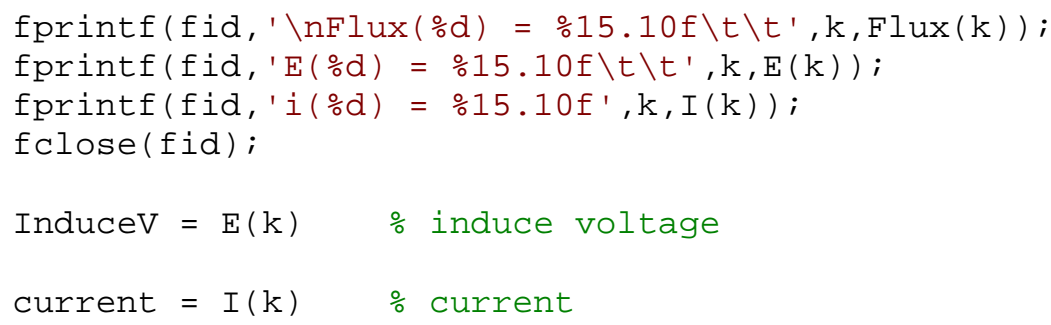

\section{fftiload.m}

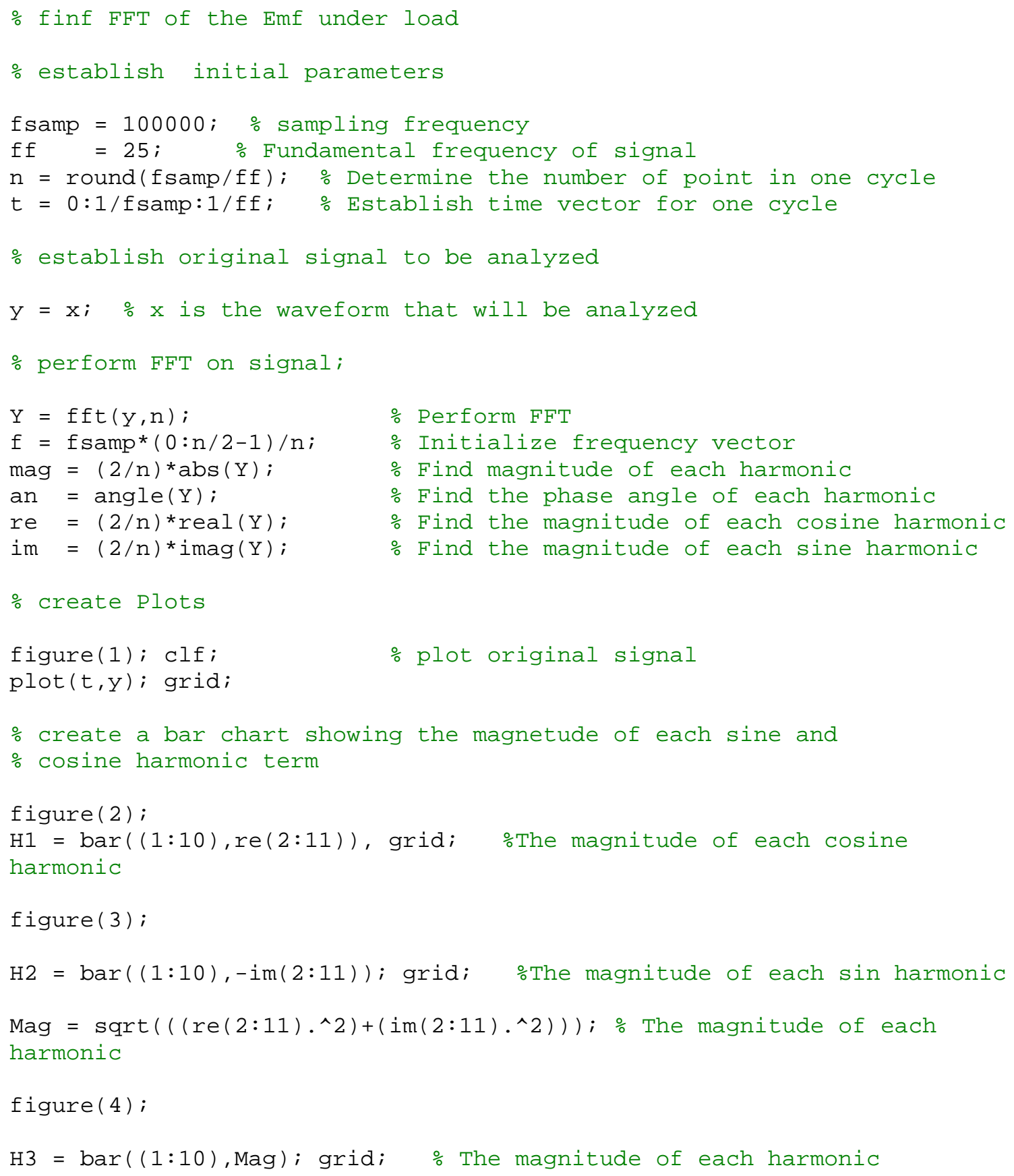




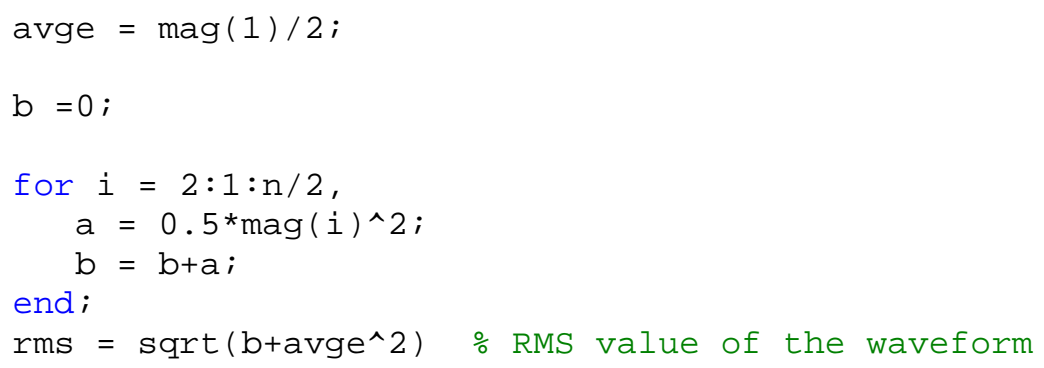

